\title{
Investigation of the Effects of Fuel Injection Nozzle Parameters on Ignition Delay and Cetane Number
}

\author{
by \\ Hamza Mostafa Abo El Ella, B. Eng. - Aerospace
}

A thesis submitted to

the Faculty of Graduate Studies and Research

in partial fulfillment of

the requirements for the degree of

Master of Applied Science - Aerospace Engineering

Ottawa-Carleton Institute for

Mechanical and Aerospace Engineering

Department of

Mechanical and Aerospace Engineering

Carleton University

Ottawa, Ontario

July 24,2006

(C) 2006

Hamza Mostafa Abo El ELla 


$\begin{array}{ll}\begin{array}{l}\text { Library and } \\ \text { Archives Canada }\end{array} & \begin{array}{l}\text { Bibliothèque et } \\ \text { Archives Canada }\end{array} \\ \begin{array}{l}\text { Published Heritage } \\ \text { Branch }\end{array} & \begin{array}{l}\text { Direction du } \\ \text { Patrimoine de l'édition }\end{array} \\ \begin{array}{l}\text { 395 Wellington Street } \\ \text { Ottawa ON K1A ON4 }\end{array} & \begin{array}{l}\text { 395, rue Wellington } \\ \text { Ottawa ON K1A ON4 } \\ \text { Canada }\end{array}\end{array}$

Your file Votre référence ISBN: 978-0-494-18310-6 Our file Notre référence ISBN: 978-0-494-18310-6

NOTICE:

The author has granted a nonexclusive license allowing Library and Archives Canada to reproduce, publish, archive, preserve, conserve, communicate to the public by telecommunication or on the Internet, loan, distribute and sell theses worldwide, for commercial or noncommercial purposes, in microform, paper, electronic and/or any other formats.

The author retains copyright ownership and moral rights in this thesis. Neither the thesis nor substantial extracts from it may be printed or otherwise reproduced without the author's permission.
AVIS:

L'auteur a accordé une licence non exclusive permettant à la Bibliothèque et Archives Canada de reproduire, publier, archiver, sauvegarder, conserver, transmettre au public par télécommunication ou par l'Internet, prêter, distribuer et vendre des thèses partout dans le monde, à des fins commerciales ou autres, sur support microforme, papier, électronique et/ou autres formats.

L'auteur conserve la propriété du droit d'auteur et des droits moraux qui protège cette thèse. $\mathrm{Ni}$ la thèse ni des extraits substantiels de celle-ci ne doivent être imprimés ou autrement reproduits sans son autorisation.
In compliance with the Canadian

Privacy Act some supporting forms may have been removed from this thesis.

While these forms may be included in the document page count, their removal does not represent any loss of content from the thesis.
Conformément à la loi canadienne sur la protection de la vie privée, quelques formulaires secondaires ont été enlevés de cette thèse.

Bien que ces formulaires aient inclus dans la pagination, il n'y aura aucun contenu manquant.

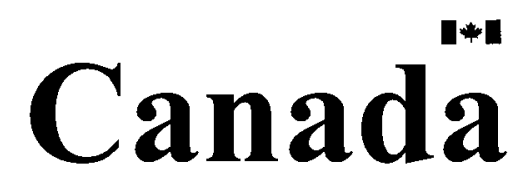




\begin{abstract}
The work undertaken aims to determine the effects of fuel injection nozzle parameters on the ignition delay and cetane number as measured using ASTM test method D6890. To determine the effects of fuel injection nozzles on the ignition delay and cetane number, a test plan was developed employing the use of several experimental apparatus. A sample of 15 delay pintle type nozzles and a single typical diesel fuel were chosen for the study.

Each of the 15 nozzles was used to test CF12, a diesel reference fuel, according to ASTM D6890 using an Ignition Quality Tester (IQT ${ }^{\mathrm{TM}}$ ) available from Advanced Engine Technology (AET). An optical spray pattern test rig was developed to analyze the spray pattern of the test nozzles. Internal geometry for each of the nozzles was then characterized in terms of choked flow rates according to ISO 4010 test methods using two test rigs that were designed and developed specifically for this task. Finally, accessible nozzle geometry was measured directly with the aid of a profile projector. All the obtained spray and geometry characteristics of each of the 15 nozzles were then compared to their corresponding ignition delay and cetane number values for examination and discussion.
\end{abstract}




\section{Acknowledgements}

My deepest gratitude and dearest thanks goes to my father and mother to whom I am eternally indebted for their many sacrifices and their support in all my endeavours. To my sister, and brothers, my heart felt appreciation goes to them for always being there for me.

I would like to thank the principal of Advanced Engine Technology (AET) Gary Webster, and my supervisor Dr. Donald Gauthier for their continuous support and guidance in completing this work. Special thanks to the professional staff of AET for their technical experience and contributions.

The financial contributions of Materials Manufacturing Ontario, and AET is also acknowledged. 
"... He who taught the use of the Pen, taught man that which he knew not."

- The Noble Qur'an $\{96: 04-05\}$ 


\section{Contents}

$\begin{array}{ll}\text { Acceptance } & \text { ii }\end{array}$

$\begin{array}{ll}\text { Abstract } & \text { iii }\end{array}$

Acknowledgements $\quad$ iv

Table of Contents $\quad$ vi

List of Tables $\quad$ ix

List of Figures $\quad$ x

Nomenclature $\quad$ xiii

1 Introduction $\quad 1$

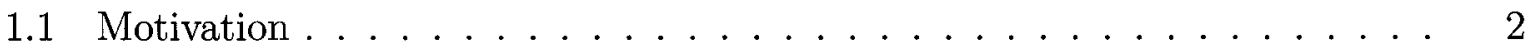

1.2 Objectives and Tasks . . . . . . . . . . . . . . . . 3

2 Background and Literature Review $\quad 4$

2.1 Cetane Number and Ignition Delay - Measurement Methods . . . . . . . . 4

2.1.1 Standard Methods . . . . . . . . . . . . . . 5 5

2.1 .2 Alternate Methods . . . . . . . . . . . . . . 7

2.2 Fuel Injection Nozzle Testing . . . . . . . . . . . . . . . . . . . . 7 
2.2.1 Spray Pattern Analysis . . . . . . . . . . . . . 8

2.2 .2 Nozzle Geometry Analysis . . . . . . . . . . . . . . . 9 9

2.3 Fuel Injection Nozzles and Ignition Delay . . . . . . . . . . . . . . . . . 10

3 Test Plan and Experimental Apparatus 13

3.1 Test Nozzles - Delay Pintle Type . . . . . . . . . . . . . . . . . . . . 14

3.2 Ignition Quality Tester . . . . . . . . . . . . . . . 17

3.3 Optical Spray Pattern Test Rig . . . . . . . . . . . . . . . 20

3.4 Pintle Clearance Air Flow Test Rig . . . . . . . . . . . . . . . . . . . 24

3.5 Needle Clearance Nitrogen Flow Test Rig . . . . . . . . . . . . . . . . 27

3.6 Profile Projector . . . . . . . . . . . . . . . . 29

4 Results and Discussion $\quad 31$

4.1 Effects of Spray Pattern _. . . . . . . . . . . . . . 33

4.2 Effects of Internal Nozzle Geometry . . . . . . . . . . . . . . . 36

4.3 Effects of Nozzle Needle Geometry . . . . . . . . . . . . . . . . . 42

5 Conclusions and Recommendations $\quad 4 \mathbf{4 3}$

$\begin{array}{ll}\text { List of References } & 45\end{array}$

$\begin{array}{ll}\text { Appendix A Nozzle Cleaning Procedure } & 49\end{array}$

Appendix B Optical Spray Pattern Test Rig Repeatability 50

Appendix C Air and Nitrogen Flow Test Rigs - Design 52

C.1 Air Flow Test Rig Drawings . . . . . . . . . . . . . . . 53

C.2 Nitrogen Flow Test Rig Drawings . . . . . . . . . . . . . . . . 62

Appendix D Air and Nitrogen Flow Test Rigs - DAQ System $\quad 67$

vii 
Appendix E Air Flow Test Rig Calibration $\quad 69$

E.1 Air Flowmetre Calibration . . . . . . . . . . . . . . . . . 69

E.2 Air Flow Test Rig Repeatability . . . . . . . . . . . . . . . . . . 70

$\begin{array}{lll}\text { Appendix F Air Flow Test Rig Testing Procedure } & 72\end{array}$

$\begin{array}{ll}\text { Appendix G Nitrogen Flow Test Rig Calibration } & 76\end{array}$

G.1 Nitrogen Flowmetre Calibration . . . . . . . . . . . . . . 76

G.2 Nitrogen Flow Test Rig Repeatability . . . . . . . . . . . . . . 77

$\begin{array}{ll}\text { Appendix H Nitrogen Flow Test Rig Testing Procedure } & 78\end{array}$

$\begin{array}{lll}\text { Appendix I } & \text { Experimental Data } & 81\end{array}$

I.1 Ignition Delay Data . . . . . . . . . . . . . . . . . 82

I.2 Spray Pattern Data . . . . . . . . . . . . . . . 83

I.3 Internal Geometry Flow Data . . . . . . . . . . . . . . . 98

I.4 Needle Profile Data . . . . . . . . . . . . . . . . . . . . . 101 


\section{List of Tables}

3.1 Fifteen test nozzles from 3 different manufacturers . . . . . . . . . . . 15

C.1 Air flow test rig nozzle holder design drawings . . . . . . . . . . . 53

C.2 Nitrogen flow test rig nozzle holder design drawings . . . . . . . . . . 62

D.1 Air and nitrogen flow test rig shared DAQ system main components . . . 67

E.1 Air flowmeter calibration data . . . . . . . . . . . . . . 69

E.2 Pintle clearance air test rig standard deviation . . . . . . . . . . . . . 71

E.3 Pintle clearance air test rig standard deviation - end of lift, and maximum flow test points $\ldots \ldots \ldots \ldots \ldots \ldots \ldots \ldots \ldots \ldots \ldots$

G.1 Nitrogen flowmeter calibration data . . . . . . . . . . . . 76

I.1 Ignition delay and $\mathrm{CN}$ values for all 15 test nozzles $\ldots \ldots \ldots$. . . . . 82

I.2 Pintle clearance air flow test rig data for all 15 test nozzles . . . . . . . . 98

I.3 Needle clearance nitrogen flow test rig data for all 15 test nozzles $\ldots \ldots 100$

I.4 Needle profile dimensions for all 15 test nozzles $\ldots \ldots$. . . . . . . . 101 


\section{List of Figures}

2.1 Planar region of illumination produced by laser array $\ldots \ldots \ldots$

2.2 Capturing of nozzle spray pattern $\ldots \ldots \ldots \ldots \ldots$

3.1 Delay pintle type nozzle $\ldots \ldots \ldots \ldots \ldots$

3.2 Minimum nozzle pintle clearance varying with lift $\ldots \ldots \ldots \ldots$

3.3 Typical variation of the throat clearance in a delay pintle type nozzle $\ldots 17$

3.4 The ignition quality tester $\left(\mathrm{IQT}^{\mathrm{TM}}\right) \ldots \ldots \ldots \ldots$

3.5 Ignition quality tester schematic . . . . . . . . . . . . . . 19

3.6 Optical spray pattern test rig schematic $\ldots \ldots \ldots \ldots$

3.7 Optical spray pattern test $\operatorname{rig} \ldots \ldots \ldots \ldots \ldots \ldots$

3.8 Time delay for spray to reach laser sheet $\ldots \ldots \ldots \ldots$

3.9 Camera frame time delay correction $\ldots \ldots \ldots \ldots \ldots \ldots$

3.10 Pintle clearance air flow test rig schematic . . . . . . . . . 25

3.11 Needle clearance nitrogen flow test rig schematic . . . . . . . . . . . 27

3.12 Needle profile shadow on the profile projector $\ldots \ldots \ldots 29$

3.13 Key nozzle needle dimensions measured . . . . . . . . . . . . . 30

4.1 Ignition delay and cetane number values for all 15 test nozzles . . . . . . 32

4.2 Comparison of spray pattern images, Sun 65 and Sun $63 \ldots \ldots 34$

4.3 Comparison of spray pattern images, Sun 68 and Sun $1 \ldots \ldots$. . . . . 34 
4.4 Typical spray pattern evolution of test nozzles . . . . . . . . . . 35

4.5 Typical data curve produced from the pintle clearance air flow test rig . . . 36

4.6 Pintle clearance data with varying ignition delay . . . . . . . . . . . 37

4.7 Effects of pintle clearance on ignition delay and cetane number . . . . . . . 38

4.8 Initial injection period of a typical injection event . . . . . . . . . . . . 40

4.9 Needle clearance effect on ignition delay . . . . . . . . . . . . . . . 41

4.10 Cone angle (dimension F) effect on ignition delay . . . . . . . . . . . . 42

B.1 Spray test rig repeatability - comparable images for test nozzle Sun $1 \ldots 50$

B.2 Spray test rig repeatability - comparable images for test nozzle Zexel 9 . . 51

B.3 Spray test rig repeatability - comparable images for test nozzle Sun 68 . . 51

C.1 Air and nitrogen flow test rigs - shared test bench . . . . . . . . . . 52

C.2 Air test rig design drawings - Nozzle Holder Assembly Sh. 1 of 2 . . . . . . 54

C.3 Air test rig design drawings - Nozzle Holder Assembly Sh. 2 of $2 \ldots$. . . . 55

C.4 Air test rig design drawings - Collet Assembly . . . . . . . . . . . 56

C.5 Air test rig design drawings - Nozzle Body . . . . . . . . . . . . . . . . 57

C.6 Air test rig design drawings - Lift Adjuster . . . . . . . . . . . . . . . . . 58

C.7 Air test rig design drawings - Collet Tube . . . . . . . . . . . . . . . 59

C.8 Air test rig design drawings - Lift Stopper . . . . . . . . . . . . . 60

C.9 Air test rig design drawings - Collet Sleeve . . . . . . . . . . . . 61

C.10 Nitrogen test rig design drawings - Nozzle Holder Assembly Sh. 1 of 2 . . . 63

C.11 Nitrogen test rig design drawings - Nozzle Holder Assembly Sh. 2 of 2 . . 64

C.12 Nitrogen test rig design drawings - Top Cap . . . . . . . . . . . . . . . 65

C.13 Nitrogen test rig design drawings - Fixture Block . . . . . . . . . . 66

D.1 Air and nitrogen flow test rig shared DAQ system wiring schematic . . . 68 
E.1 Pintle clearance air test rig repeatability with one standard deviation $\ldots .70$

I.1 Sun 65 captured spray images, $3.355 \mathrm{~ms}$ ignition delay . . . . . . . . . 83

I.2 Zexel 71 captured spray images, $3.425 \mathrm{~ms}$ ignition delay . . . . . . . . . . 84

I.3 Sun 68 captured spray images, $3.429 \mathrm{~ms}$ ignition delay . . . . . . . . . . . 85

I.4 Sun 1 captured spray images, $3.443 \mathrm{~ms}$ ignition delay . . . . . . . . . . . 86

I.5 Zexel 35 captured spray images, 3.472 ms ignition delay . . . . . . . . . . . 87

I.6 Zexel 9 captured spray images, 3.473 ms ignition delay . . . . . . . . . . 88

I.7 Zexel 15 captured spray images, 3.477 ms ignition delay . . . . . . . . . . . 89

I.8 Sun 63 captured spray images, $3.512 \mathrm{~ms}$ ignition delay . . . . . . . . . . . 90

I.9 Sun 66 captured spray images, 3.516 ms ignition delay . . . . . . . . . 91

I.10 Zexel 76 captured spray images, 3.517 ms ignition delay . . . . . . . . . . 92

I.11 CAV 14 captured spray images, $3.540 \mathrm{~ms}$ ignition delay . . . . . . . . . 93

I.12 Sun 69 captured spray images, $3.544 \mathrm{~ms}$ ignition delay . . . . . . . . . . . 94

I.13 Sun 32 captured spray images, $3.561 \mathrm{~ms}$ ignition delay . . . . . . . . . 95

I.14 Zexel 70 captured spray images, $3.582 \mathrm{~ms}$ ignition delay . . . . . . . . . . . 96

I.15 Zexel 22 captured spray images, $3.585 \mathrm{~ms}$ ignition delay . . . . . . . . . . 97 


\section{Nomenclature}

$\bar{h} \quad$ Average convection heat transfer coefficient

$\sigma \quad$ Standard deviation

$A_{s} \quad$ Surface area

API American Petroleum Institute Specific Gravity

$D C N$ Derived Cetane Number

ID Ignition Delay

$n \quad$ Number of readings

$q \quad$ Heat transfer rate

$T_{\infty} \quad$ Combustion air temperature

$T_{s} \quad$ Surface temperature of fuel droplet

$x \quad$ Deviation of reading from estimated correct value 


\section{Chapter 1}

\section{Introduction}

The combustion of sprays of liquid fuels is of considerable technological importance to a variety of applications ranging from diesel engines to rocket motors. First introduced in the 1880's [1], spray combustion remains the major way of burning liquid fuels today.

A critical component in obtaining successful combustion of liquid fuels is the fuel injection nozzle. These nozzles are generally designed with two primary functions. First, they atomize or finely divide the metered fuel to promote ignition and combustion. The atomization or disintegration of the liquid fuel by the nozzle produces a spray of small droplets in order to increase the surface area resulting in a significant enhancement to the heat and mass transfer rates. Second, they distribute the fuel spray through the combustion chamber to mix with the air to obtain a combustible mixture. Given the key functions that the nozzle carries out, it is easily deduced that nozzle parameters such as its physical dimensions, and spray pattern produced could play a major role in the combustion quality of a given fuel.

In the diesel engine industry, a desirable combustion quality of fuels is easy autoignition under compression. A well established and regulated rating for this quality is the Cetane Rating. A high cetane number $(\mathrm{CN})$ indicates a high performance diesel fuel that 
auto-ignites faster and easier, while a low CN indicates a lower performance diesel fuel that auto-ignites slower and is harder to ignite. The cetane number for a fixed compression ratio is a function of the ignition delay of the fuel. A more thorough discussion of the cetane number and the ignition delay is given in Section 2.1.

The purpose of this research was to try to identify the effects of various nozzle parameters on the ignition delay and the cetane number. In the following sections, the overall scope of the research undertaken is presented and the objectives and tasks of the work carried out are outlined.

\subsection{Motivation}

Since the 1940's [2] the cetane number has been used to characterize the ignition quality of commercially available diesel fuels. The $\mathrm{CN}$ is a regulated diesel fuel specification and is used by the petroleum and automotive industries, and regulatory bodies to ensure diesel fuels produced are able to ignite as completely as possible in the allotted time. For the engine manufacturer, the $\mathrm{CN}$ becomes a key parameter when considering engine performance in terms of fuel efficiency, engine durability, and exhaust emissions.

One of the standard tests for determining the CN is an ASTM standard, test method D6890 (see Section 2.1). This test method relies on measuring the ignition delay of a specimen of fuel which has been injected into a heated, temperature-controlled constant-volume chamber [3]. Presently, most of the world's major oil companies have acquired technology that conforms to D6890 to test their fuels [4] in the form of the Ignition Quality Tester $\left(\mathrm{IQT}^{\mathrm{TM}}\right.$ ) available from Advanced Engine Technology Inc. (AET). The test method specifies a particular nozzle type built to a specific standard (ISO 4010) to be used. However, research and development efforts by AET have demonstrated that different fuel injection 
nozzles built to the same design and standards can have a significant impact in the variability of results, suggesting that small differences in nozzle parameters, such as physical dimensions and spray pattern, can have an effect on the ignition delay measurement.

Understanding the effects of fuel injection nozzles on ignition delay and the CN will lead to a more accurate determination of the ignition quality for diesel fuels. Refineries frequently employ a buffer of CNs (using cetane improvers and additives) to ensure they are meeting the legislated minimum for a particular fuel product within the accuracy of their CN measurement. This CN buffer is known in the oil industry as "cetane giveaway". An improvement in the accuracy of determining the $\mathrm{CN}$ would lead to an overall improvement of fuel quality control, as well as an overall reduction in production costs by reducing the "cetane giveaway".

\subsection{Objectives and Tasks}

The objective of the research undertaken was to determine the effects of the fuel injection nozzle on the ignition delay and cetane number as measured using ASTM test method D6890 (using an $\mathrm{IQT}^{\mathrm{TM}}$ ), and to determine the key parameters of the nozzle that affect the ignition delay.

Nozzles are responsible for atomization of the fuel and distributing the fuel inside the combustion chamber. Therefore, to identify key parameters of the nozzle used in the IQT ${ }^{\mathrm{TM}}$, the physical dimensions that drive the atomization process needed to be investigated, as well as the distribution pattern that the nozzle produces. In Chapter 3 , the test plan along with the experimental apparatus used to carry out these tasks is presented. The following chapter will present the necessary topic background, as well as a review of the pertinent literature. 


\section{Chapter 2}

\section{Background and Literature Review}

In this chapter, the cetane number and ignition delay are presented in detail. The relationship between the two is defined, and several methods of measurement are explained. A summary of nozzle testing techniques developed is also presented, along with a literature review of studies concerning fuel injection nozzles and their effects on combustion characteristics.

\subsection{Cetane Number and Ignition Delay - Measure- ment Methods}

Combustion does not commence at the instant of fuel injection into a combustion chamber, but only after a small amount of the injected fuel has been raised to the temperature of self ignition. This delay period from the beginning of injection to the initiation of ignition is defined as the ignition delay, and is in the order of milliseconds. The ignition delay period itself, can be divided into two separate periods, a physical and a chemical delay period. The physical delay period is the time required for the atomization, heating, vaporization and mixing of the fuel with air before ignition takes place. Proceeding, or 
even overlapping the physical delay is the chemical delay, which is the time required by pre-flame reactions to reach flame conditions, reactions proceeding so slowly that no effect is discernible [5].

In the diesel engine industry, ignition delay is very important. If a fuel has an ignition delay that is too long, the bulk of the charge in the cylinder tends to fire simultaneously, causing violent combustion. With a short delay, ignition is initiated at several points, and the flame subsequently spreads progressively throughout the charge [6]. However, the injection into the cylinder has to be timed appropriately for the ignition delay of the fuel being used, otherwise excessive vibrations, and low fuel efficiency may occur. This has led to the development of the Cetane Scale. A high cetane number indicates a high performance diesel fuel that auto-ignites faster, while a low $\mathrm{CN}$ indicates a lower performance diesel fuel that auto-ignites slower.

\subsubsection{Standard Methods}

First introduced in 1941 [2] in ASTM test method D613, the Cetane Scale is an arbitrary scale from 0 to 100 . N-cetane, a hydrocarbon fuel, ignites very easily under compression and was therefore assigned a CN of 100 . Alpha-methylnaphthalene (AMN), another hydrocarbon fuel, is very hard to ignite and was therefore assigned a CN of 0 . The CN of a fuel sample is then determined as the percent volume of n-cetane in AMN, that provides the same ignition delay of the fuel sample at a given compression ratio. A special engine is used to determine this volume percent of cetane (i.e., the $\mathrm{CN}$ ), known as the Cooperative Fuel Research (CFR) engine [2]. The CFR engine, is a single-cylinder diesel engine, with a variable compression ratio. The fuel sample to be tested is used in the test cylinder and the compression ratio is adjusted until a standard ignition delay period in terms of crankshaft angle (13 degrees) is reached [2]. Using the same compression ratio, various 
volumetric mixtures of $\mathrm{n}$-cetane and $\mathrm{AMN}$ are used until the standard ignition delay value is attained again. The $\mathrm{CN}$ of the fuel sample tested is then equal to the percent volume of cetane in the n-cetane/AMN mixture that yielded the same standard ignition delay period with the same compression ratio. In 1962, a change was made from AMN to heptamethylnonane (HMN) to utilize a material of better storage stability and availability. HMN was determined to have $\mathrm{CN}$ of 15 using blends of n-cetane and AMN [2].

While the CFR engine using ASTM D613 method is currently the primary standard in determining $\mathrm{CN}$ of fuels, there is another method that has recently been developed. A combustion-based analytical method, initially developed by the Southwest Research Institute (SwRI)[7], has been further developed by Advanced Engine Technology (AET) [8]. A small fuel sample is injected into a constant-volume combustion chamber that is pre-charged with air and heated by electrical heaters. The ignition delay of several single injections of the fuel sample is then measured and averaged. The ignition delay is defined as the time delay between start of injection (initial nozzle needle lift) and the start of ignition (start of increase in combustion chamber pressure). This is measured by a proximity sensor that detects the initial needle lift, and a pressure transducer detecting the combustion pressure rise [8]. Once the ignition delay (ID) is determined in ms, it can be converted to a derived cetane number (DCN) using the following correlation [3],

$$
D C N=83.99(I D-1.512)^{(-0.658)}+3.547
$$

In 2004, this method was made a standard ASTM test method under the designation D6890 [3]. A testing apparatus conforming to ASTM D6890 is available from AET in the form of the Ignition Quality Tester (IQT ${ }^{\mathrm{TM}}$ ). The IQT ${ }^{\mathrm{TM}}$ was used as part of the experimental apparatus in the research undertaken, and will be presented in more detail in Chapter 3. 


\subsubsection{Alternate Methods}

The cetane number of different fuels (assuming the same injection and combustion conditions) is ultimately a function of molecular properties of the fuel. Numerous attempts have been made to correlate the $\mathrm{CN}$ with various physical and chemical attributes of the diesel fuel. These include correlations based on either bulk properties such as API gravity, boiling points, and aniline points [9], or based on molecular composition, measured by gas chromatography [10] or inferred from different spectroscopic methods such as Fourier transform infrared spectroscopy, and nuclear magnetic resonance [11].

Several of these correlations have enjoyed enviable success in determining the CN of various diesel fuels and their blends. One in particular developed by the Institute of Petroleum [12], is used extensively in the petroleum industry and is referred to as the Cetane Index. However, these correlations are based on empirical data from commonly used fuels at the time of development, and with the push towards low sulfur diesel fuels and the addition of cetane improvers to fuels, the results of such equations are becoming progressively less satisfactory. Thus, they need constant updating, or risk being not applicable to new future fuels being developed.

Some research has been to done to try to determine the the ignition delay of a fuel numerically [13] instead of experimentally in a combustion chamber. However, no further development has been done to correlate numerical ignition delay values to the CN.

\subsection{Fuel Injection Nozzle Testing}

Fuel injection nozzles being a very critical component of spray combustion systems are frequently tested to ensure they conform to certain standards. This has led to the development of several testing methods to characterize key nozzle parameters such as the 
spray pattern produced by the nozzle, and the critical physical geometries responsible for the atomization of the fuel and the injection rate.

\subsubsection{Spray Pattern Analysis}

The spatial distribution of drops in sprays is critical to the performance of many atomization systems, including diesel engine injectors, gas turbine injectors, spray coating systems, and furnace burners. An approach to obtain reliable pattern information from laser light sheet imaging was developed at Queen's University and the Royal Military College [14]. This technology is now available as the Optical Spray Pattern Analyzer (OSPA) from Nexum Instrumentation.

The technique uses an array of laser diodes to produce a planar region of illumination, as shown in Figure 2.1. Objects crossing this region of illumination scatter light in different

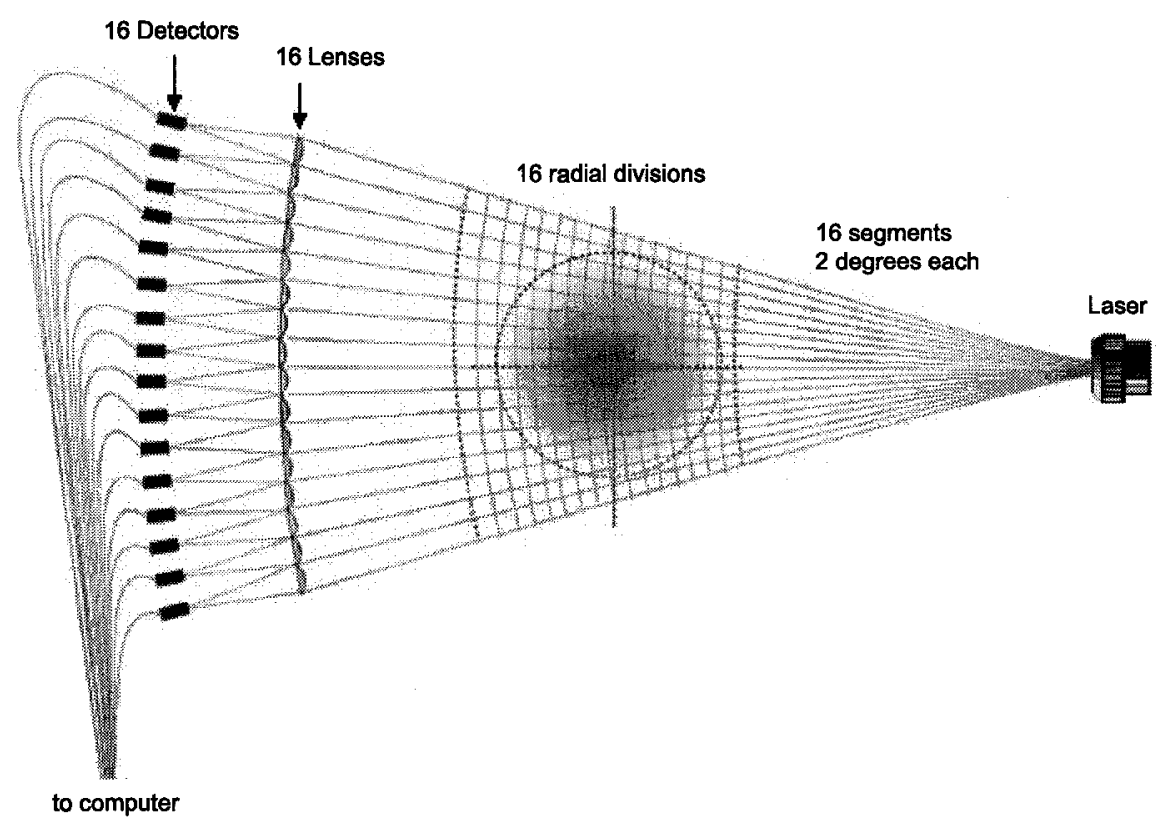

Figure 2.1: Planar region of illumination produced by laser array [15] 
directions through refraction and reflection. The scattered light is then captured and recorded by a high-speed CCD camera [14].

This system is used to capture images of the spray pattern of a nozzle as illustrated in Figure 2.2. Post processing of the signal corrects for illumination non-uniformities that exist within the planar region of illumination, as well as for the skewness of the image due to the position of the camera [14]. The resulting image is a true representation of the spray pattern, and quantitative data of the spray such as the average diameter, circumferential distribution, and radial distribution can be obtained.

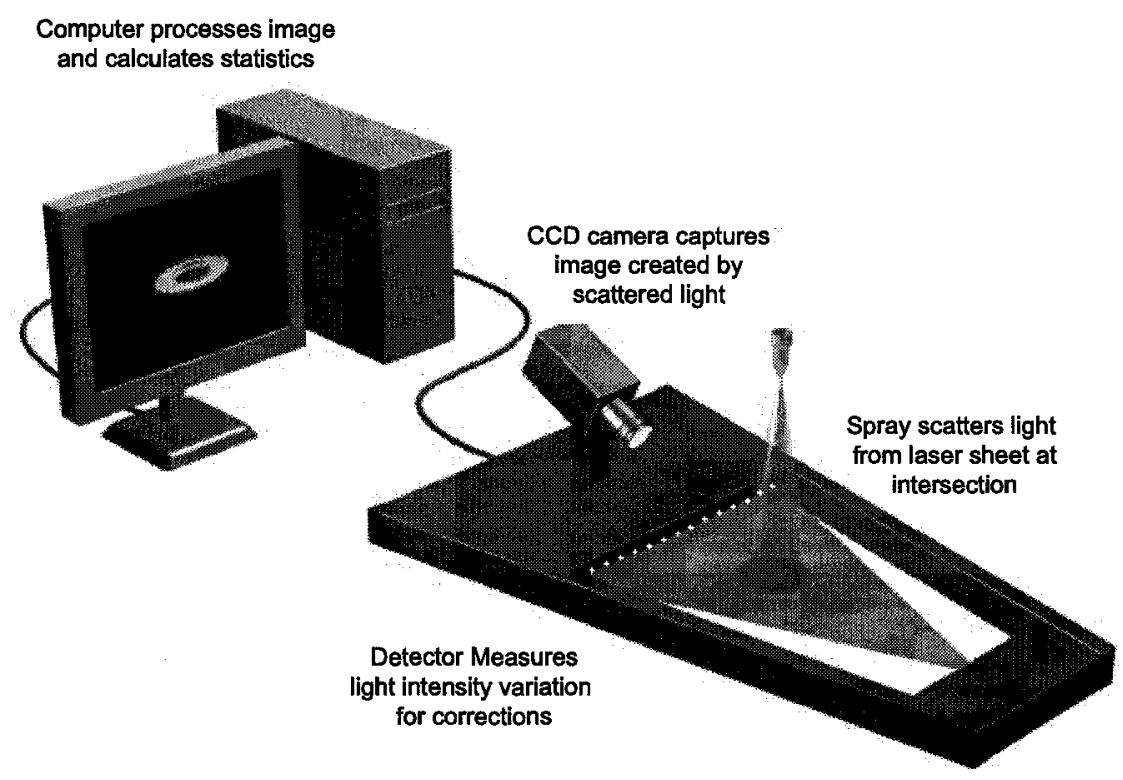

Figure 2.2: Capturing of nozzle spray pattern [15]

\subsubsection{Nozzle Geometry Analysis}

Nozzle geometry is a critical factor in determining the level of atomization of the fuel spray, the spray shape, and the injection rate. It is therefore important to be able to characterize the key nozzle parameters that drive those properties. 
Many dimensions of the nozzle are easily accessible and can be directly measured on a profile projector. This was done in the research undertaken and is presented in Chapter 3. However, internal nozzle dimensions such as the pintle clearance, or the clearance between the needle and the barrel are so small and inaccessible that they can only be measured indirectly.

A particular standard test method (ISO 4010) [16] developed for a nozzle design known as a delay pintle type nozzle, employs choked gas flow to quantify small clearances that are inaccessible for direct measurement. Once gas flow is choked at a constant upstream stagnation pressure, it becomes a direct function of the minimum cross sectional area. ISO 4010 specifies two test methods for delay pintle type nozzles. One for quantifying clearance at the pintle and the other for quantifying clearance at the needle guide. The ISO standard specifies a particular range of flow values that must be achieved by the test nozzle in order for it to be classified as an ISO 4010 nozzle. The standard also specifies needle dimensions that can be measured directly on a profile projector.

The nozzles used in the IQT ${ }^{\mathrm{TM}}$, and specified in ASTM D6890 are specified as ISO 4010 nozzles [3]. The test methods specified in ISO 4010 were used in the experimental apparatus of the research undertaken, which is discussed in detail in Chapter 3.

\subsection{Fuel Injection Nozzles and Ignition Delay}

The self-ignition process of diesel fuels is influenced by many parameters which are partially interrelated. There is a limited amount of work in the literature that has sought to narrow down the effects of the fuel injection systems on ignition delay. Several studies can be found where the effects of the fuel injection system on overall combustion characteristics such as $\mathrm{NO}_{x}$ emissions, soot-formation, and flame structure where investigated [17; 18], but not specifically on ignition delay. 
Of the limited amount of work relating to ignition delay, one particular study has investigated the effects of varying nozzle orifice diameter on ignition delay [19]. In this study, a high-pressure chamber at pressures up to $60 \mathrm{bar}$ and temperatures up to $600^{\circ} \mathrm{C}$ was used as a combustion chamber for injected fuel. The ignition was detected by a photomultiplier, where start of ignition was indicated by a steep increase of the photomultiplier signal. The needle lift signal of the injection nozzle was also measured, and thus the ignition delay was calculated as the time between the start of the needle lift and the first light signal. Bosch type one-hole injection nozzles with orifice diameters ranging from 0.30 to $0.20 \mathrm{~mm}$ $(0.30,0.27,0.25,0.20 \mathrm{~mm})$ were tested. The study shows that in their results, the ignition delay for high-pressure injections through a single hole nozzle of small diameter was longer than in the case of the low-pressure injection through a single hole nozzle of large diameter [19]. The authors attributed the longer ignition delay in the smaller hole nozzle to a drop of local mixture temperature caused by the more rapid vaporization resulting from finer atomization.

Another study [20] compared the ignition delay between a two-stage and a single-stage injection diesel spray using a high-speed video system in a constant-volume combustion chamber. The results showed that the ignition delay of a two-stage injection spray was shorter than that of a single-stage injection spray. The authors attributed this to the enhancement of the mixing effect between fuel and surrounding air caused by the twostage injection. 
To date, no studies have been found in the literature that explicitly address the effects of the nozzle spray pattern on the ignition delay or cetane number. Although several studies have been carried out on spray characteristics of nozzles, there do not appear to be any results published in the open literature with specific references to the spray pattern and ignition delay or cetane number. 


\section{Chapter 3}

\section{Test Plan and Experimental}

\section{Apparatus}

To determine the effects of fuel injection nozzles on the ignition delay and cetane number, a test plan was developed employing the use of several experimental apparatus. A sample of 15 delay pintle type nozzles and a single typical diesel fuel were chosen for the study.

Each of the 15 nozzles was used to test CF12, a diesel reference fuel, according to ASTM D6890 using an Ignition Quality Tester (IQT ${ }^{\mathrm{TM}}$ ) available from Advanced Engine Technology (AET). Each one of the nozzles was placed in the same IQT ${ }^{\mathrm{TM}}$ unit, and the same fuel from the same source was tested. This ensured to a reasonable degree that any fluctuation of the ignition delay and cetane number was a function of the nozzle. Once completed, a data set of ignition delay and cetane values was obtained for CF12 for each corresponding test nozzle.

The spray pattern for each of the nozzles was analyzed using the developed optical spray test rig. Internal geometry for each of the nozzles was then characterized in terms of flow rates according to an ISO test method [16] using two test rigs that were designed 
and developed specifically for this task. Finally, accessible nozzle geometry was measured directly with the aid of a profile projector. All the obtained spray and geometry characteristics of each of the 15 nozzles were then compared to their corresponding ignition delay and cetane number values for examination and discussion. This is presented in Chapter 4 . The delay pintle type nozzle and its injection properties are presented in detail in the following section, followed by a detailed presentation of each of the experimental apparatus used.

\subsection{Test Nozzles - Delay Pintle Type}

ASTM D6890 specifies a delay pintle type nozzle [3] to be used in the test method. Therefore, the test nozzles had to be of the delay pintle type shown in Figure 3.1.

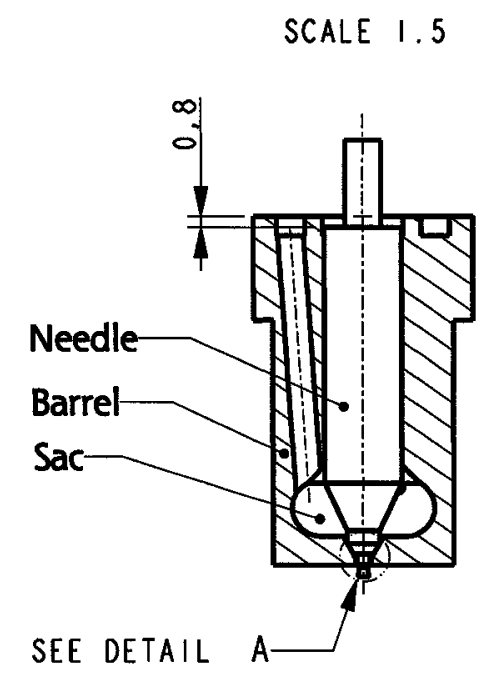

ALL DIMENSIONS IN MM
SCALE 10.0

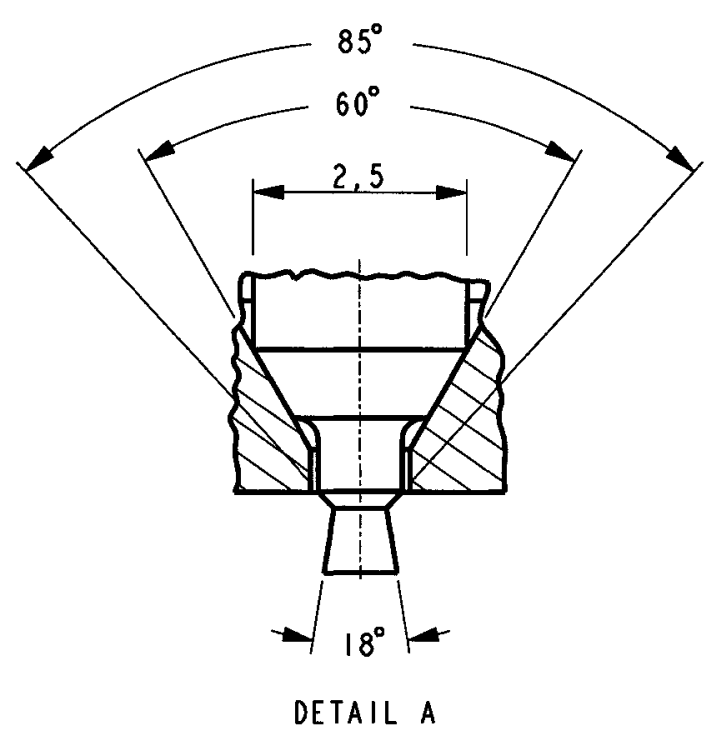

Figure 3.1: Delay pintle type nozzle 
To accentuate the effect of the nozzle on the ignition delay, the test nozzles were chosen from several manufactures or from different batches. The idea was, nozzles, even though of the same design, being from different manufactures or from different assembly lines, would have slightly different characteristics that would show up in our measurements of the ignition delay and cetane number. The 15 test nozzles are identified in Table 3.1. All 15 nozzles where thoroughly cleaned before and after each of the tests to avoid contamination of the nozzles. The cleaning procedure is outlined in Appendix A.

Table 3.1: Fifteen test nozzles from 3 different manufacturers

\begin{tabular}{|c|}
\hline Nozzle ID \\
\hline Sun 1 \\
\hline Sun 32 \\
\hline Sun 63 \\
\hline Sun 65 \\
\hline Sun 66 \\
\hline Sun 68 \\
\hline Sun 69 \\
\hline Zexel 9 \\
\hline Zexel 15 \\
\hline Zexel 22 \\
\hline Zexel 35 \\
\hline Zexel 70 \\
\hline Zexel 71 \\
\hline Zexel 76 \\
\hline CAV 14 \\
\hline
\end{tabular}

The delay pintle type nozżle is designed in such a way that at beginning of injection the initial rate of injection is slow. The fuel enters the nozzle from three holes in the barrel and sits in a sac at the bottom of the nozzle. The valve at the bottom of the nozzle formed by the needle and the barrel is kept shut typically by spring pressure pushing the needle against the barrel. Once the fuel pressure increases (from the injection pump), and overcomes the spring pressure, the fuel pushes on the needle and is sprayed through the 
clearance between the barrel orifice and the needle pintle known as the pintle clearance. The rate of injection is controlled by the minimum cross sectional area that the fuel encounters as it flows through the valve. The needle typically lifts to a maximum of about $0.8 \mathrm{~mm}$. As the needle lifts, the minimum cross sectional area changes as illustrated in Figure 3.2, effectively controlling the injection rate.

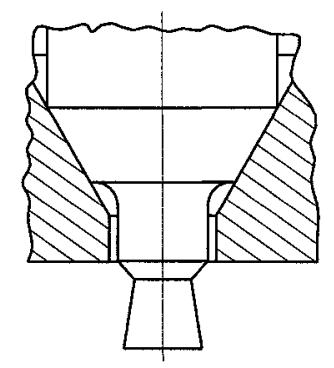

(a)

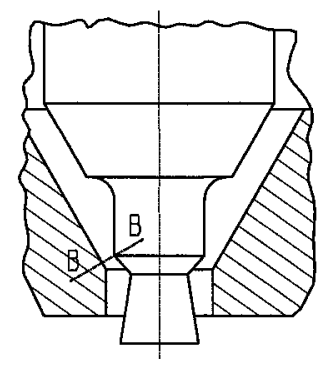

(c)

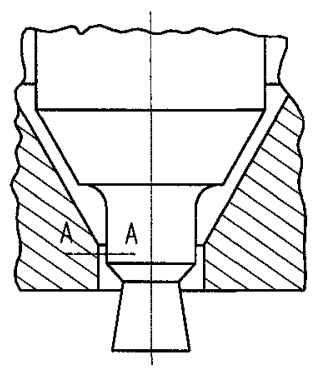

(b)

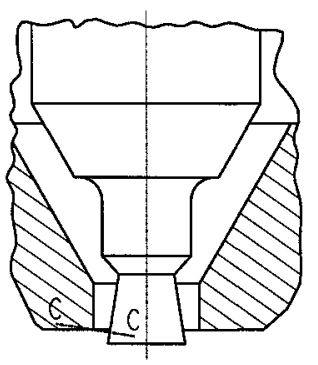

(d)

Figure 3.2: Minimum nozzle pintle clearance varying with lift - (a) no lift, closed position (b) beginning of lift to $0.45 \mathrm{~mm}$, flow controlled by $A A$ surfaces (c) 0.45 to 0.65 $\mathrm{mm}$, flow controlled by $B B$ surfaces (d) 0.65 to end of lift, flow controlled by $C C$ surfaces

Figure 3.3 shows a typical variation of the throat clearance as the needle lifts. From the figure, the delaying effect from 0 to $0.45 \mathrm{~mm}$ is clearly visible. This pintle clearance along with the needle clearance slightly vary from nozzle to nozzle due to manufacturing differences. This variation was characterized for all 15 test nozzles using the apparatus described in Sections 3.4, and 3.5. 


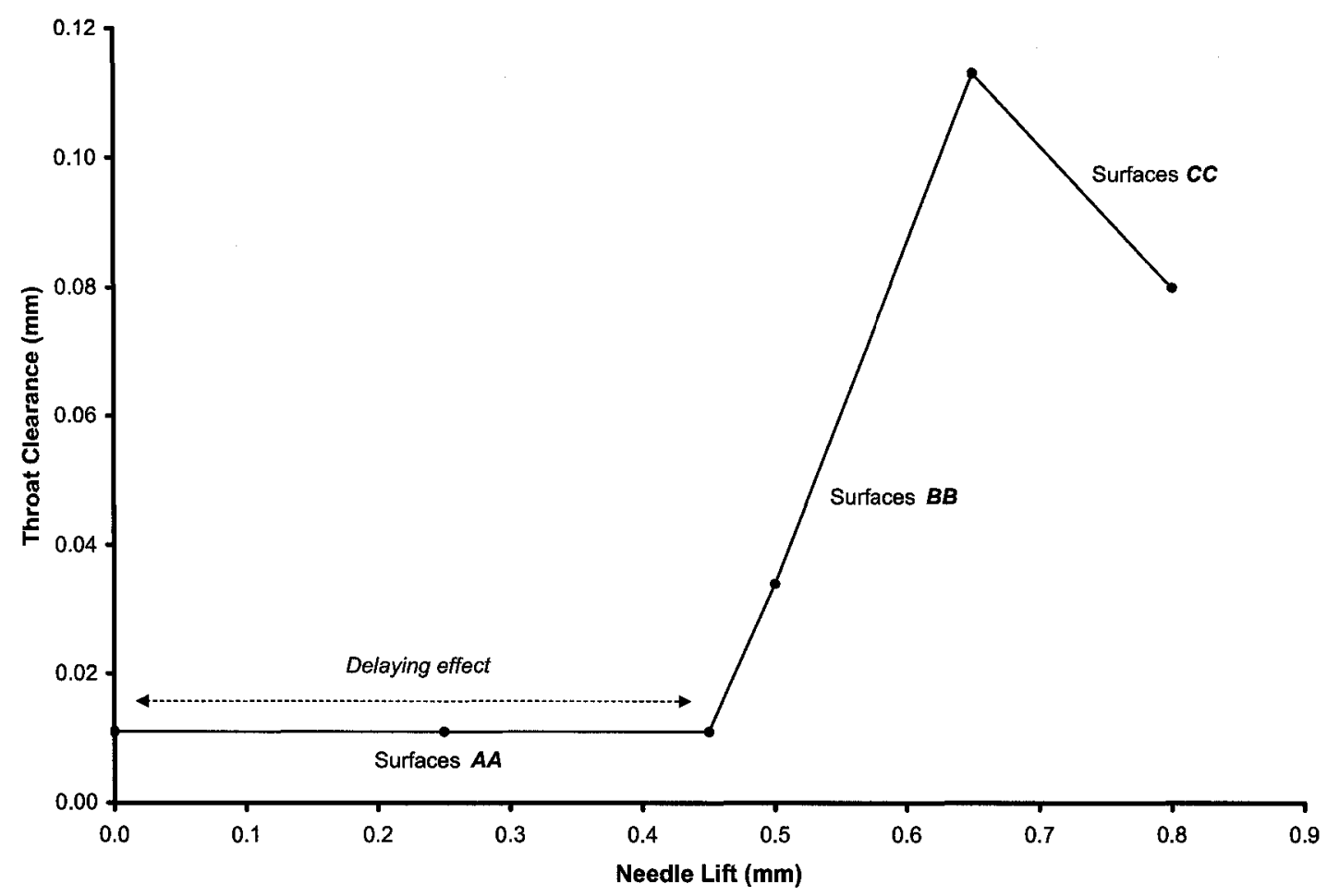

Figure 3.3: Typical variation of the throat clearance in a delay pintle type nozzle

\subsection{Ignition Quality Tester}

The ignition quality tester (IQT ${ }^{\mathrm{TM}}$ ) available from Advanced Engine Technology (AET) shown in Figure 3.4, is an automated experimental apparatus for measuring ignition quality of diesel fuels using ASTM test method D6890 [21]. The IQT ${ }^{\mathrm{TM}}$ as per ASTM D6890 test method, measures the ignition delay of a fuel sample, utilizing a constant-volume combustion chamber with direct fuel injection into heated, pressurized air.

The IQT ${ }^{\mathrm{TM}}$ injects a small fuel sample into a constant-volume combustion chamber that is pre-charged with air and heated by electrical heaters. Fifteen pre-injections are carried out to prepare the injection system, followed by 32 injections. The ignition delay of the 32 injections of the fuel sample is measured and averaged. The ignition delay is defined as the time delay between start of injection (initial nozzle needle lift) and the 
start of ignition (start of increase in combustion chamber pressure). This is measured by a proximity sensor that detects the initial needle lift, and a pressure transducer detecting the combustion pressure rise [8]. Once the averaged ignition delay is determined, the $\mathrm{IQT}^{\mathrm{TM}}$ converts it to a derived cetane number (DCN) as per the ASTM test method using equation 2.1.

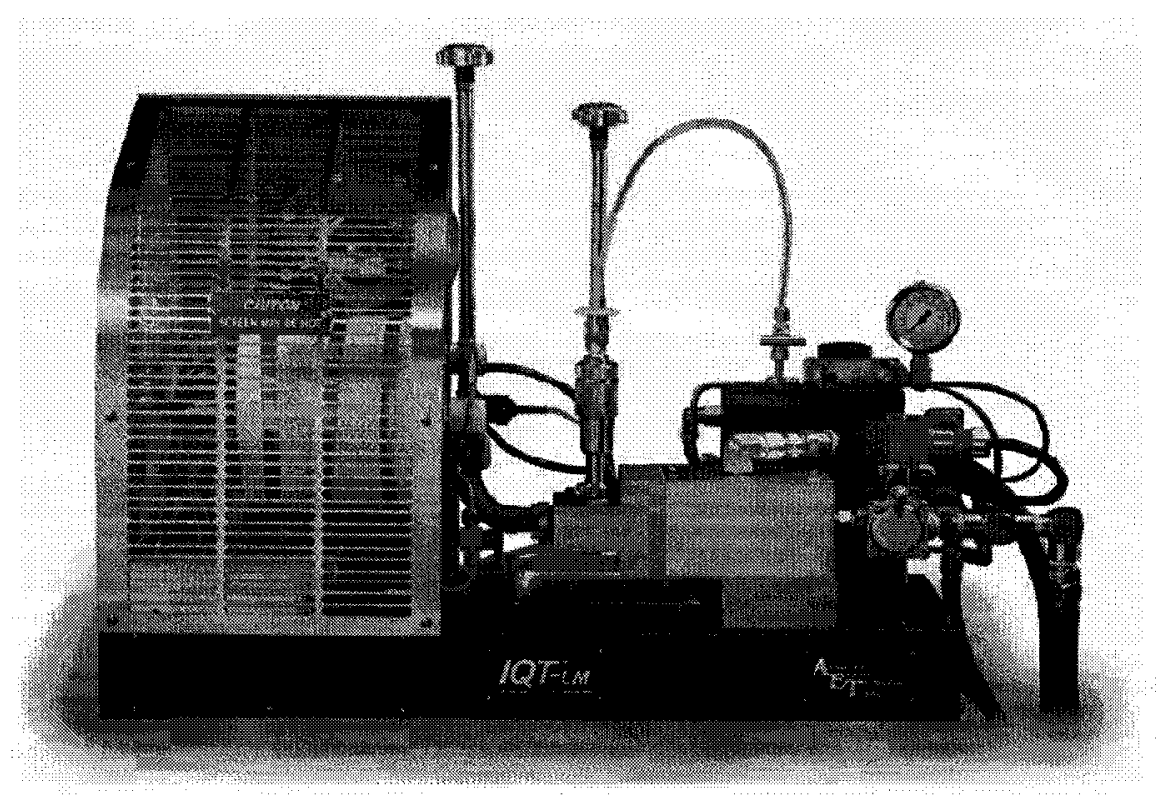

Figure 3.4: The ignition quality tester $\left(\mathrm{IQT}^{\mathrm{TM}}\right)[21]$

The ASTM test method covers the ignition delay range from 3.3 to $6.4 \mathrm{~ms}$ (60 to 33 DCN). The repeatability of the test method for the DCN is the same throughout the covered DCN range, and is equal to 0.76 DCN. For the ignition delay range of 3.3 to 6.4 $\mathrm{ms}$, the repeatability varies accordingly from 0.059 to $0.175 \mathrm{~ms}$ [3]. A detailed schematic of the $\mathrm{IQT}^{\mathrm{TM}}$ is given in Figure 3.5. 


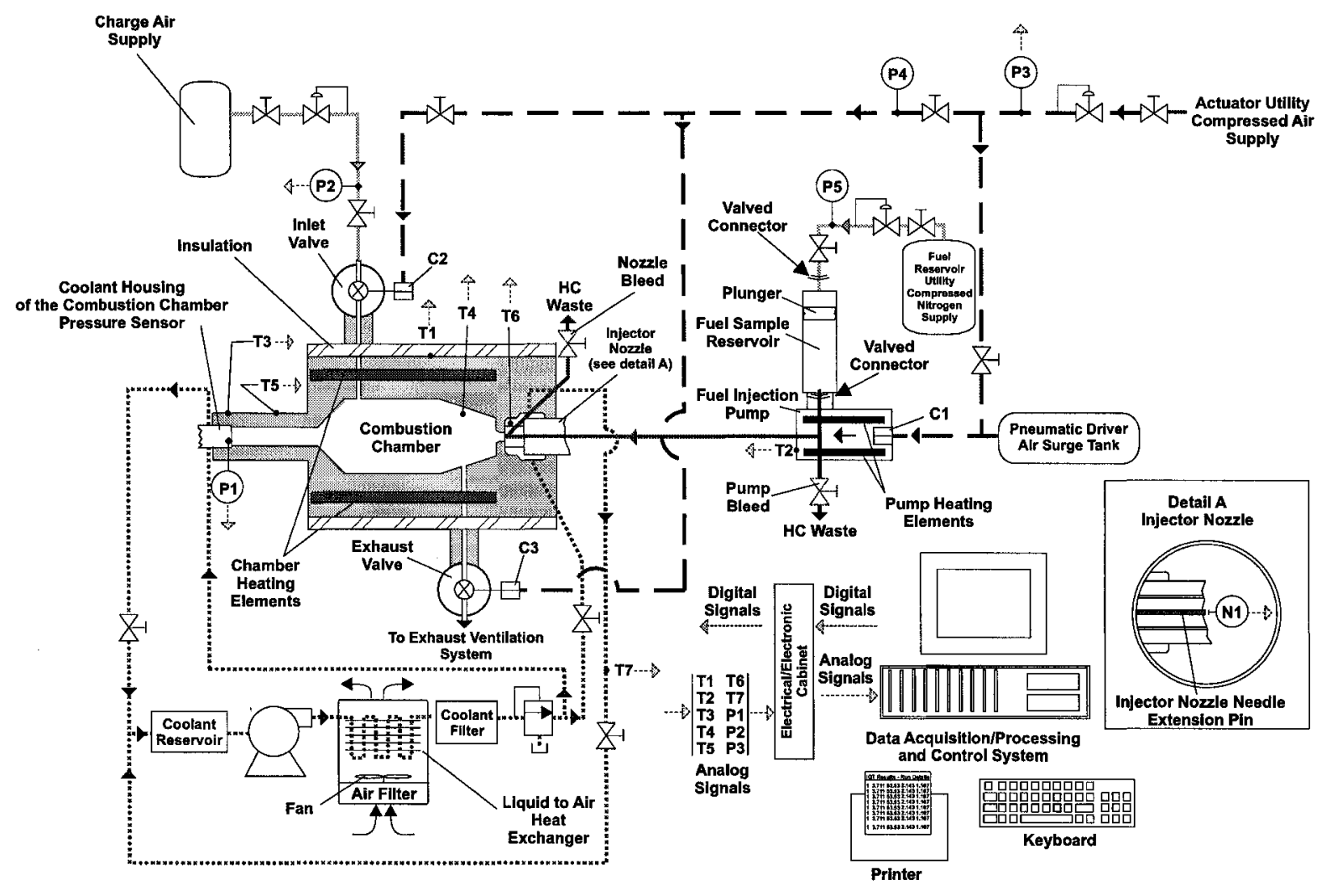

Legend

P1: Combustion Chamber Pressure

P2: Charge Air Pressure

P3: Injection Actuator Air Pressure

P4: Inlet/Exhaust Valve Actuator Air Pressure (Gauge)

P5: Sample Fuel Reservoir Pressure (Gauge)

T1: Combustion Chamber Outer Surface Temperature

T2: Fuel Injection Pump Temperature

T3: Combustion Chamber Pressure Sensor Temperature

T4: Charge Air Temperature

T5: (used for diagnostic functions)

T6: Injector Nozzle Coolant Passage Temperature

T7: Coolant Return Temperature

N1: Injector Nozzle Needle Motion Sensor

C1: Digital Signal - Fuel Injection Actuator

C2: Digital Signal - Inlet Valve Actuator

C3: Digital Signal - Exhaust Valve Actuator

Figure 3.5: Ignition quality tester schematic, courtesy of AET

All 15 test nozzles were used one at a time in one IQT ${ }^{\mathrm{TM}}$ machine to test one fuel (CF12 with an established ignition delay of $3.472 \mathrm{~ms}$ and DCN of 57.5) according to ASTM D6890. This resulted in 15 ignition delay and $\mathrm{DCN}$ values corresponding to each of the 15 test nozzles. 


\subsection{Optical Spray Pattern Test Rig}

To determine the effects of spray pattern on ignition delay and cetane number, an optical spray pattern test rig was developed. The test rig was comprised of the $\mathrm{IQT}^{\mathrm{TM}}$ fuel injection system and data acquisition system, and the Optical Spray Pattern Analyzer from Nexum. The opening spring pressure was kept the same as in the IQT ${ }^{\mathrm{TM}}$ for all the nozzles at 3000 psi. A schematic of the test rig is shown in Figure 3.6.

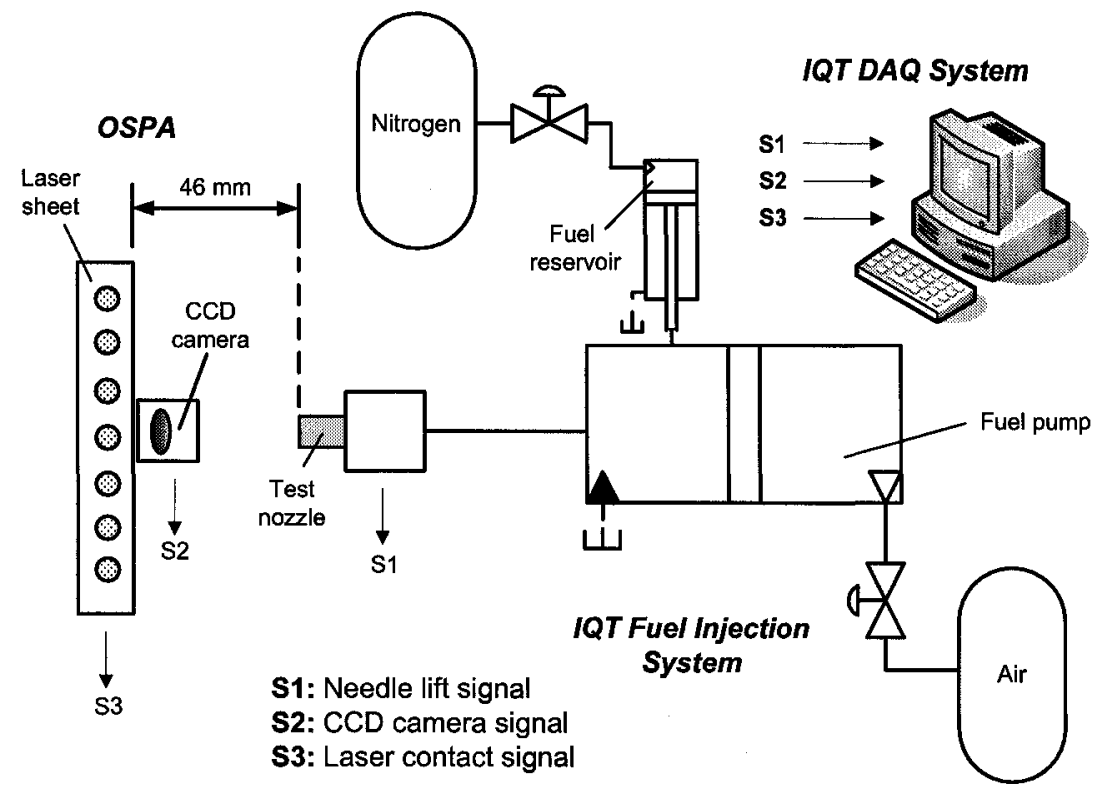

Figure 3.6: Optical spray pattern test rig schematic

The OSPA system uses an array of laser diodes to produce a planar region of illumination. Spray droplets crossing this region of illumination scatter light in different directions through refraction and reflection. The scattered light is then captured and recorded by a high-speed CCD camera at a rate of one frame every $2 \mathrm{~ms}$ with a temporal resolution of $0.18 \mathrm{~ms}$, and a spatial resolution of 320 by 320 pixels. The laser sheet was placed $46 \mathrm{~mm}$ from the nozzle, and injection was done horizontally as was the case in the IQT ${ }^{\mathrm{TM}}$. This is illustrated in Figure 3.7. 


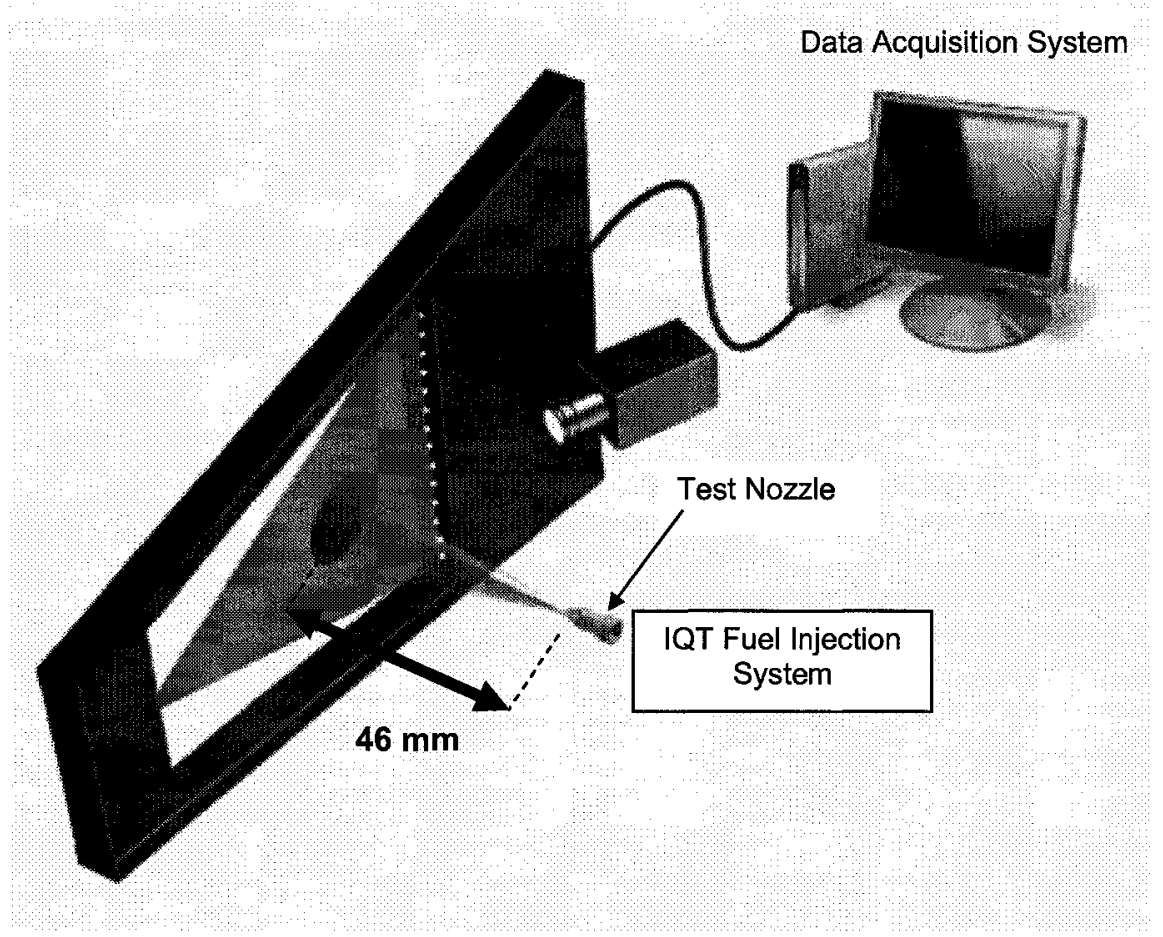

Figure 3.7: Optical spray pattern test rig - horizontal injection, $46 \mathrm{~mm}$ from test nozzle

The images were corrected through the OSPA system for illumination non-uniformities, and the skewness of the image due to the angled position of the camera. Essentially, this setup produced planar images of the spray pattern of the nozzle that would have occurred inside the combustion chamber of the $\mathrm{IQT}^{\mathrm{TM}}$, with the exception that injections were done in free quiescent air, instead of inside the $\mathrm{IQT}^{\mathrm{TM}}$ combustion chamber. A spray collection system, consisting of a large plastic collector, connected to a vacuum pump was placed sufficiently downstream of the spray (so as to not disturb the spray behaviour) to collect the diesel fuel after injection. 
The main injection event typically lasted for just over $2 \mathrm{~ms}$. This presented a challenge since the camera was capable of only 1 frame every $2 \mathrm{~ms}$, which would have allowed for a possibility of only one frame inside the main injection event. To add to this, the OSPA system does not allow for direct control of the CCD camera. The camera is constantly running, taking a frame every $2 \mathrm{~ms}$ with no way to synchronize to the injection event. To overcome this, a test procedure was developed to test each nozzle that would allow for several frames of the main injection event to be captured along with the time in the injection event (zero being start of injection event) corresponding to each frame.

To accomplish this, each of the 15 nozzles were tested using the same fuel (CF12), and 5 injections were done using each nozzle. The camera was constantly running during all 5 injections, which resulted in frames falling randomly inside the main injection event. By repeating the test with each nozzle 5 times, at least 5 frames within the main injection event were captured. To determine the temporal location of each captured frame relative to the start of injection event, two signals from the OSPA system were routed to the IQT $^{\mathrm{TM}}$ data acquisition (DAQ) system. The two signals were the CCD camera on/off signal indicating when the frames were being taken in time, and an average signal of the 16 laser detectors indicating when the spray contacts the laser sheet. By combining these two signals with the needle lift sensor signal of the IQT ${ }^{\mathrm{TM}}$ fuel injection system, the temporal location of the captured frame could be determined. This is illustrated in Figures 3.8, and 3.9. 
Each test nozzle was tested in this manner, resulting in at least 5 captured frames within the main injection event with temporal location information allowing for comparison of the spray pattern among all of the 15 test nozzles. To determine the repeatability of the test rig, it was necessary to obtain images for the same nozzle during the same time within the injection event. This was achieved by repeated testing of a nozzle until two frames were obtained that fell at the same time (or very close) on the injection event. The images were then visually compared, and were found to be fairly close. This repeatability study was done using two test nozzles and is included in Appendix B.

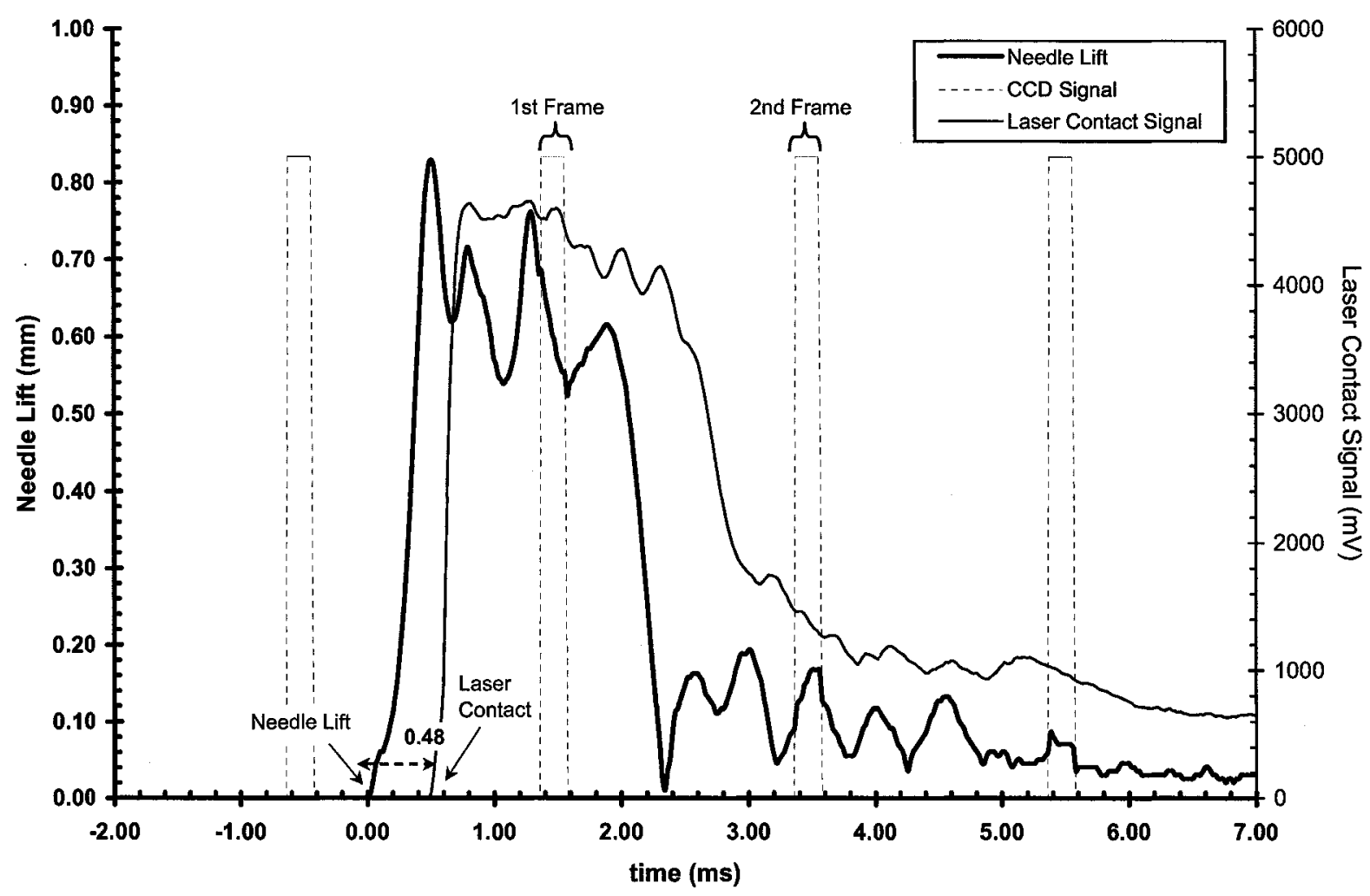

Figure 3.8: The time difference between the start of needle lift and first laser contact, is the time it takes for the first nozzle spray drops to reach the laser sheet 


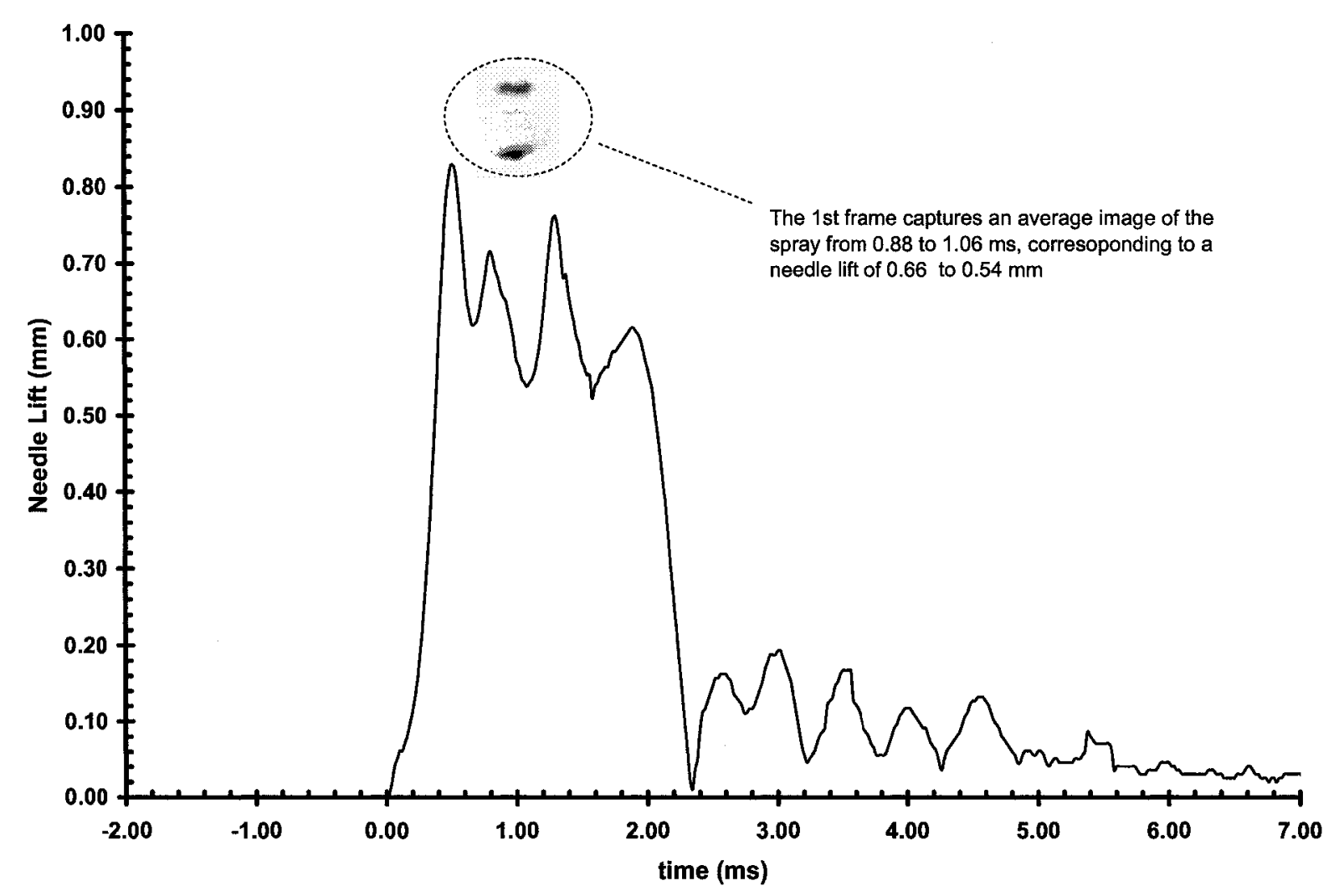

Figure 3.9: By knowing the time delay for the spray, the camera frame can be corrected back by that delay to give us the temporal location on the needle lift of the captured spray

\subsection{Pintle Clearance Air Flow Test Rig}

An important nozzle parameter in terms of combustion performance, is the clearance between barrel orifice and the needle protrusion known as the pintle clearance. To characterize this clearance for the 15 test nozzles, a test rig was designed conforming to ISO 4010 Test Method 1 [16]. A schematic of the developed test rig is given in Figure 3.10.

The test method employs ambient air flow driven by a vacuum pump using pressures sufficiently below ambient pressure so as to choke the flow (sonic velocity reached) in the effective cross section and at the outlet of the nozzle. Once the flow is choked, the flow rate becomes proportional to the effective cross-section of the nozzle [16]. 


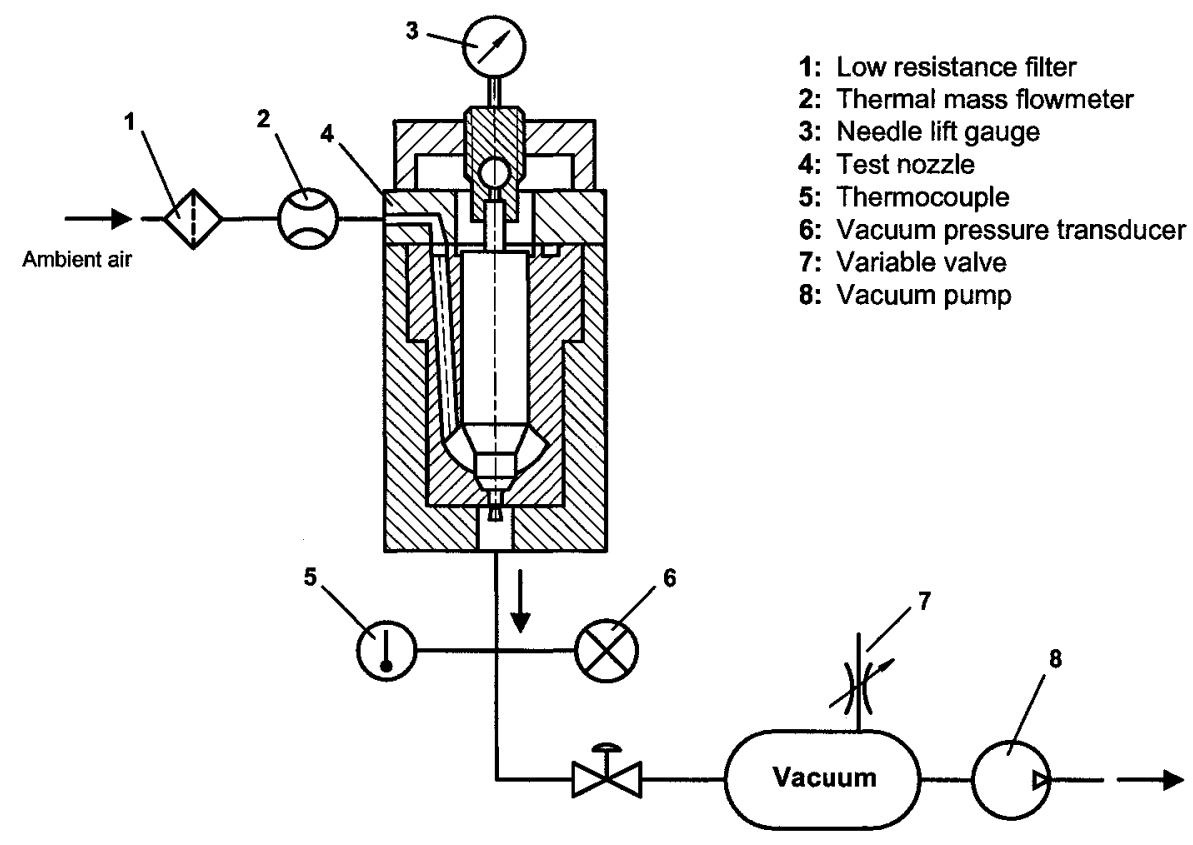

Figure 3.10: Pintle clearance air flow test rig schematic

The needle lift can then be varied and flow rate readings can be taken corresponding to each lift value. This results in a flow vs. lift curve representative of the throat area variation as needle lift varies. Since the flow rate is proportional to the pintle clearance, the resulting curve is very similar to Figure 3.3 .

The test rig developed adheres to the ISO 4010 test method. A nozzle holder was designed that would allow for varying the needle lift of the test nozzle. Detailed drawings of the design are provided in Appendix $\mathrm{C}$ along with a list of main parts and components of the test rig. The needle lift was measured using a high accuracy Mitutoyo Model 543-262 dial gauge indicator. A vacuum pump was used to provide up to 0.96 bar below ambient vacuum pressure, which was measured using a manufacturer calibrated Cole-Parmer Model 68075 vacuum pressure transducer. A Brooks Model 5850S thermal mass flowmeter was used to measure the flow rate. The flowmeter was manufacturer calibrated for air at ambient conditions, and outputs a volume flow rate reading standardized to calibration 
conditions density. The manufacturer calibration data is reproduced in Appendix E.1. A PC using a 12 bit ComputerBoards Inc. CIO-DAS16/Jr ISA interface data acquisition card was used for data collection. The data acquisition system was shared with the Needle Clearance Nitrogen Flow Test Rig. Details and wiring schematic of the data acquisition system developed are included in Appendix D.

To ensure that the flow was indeed choked at the nozzle outlet, all piping was chosen such that the nozzle outlet geometry was the smallest throat area that was encountered by the flow. The test method specifies a minimum pressure of 0.8 bar below ambient downstream of the nozzle to achieve choked flow. Compressible flow theory states that once sonic velocity is established in the nozzle throat, decreases in the downstream pressure will have no influence on the nozzle inlet flow [22]. To ensure that the flow was in fact choked, the pressure downstream was decreased from an initial 0.8 bar below ambient to 0.96 below ambient with no resulting change in flow rate, suggesting that the flow was indeed choked at the throat.

All 15 test nozzles were tested in the test rig. Flow rate measurements were taken at $0.05 \mathrm{~mm}$ increments of needle lift, resulting in a flow rate vs. needle lift curve for each of the 15 test nozzles. The testing procedure that was developed and used for each test nozzle is given in Appendix F. A repeatability study was also conducted to determine the precision of the test rig, and is included in Appendix E.2. 


\subsection{Needle Clearance Nitrogen Flow Test Rig}

The clearance between the needle and the barrel was quantified in terms of nitrogen flow rate for each of the 15 test nozzles. ISO 4010 Test Method 2 [16], is a standard test method for such measurement. A test rig was designed conforming to this standard, and a schematic of the developed test rig is given in Figure 3.11.

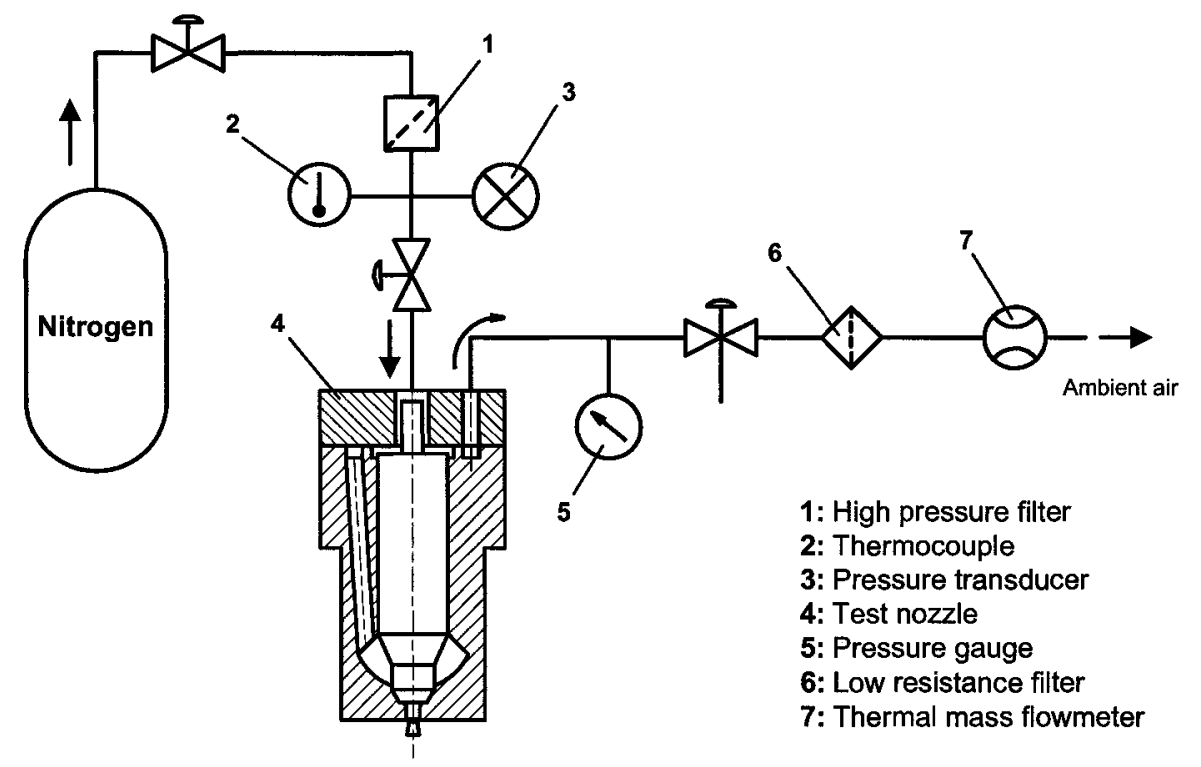

Figure 3.11: Needle clearance nitrogen flow test rig schematic

The test method employs nitrogen pressurized at 20 bar to be forced through the clearance between the barrel and the needle exiting to ambient air. The significant drop from 20 bar to atmospheric pressure leads to sonic flow conditions with the flow rate becoming a direct function of the needle clearance [16]. The test rig developed adheres to the ISO 4010 test method. A nozzle holder was designed that would allow for the nitrogen to flow through the needle clearance of the test nozzle. Detailed drawings of the design are provided in Appendix $\mathrm{C}$ along with a list of main parts and components of the test rig. 
An ASCO Model 40 manufacturer calibrated pressure transducer was used to ensure the nitrogen pressure was at the required 20 bar. A Cole-Parmer Model FMA1710 thermal mass flowmeter was used to measure the flow rate. The flowmeter was manufacturer calibrated for air at ambient conditions, and outputs a volume flow rate reading standardized to calibration conditions density. The manufacturer calibration data is given in Appendix G.1. A PC using a 12 bit ComputerBoards Inc. CIO-DAS16/Jr ISA interface data acquisition card was used for data collection. The data acquisition system was shared with the Pintle Clearance Air Flow Test Rig. Details and wiring schematic of the data acquisition system developed are included in Appendix D.

All 15 test nozzles were tested in the test rig. The testing procedure that was developed and used for each test nozzle is given in Appendix H. A repeatability study was also conducted to determine the precision of the test rig, and is included in Appendix G.2. 


\subsection{Profile Projector}

A Mitutoyo profile projector Model PJ-300 was used to take key measurements of nozzle needles for each of the 15 test nozzles. $\mathrm{X}$ and $\mathrm{Y}$ measurements, as well as angle measurements were made on the profile projector at 50 times magnification. Figure 3.12 shows the profile of a nozzle needle in position for measurement.

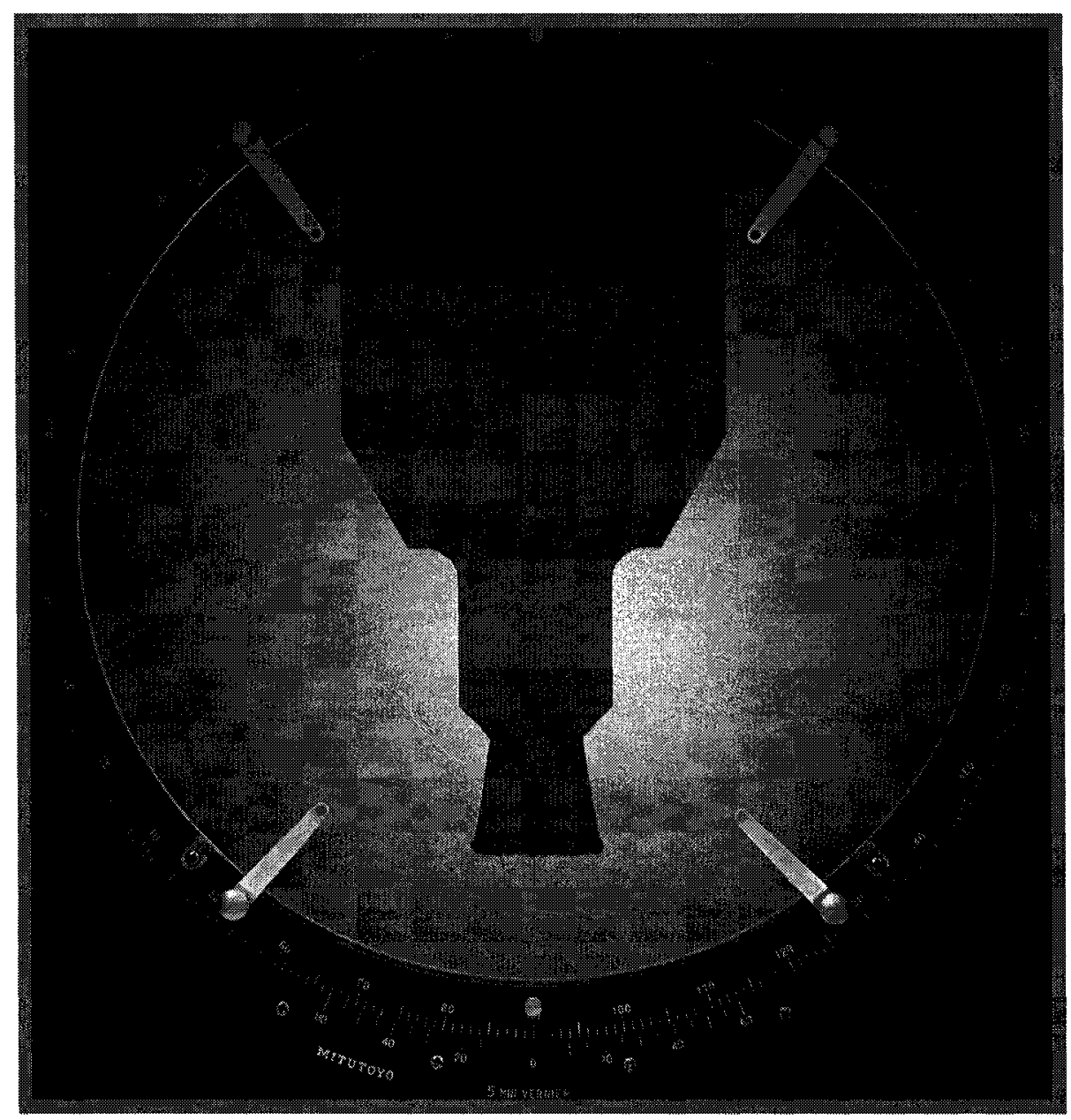

Figure 3.12: Needle profile shadow on the profile projector 
The key dimensions measured are identified in Figure 3.13, and were measured to an accuracy of $0.01 \mathrm{~mm}$, and $0.25^{\circ}[23]$ using the profile projector.

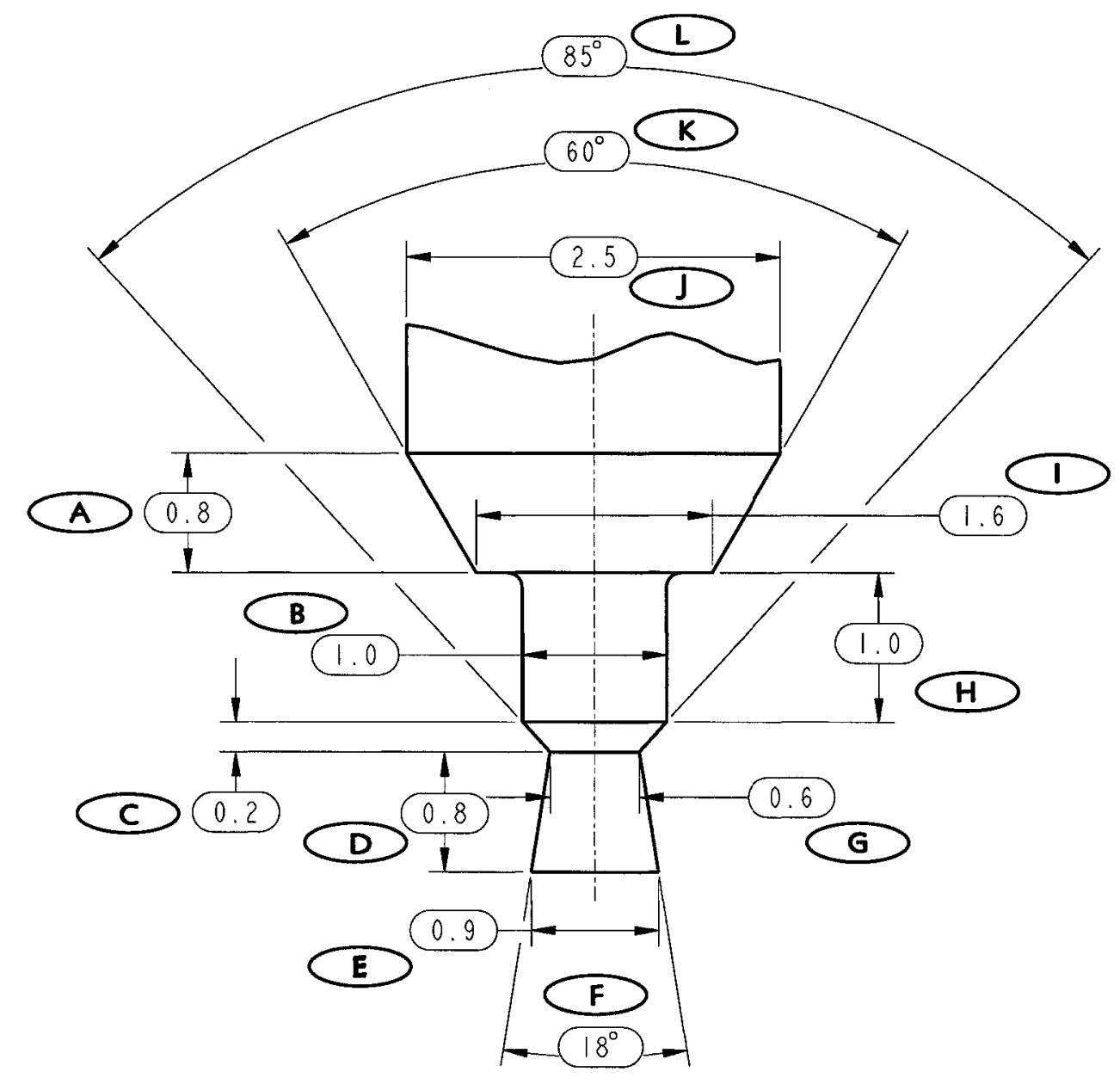

Figure 3.13: Key nozzle needle dimensions measured, reference values shown (mm) 


\section{Chapter 4}

\section{Results and Discussion}

By using the experimental apparatus described in Chapter 3, data was collected for all 15 test nozzles. For each of the nozzles, ignition delay and cetane number values were obtained using CF12 as fuel, along with nozzle spray images, internal geometry flow data, and needle profile dimensions. The complete data set is given in Appendix I. 
The ignition delay and cetane number values found for each of the nozzles using ASTM D6890 test method are summarized in Figure 4.1. By comparing the nozzle spray and geometry data to the corresponding nozzle ignition delay data, the effects of the various nozzle parameters on ignition delay and cetane number were investigated. The results along with a discussion of the findings are presented in the following sections.

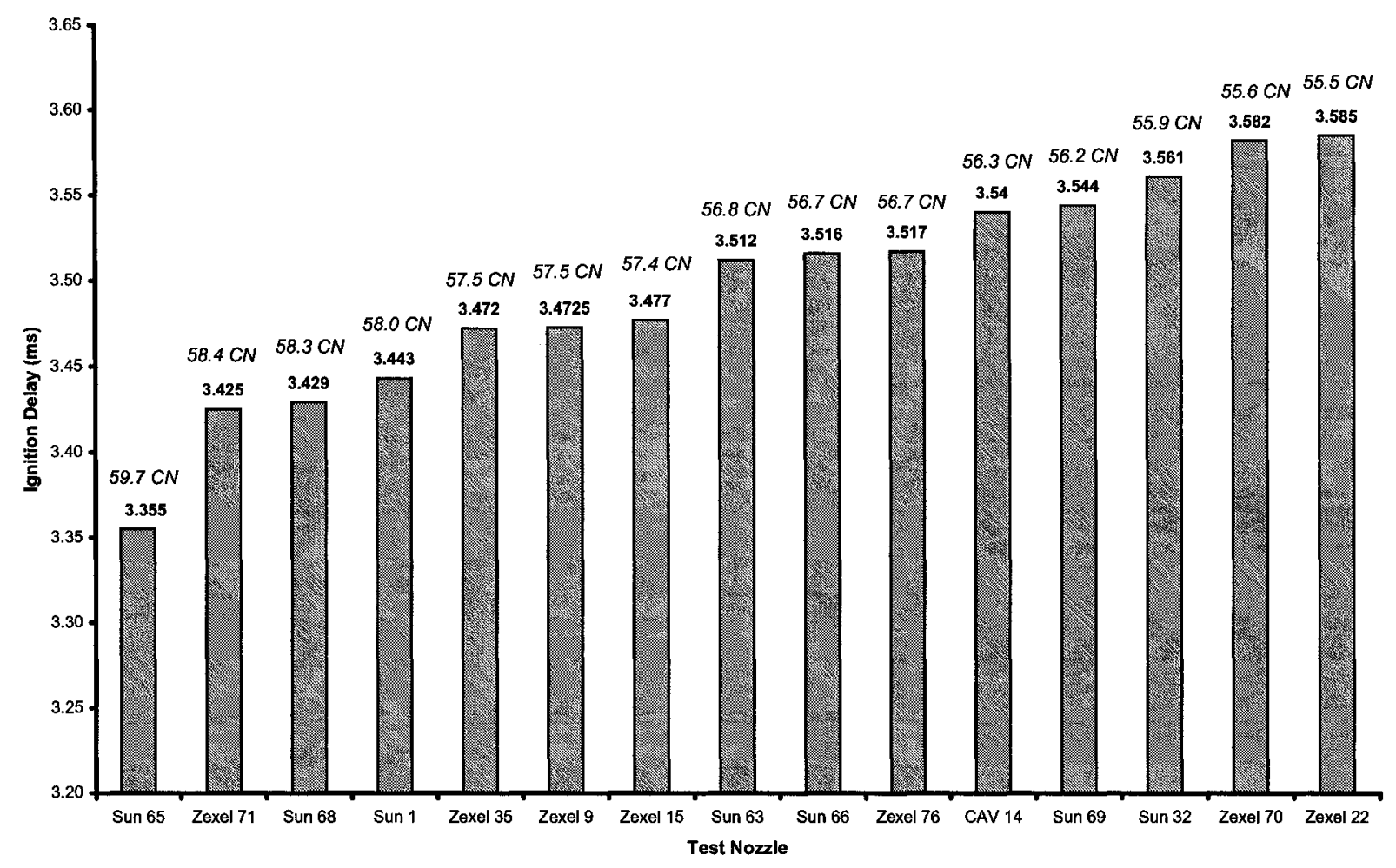

Figure 4.1: Ignition delay and cetane number values for all 15 test nozzles 


\subsection{Effects of Spray Pattern}

The optical spray pattern test rig resulted in several spray images being captured corresponding to a particular time in the injection event for each of the test nozzles. The same fuel was used for all the nozzles along with the same injection pump to ensure that any changes in spray pattern were a sole function of the test nozzle. The complete set of images captured is given in Appendix I.2.

By comparing spray images of test nozzles that have different ignition delay values, the effects of spray pattern on ignition delay can be investigated. Test nozzle Sun 65 has an ignition delay value of $3.355 \mathrm{~ms}$ and a cetane number (CN) of 59.7, while at the other end test nozzle Sun 63 has an ignition delay of $3.512 \mathrm{~ms}$ and a CN of 56.8. Given that Sun 65 and Sun 63 are on either end of the obtained ignition delay range of values, any captured effect of the spray pattern on ignition delay would be most visible between these two nozzles. However, a direct comparison of spray images from Sun 65 and Sun 63 corresponding to the same time intervals in the injection event shows little or no difference in the spray pattern as illustrated in Figure 4.2 .

On the other hand, Sun 68 with an ignition delay of $3.429 \mathrm{~ms}$ and a $\mathrm{CN}$ of 58.3 , and Sun 1 with an ignition delay of $3.443 \mathrm{~ms}$ and a CN of 58.0, are very close in terms of their ignition delay values. Yet, when comparing their spray images corresponding to similar times in the injection event, it is evident that there is a large difference in the spray pattern. The Sun 68 pattern is small and focused, while that of Sun 1 is larger and scattered as shown in Figure 4.3. 


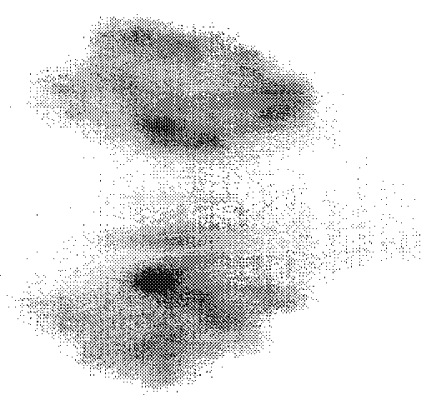

(a) Sun 65: $0.28-0.46 \mathrm{~ms}$

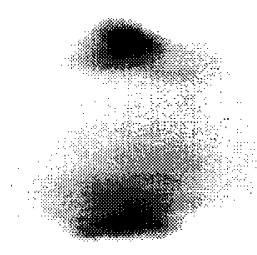

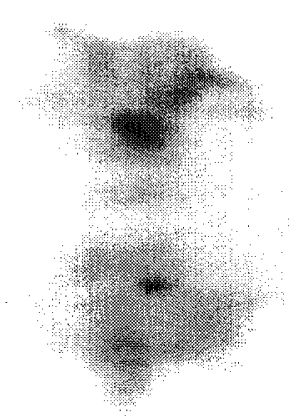

(b) Sun 63: $0.28-0.46 \mathrm{~ms}$

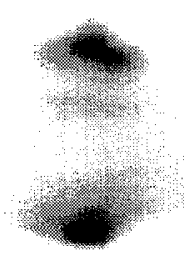

(c) Sun 65: $1.20-1.38 \mathrm{~ms}$

(d) Sun 63: $1.20-1.38 \mathrm{~ms}$

Figure 4.2: Comparison of spray pattern images at similar time intervals between Sun $65,3.355 \mathrm{~ms}$ ignition delay and Sun $63,3.512 \mathrm{~ms}$ ignition delay

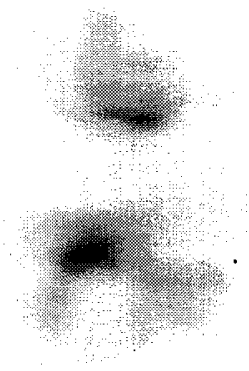

(a) Sun 68: $0.40-0.58 \mathrm{~ms}$
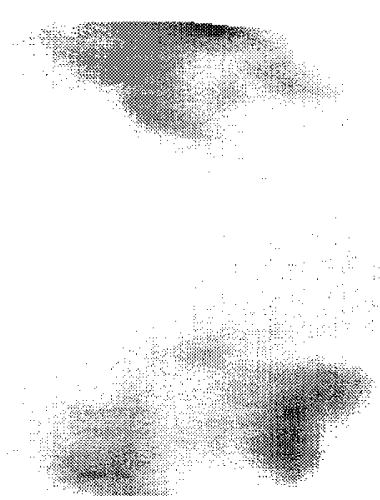

(b) Sun 1: $0.40-0.58 \mathrm{~ms}$

Figure 4.3: Comparison of spray pattern images at similar time intervals between Sun $68,3.429 \mathrm{~ms}$ ignition delay and Sun 1, $3.443 \mathrm{~ms}$ ignition delay 
Further qualitative visual inspection of the captured images appeared to yield no connection between the spray pattern and ignition delay, and quantitative comparison of the images between the nozzles was not warranted. However, by examining the entire data set for all the images obtained, a typical evolution of the spray pattern across the main injection event can be estimated. This is illustrated in Figure 4.4. This spray behaviour appears to be typical of all the nozzles regardless of their ignition delay or cetane number values.

Nozzle spray pattern has been determined to have an effect on emissions in several studies $[24 ; 25]$. However it does not appear to have any noticeable effect on the ignition delay and the cetane number.

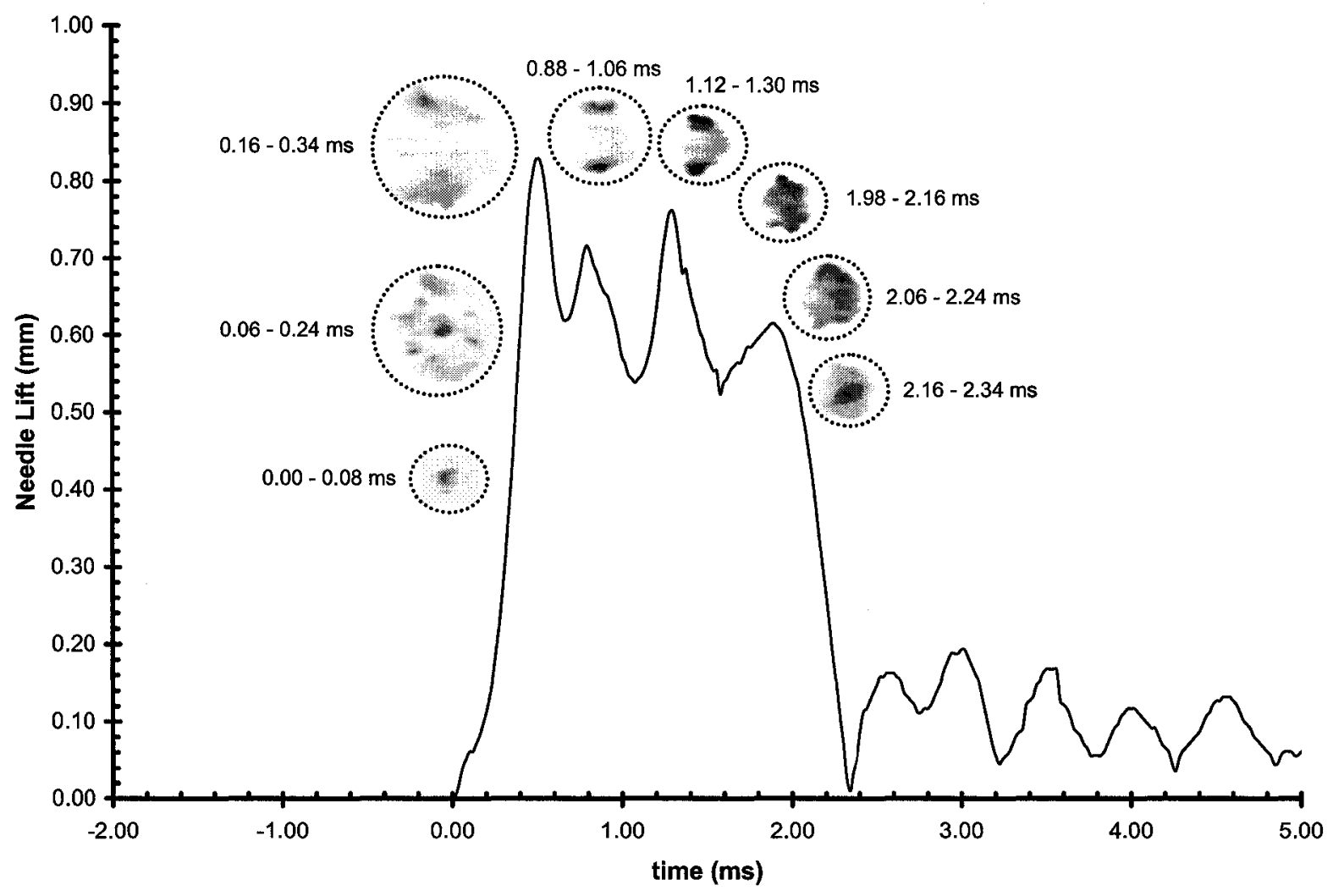

Figure 4.4: Typical spray pattern evolution of test nozzles 


\subsection{Effects of Internal Nozzle Geometry}

Using the Pintle Clearance Air Flow Test Rig and the Needle Clearance Nitrogen Flow Test Rig, employing ISO 4010 test methods, the internal geometry of the 15 test nozzles was determined in terms of choked volume flow rate.

The air flow rig resulted in several flow values corresponding to different lift points as shown in Figure 4.5, with the choked volume flow rate being directly proportional to the pintle clearance at each of the lift values for each of the test nozzles. Similarly, the nitrogen flow rig resulted in an average choked volume flow rate directly related to the clearance between the needle and the barrel for each of the test nozzles. The complete set of flow data is presented in Appendix I.3.

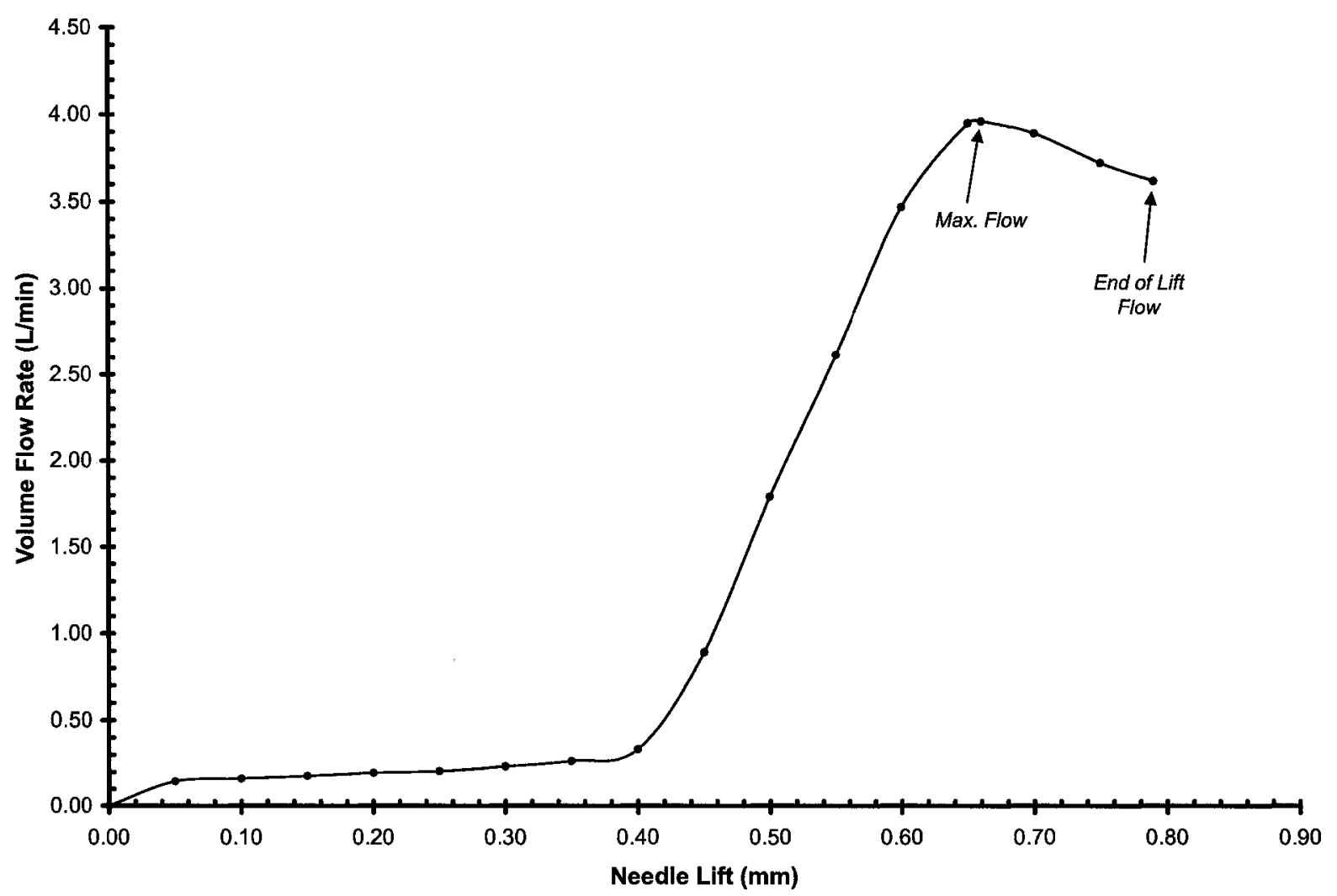

Figure 4.5: Typical data curve produced from the pintle clearance air flow test rig 
By comparing the different flow rate vs. needle lift curves for test nozzles with large differences in their ignition delay and cetane number values, the effects of the nozzle pintle clearance on ignition delay and the cetane number can be investigated. Figure 4.6 shows several curves for nozzles spanning the entire ignition delay and cetane number range of values. At needle lifts 0.0 to $0.65 \mathrm{~mm}$, there does not appear to be any correlation between the pintle clearance (in terms of flow rate) and the ignition delay. However, at needle lifts over $0.65 \mathrm{~mm}$, there appears to be a clear trend as illustrated in Figure 4.7.

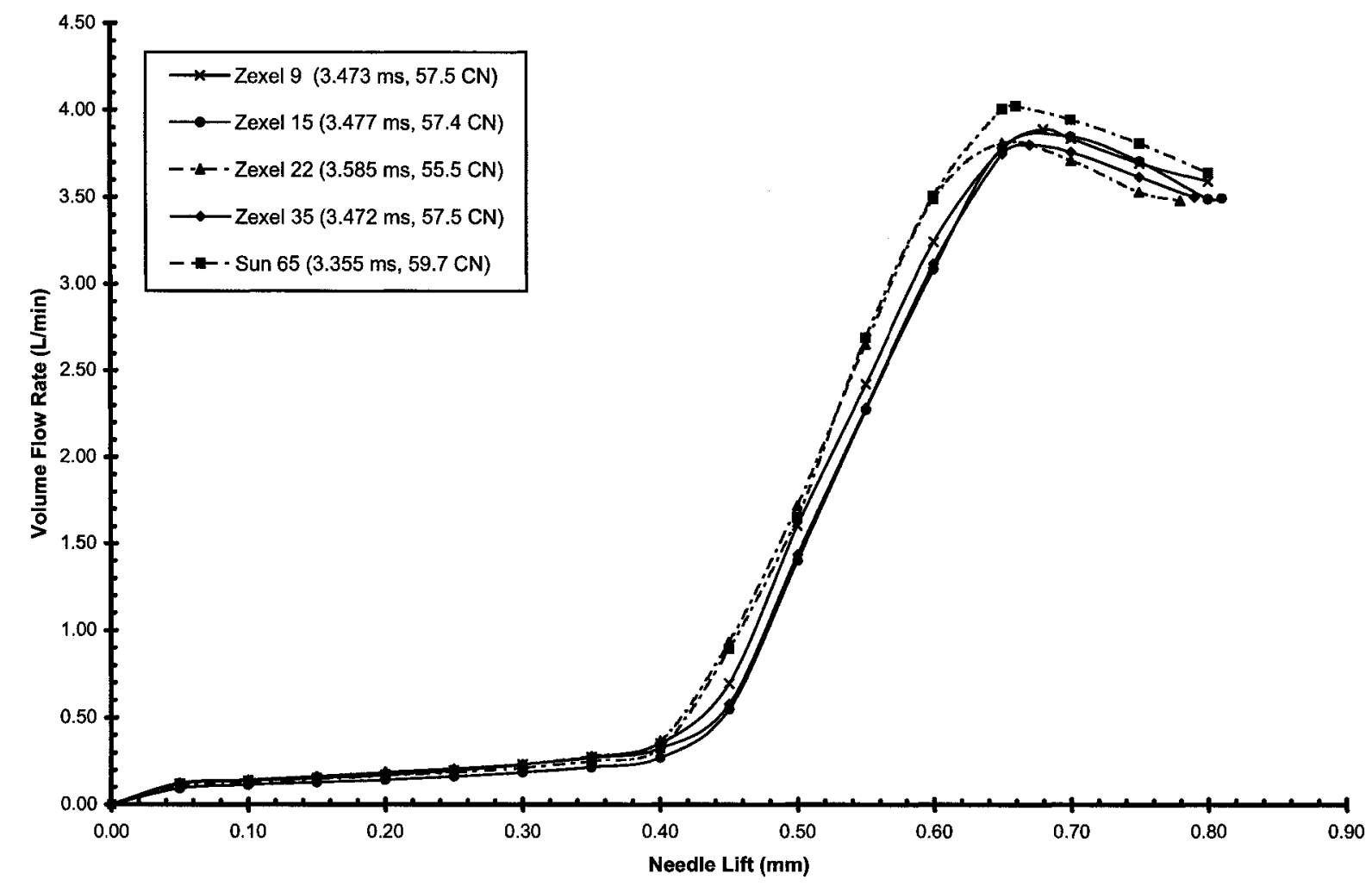

Figure 4.6: Pintle clearance data for nozzles spanning the ignition delay range of values

Figure 4.7 shows that at high needle lift values $(0.70 \mathrm{~mm}$ and higher $)$, as the pintle clearance increases (higher flow rate values), the ignition delay decreases. 


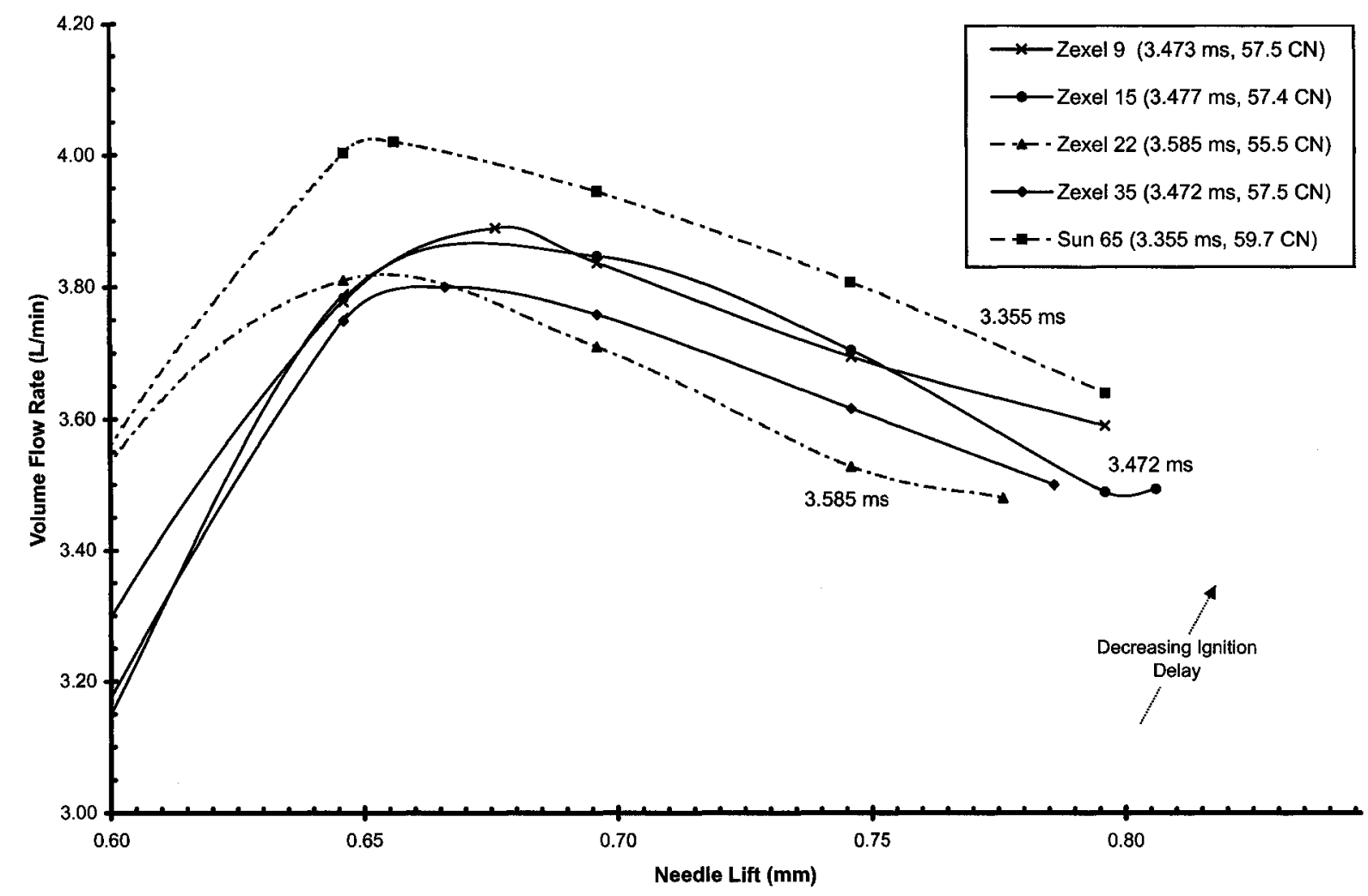

Figure 4.7: Effects of pintle clearance on ignition delay and cetane number

The pintle clearance is the annular orifice area between the needle and the barrel as shown in Figure 3.2. As the fuel is forced through the annular orifice under pressure, an unstable jet is formed, which disintegrates as it leaves the nozzle and comes into contact with the air in the combustion chamber [26]. This disintegration of the unstable jet results in the atomization of the fuel into small droplets, where the droplet size is primarily influenced by the nozzle orifice area for a given injection pump. The smaller the orifice area, the higher the injection pressure will be, and the smaller the droplet size [27].

The ignition delay is divided into two separate periods, a physical and a chemical delay period. The physical delay period being the time required for the atomization, heating, vaporization and mixing of the fuel with air before ignition takes place, and the chemical 
delay period being the time required by pre-flame reactions to reach flame conditions. The rate of heating and vaporization is driven by the rate of heat transfer to the atomized fuel, which is a direct function of the surface area as shown by this simple convective heat transfer equation [28],

$$
q=\bar{h} A_{s}\left(T_{s}-T_{\infty}\right)
$$

Finer atomization will result in a larger surface area and therefore faster vaporization, reducing the physical delay period of the ignition delay. However, a more rapid vaporization will result in a reduction of the local temperature leading to a decrease in the pre-flame reaction rates. Reaction rates are an exponential function of temperature [29], and thus a nozzle that results in slightly lower local temperatures (due to finer atomization and rapid vaporization) can have a substantially longer chemical delay period leading to a longer overall ignition delay. Figure 4.7 suggests that nozzles with smaller orifice areas will lead to longer ignition delays, which could be explained by the latter. Similar trends were obtained by [19], where their results showed the ignition delay for high-pressure injections through a single hole nozzle of small diameter was longer than in the case of the lowpressure injection through a single hole nozzle of large diameter. The authors attributed this to a drop of local mixture temperature caused by the more rapid vaporization due to finer atomization in the smaller diameter nozzle.

The ignition delay is driven by the first initial amount of injected fuel, and not the entire amount of the fuel from the complete injection event [6]. Figure 4.8 shows how the initial period of a typical injection event encounters high needle lift values, which could explain the apparent dependence of ignition delay on the nozzle pintle clearance at the higher needle lifts, and not so much at lower needle lifts. 


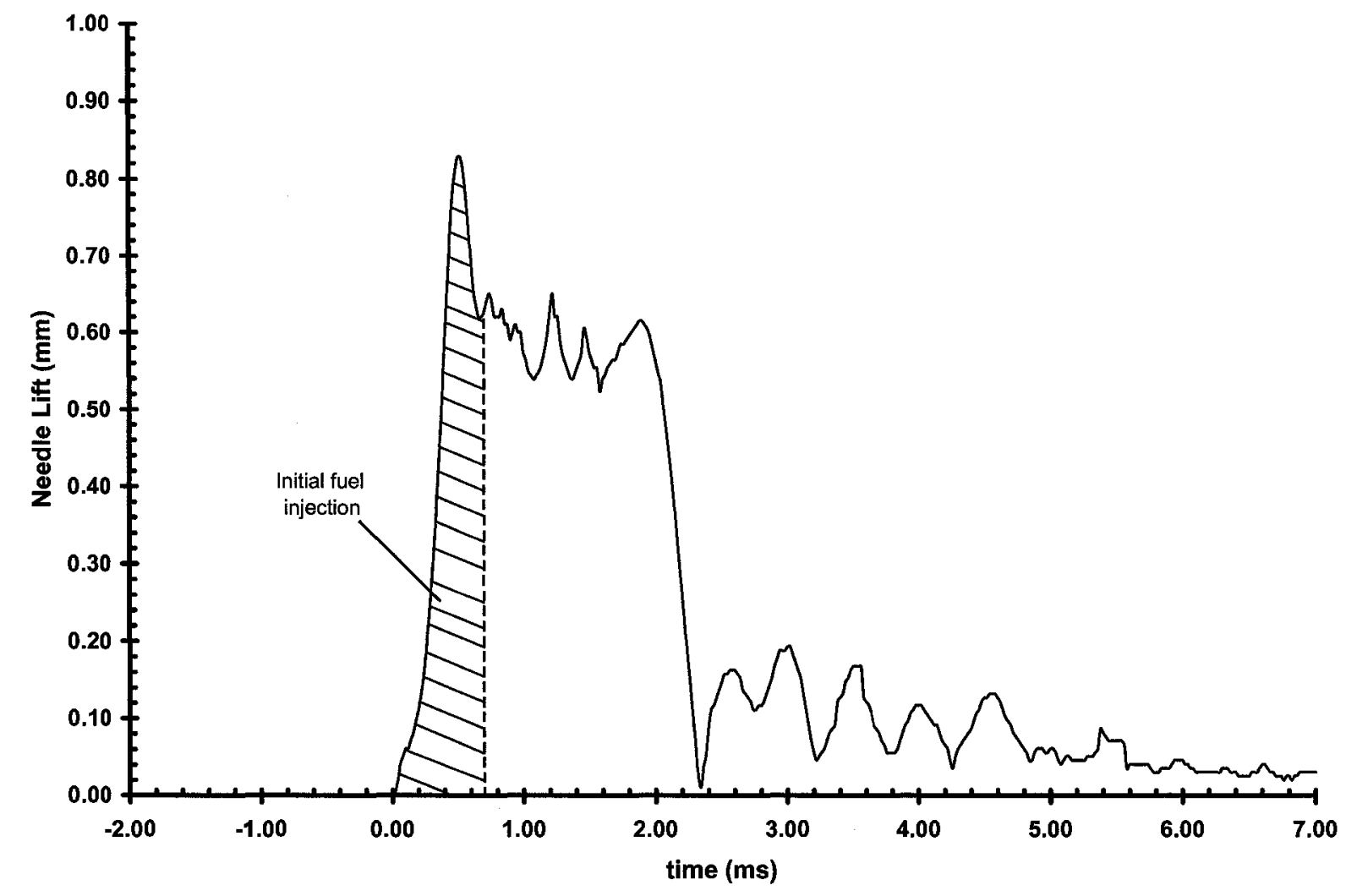

Figure 4.8: Initial injection period of a typical injection event

The needle clearance, is the clearance between the barrel and the needle. If this clearance is too tight, the nozzle could jam, on the other hand, if the clearance is too large, excessive leaking from the nozzle fuel sac through the needle clearance can occur. To examine the effects of the needle clearance on ignition delay, the choked nitrogen flow rate was plotted against the ignition delay values for all 15 test nozzles. However, as seen in Figure 4.9 , there does not appear to be any clear trend in the data. 


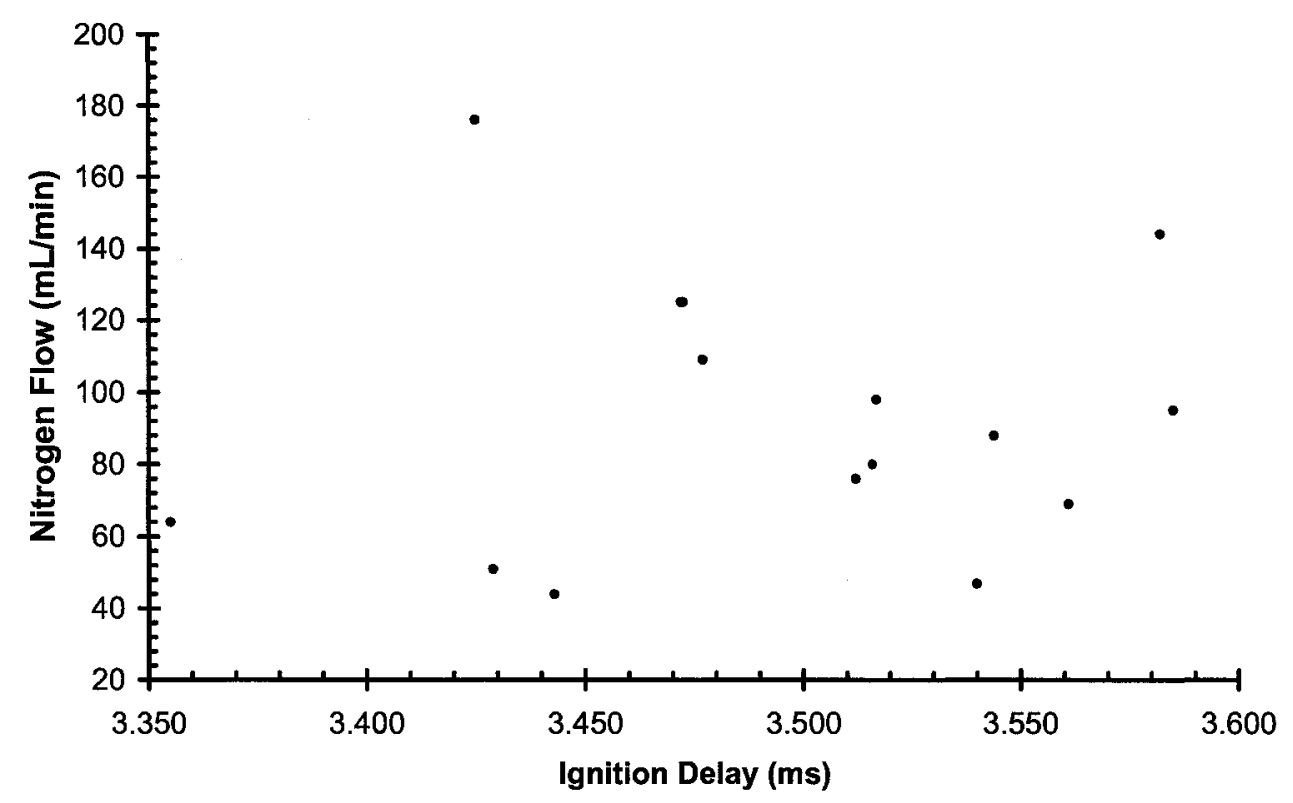

Figure 4.9: Needle clearance effect on ignition delay

ASTM D6890 test method specifies a mass calibration with each new nozzle. As this was the case for the tests carried out, it is likely the variation in needle clearance and therefore fuel leakage was compensated for by the mass calibration of each nozzle. Thus, no clear effect of the nozzle needle clearance on the ignition delay was found. 


\subsection{Effects of Nozzle Needle Geometry}

With the aid of a profile projector, the key dimensions shown in Figure 3.13 were measured for all 15 test nozzles. The obtained needle dimensions for all 15 test nozzles are given in Appendix I.4. Comparison of all key needle dimensions yielded no clear correlations to ignition delay as shown for the cone angle (dimension F) in Figure 4.10 .

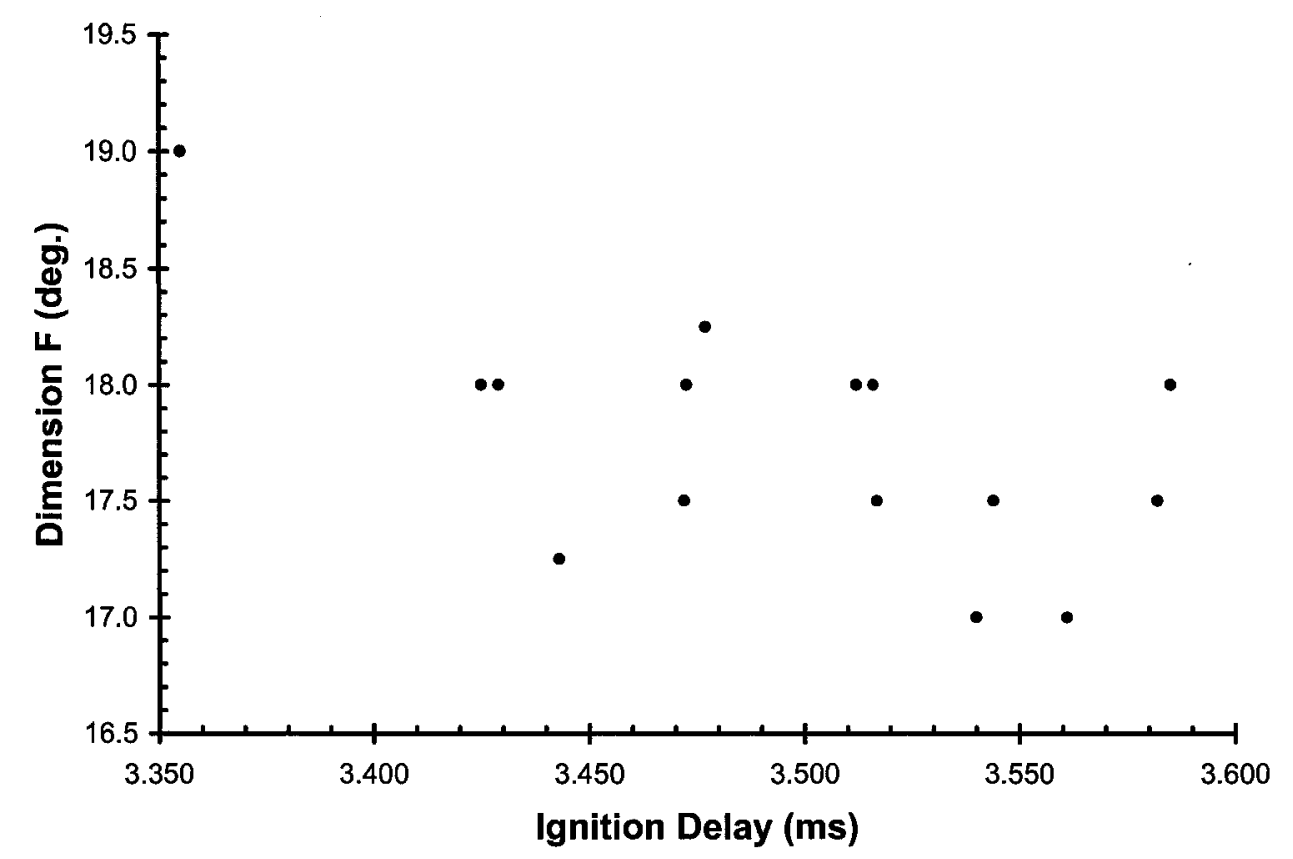

Figure 4.10: Cone angle (dimension F) effect on ignition delay

These key needle dimensions are primarily responsible for the injection spray pattern. Therefore, not finding any strong effects of the needle dimensions on ignition delay is consistent with our previous results regarding the spray pattern in section 4.1. 


\section{Chapter 5}

\section{Conclusions and Recommendations}

The effects of fuel injection nozzle parameters on ignition delay and the cetane number has been investigated. The results of the investigation have shown that nozzle spray pattern does not appear to have any effect on the ignition delay and cetane number. Similarly, needle dimensions that drive the nozzle spray pattern do not appear to have any effect on the ignition delay and cetane number.

Nozzle pintle clearance was found to have a strong effect on ignition delay and cetane number, with ignition delay decreasing as the pintle clearance increases. On the other hand, nozzle needle clearance had no clear effect on the ignition delay and the cetane number. 
To further the research, the following items may be recommended for future work,

- A similar numerical investigation can be pursued to complement the experimental work undertaken

- To build on this investigation, the effects of nozzle deposits on the various nozzle parameters could be investigated

- A better understanding of the ignition process within the IQT ${ }^{\mathrm{TM}}$ by use of an optically accessible combustion chamber can be developed 


\section{References}

[1] A. Williams, Combustion of Liquid Fuel Sprays. Butterworths, Toronto, 1990.

[2] American Society for Testing and Materials, "D613 - Standard test method for cetane number of diesel fuel oil," Annual Book of ASTM Standards, vol. 5, no. 4, 1997.

[3] American Society for Testing and Materials, "D6890 - Standard test method for determination of ignition delay and derived cetane number (DCN) of diesel fuel oils by combustion in a constant volume chamber," ASTM Standards, 2004.

[4] Advanced Engine Technology Ltd., "Study to improve the factory calibration and quality control of ISO 4010 fuel injection nozzles used in the ignition quality tester (IQT)," tech. rep., AET, January 2004.

[5] R. S. Benson and N. D. Whitehouse, Internal Combustion Engines. Pergamon Press, Toronto, 1979.

[6] T. K. Garrett, Automative Fuels and Fuel Systems, Volume 2: Diesel. Pentech Press, London, 1994.

[7] T. W. Ryan III and B. Stapper, "Diesel fuel ignition quality as determined in a constant volume combustion bomb," SAE Technical Paper Series, no. 870586, 1987. 
[8] L. N. Allard, G. D. Webster, N. J. Hole, T. W. Ryan III, D. Ott, and C. W. Fairbridge, "Diesel fuel ignition quality as determined in the ignition quality tester (IQT)," $S A E$ Technical Paper Series, no. 961182, 1996.

[9] N. Ladommatos and J. Goacher, "Equations for prediction of cetane number of diesel fuels from their physical properties," Fuel, vol. 74, no. 7, 1995.

[10] H. Yang, Z. Ring, Y. Briker, N. McLean, W. Friesen, and C. Fairbridge, "Neural network prediction of cetane number and density of diesel fuel from its chemical composition determined by LC and GC-MS," Fuel, vol. 81, no. 2, 2002.

[11] B. Basu, G. Kapur, A. Sarpal, and R. Meusinger, "A neural network approach to the prediction of cetane number of diesel fuels using nuclear magnetic resonance (NMR) spectroscopy," Energy and Fuels, vol. 17, no. 6, 2003.

[12] American Society for Testing and Materials, "D4737 - Standard test method for calculated cetane index by four variable equation," ASTM Standards, 2004.

[13] T. Minagawa, H. Kosaka, and T. Kamimoto, "A study on ignition delay of diesel fuel spray via numerical simulation," SAE Technical Paper Series, no. 2000-01-1892, 2000.

[14] R. Deljouravesh, "An optical patternator for quantitative and on-line spray diagnostics," Master's thesis, Queens University, 1997.

[15] Nexum Instumentation, OSPA Flash Demo - OSPA 210 Marketing CD. Nexum, 615 Norris Cr., Kingston, Ontario K7P 2R9, Canada, 2005.

[16] International Organization for Standardization, "ISO 4010: Diesel engines - Calibration nozzle, delay pintle type," ISO Standards, 1998. 
[17] L. C. Ganippa, S. Andersson, J. Chomiak, and A. Matsson, "Combustion characteristics of diesel sprays from equivalent nozzles with sharp and rounded inlet geometries," Combustion Science and Technology, vol. 175, no. 6, 2003.

[18] F. Payri, J. Benajes, and C. Gonzalez, "The effects of injector hole convergence on diesel combustion and emissions," Combustion Science and Technology, vol. 36, no. 4, 2004 .

[19] F. Pischinger, U. Reuter, and E. Scheid, "Self-ignition of diesel sprays and its dependence on fuel properties and injection parameters," Journal of Engineering for Gas Turbines and Power, Transactions of the ASME, vol. 110, no. 3, 1988.

[20] K. Amagai, Y. Hashimoto, and M. Arai, "Ignition and combustion characteristics of two-stage injection diesel spray," JSAE Review, vol. 20, no. 3, 1999.

[21] Advanced Engine Technology Ltd., Ignition Quality Tester, IQT Brochure. AET, 17 Fitzgerald Road, Suite 102 Ottawa, Ontario K2H 9G1, Canada, 2005.

[22] R. D. Blevins, Applied Fluid Dynamics Handbook. VNR Company, New York, 1984.

[23] Mitutoyo, PJ-300 Profile Projector Specification Sheet.

[24] J. V. Pastor, R. Payri, J. J. Lopez, and J. E. Julia, "Effect of injector nozzle geometry of diesel engines on the macroscopic spray characteristics by means of optical techniques," iMechE Conference Transactions, vol. 2, 2003.

[25] D. A. Pierpont and R. D. Reitz, "Effects of injection pressure and nozzle geometry on D.I. diesel emissions and performance," SAE Technical Paper Series, no. 950604, 1995.

[26] P. G. Burman and F. DeLuca, Fuel Injection and Controls for Internal Combustion Engines. Library of Congress, Washington, 1962. 
[27] K. W. Stinson, Diesel Engineering Handbook. Diesel Publications, Stamford, 11th ed., 1969.

[28] F. P. Incropera and D. P. DeWitt, Fundamentals of Heat and Mass Transfer. John Wiley \& Sons, Toronto, 3rd ed., 1990.

[29] S. R. Turns, An Introduction to Combustion: Concepts and Applications. McGrawHill, Toronto, 2nd ed., 2000.

[30] Trillium Measurement and Control, Calibration Data Sheet. Brooks 5850S, 2600 John Street, Unit 217 Markham, Ontario L3R 3W3, Canada, 2004.

[31] H. Schenck Jr., Theories of Engineering Experimentation. McGraw-Hill, Toronto, 2nd ed., 1968.

[32] Cole-Parmer, Mass Flow Calibration Data Sheet. FMA1710, 2004. 


\section{Appendix A}

\section{Nozzle Cleaning Procedure}

This cleaning procedure was carried out on each test nozzle prior to testing in any of the experimental apparatus.

The cleaning procedure employs an ultrasonic cleaner,

1. Remove nozzle from its storage case

2. Separate the needle from the barrel

3. Place the needle and the barrel in a $250 \mathrm{~mL}$ glass beaker filled with a clean solution of Varsol

4. Place the beaker in a water bath inside an ultrasonic cleaner for 15 minutes

5. Remove the barrel and needle from the beaker and rinse with Alcohol

6. Blow dry the needle and the barrel using clean compressed air, or a blow dryer

7. Place the needle back inside the barrel

8. Return the nozzle to its storage case 


\section{Appendix B}

\section{Optical Spray Pattern Test Rig Repeatability}

By repeated testing of a nozzle, two frames were obtained that fell at the same time, or very close on the injection event. Two such images were obtained for three of the test nozzles. They are presented in Figures B.1, B.2, and B.3. From visual comparison of the two images for all three nozzles, the level of precision of the spray test rig can be assessed.

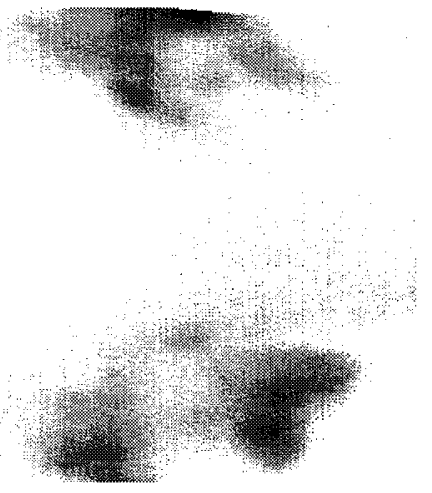

(a) $0.40-0.58 \mathrm{~ms}$

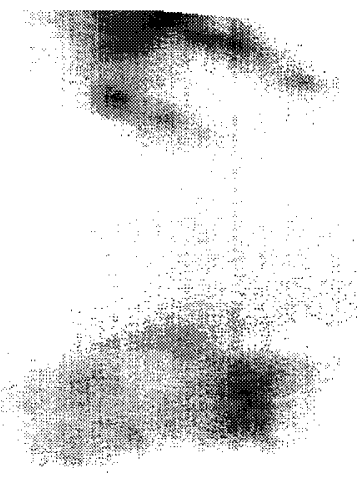

(b) $0.42-0.60 \mathrm{~ms}$

Figure B.1: Spray test rig repeatability - comparable images for test nozzle Sun 1 

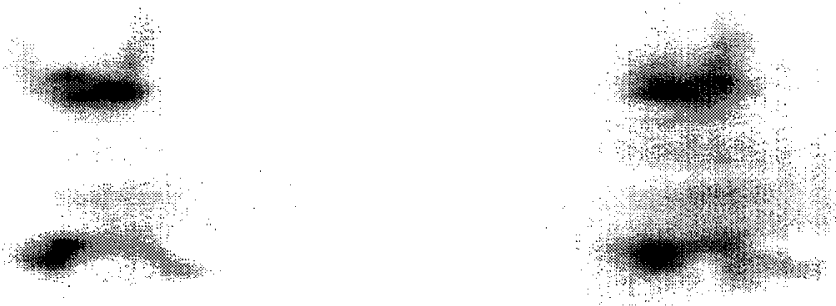

(a) $0.42-0.60 \mathrm{~ms}$

(b) $0.42-0.60 \mathrm{~ms}$

Figure B.2: Spray test rig repeatability - comparable images for test nozzle Zexel 9
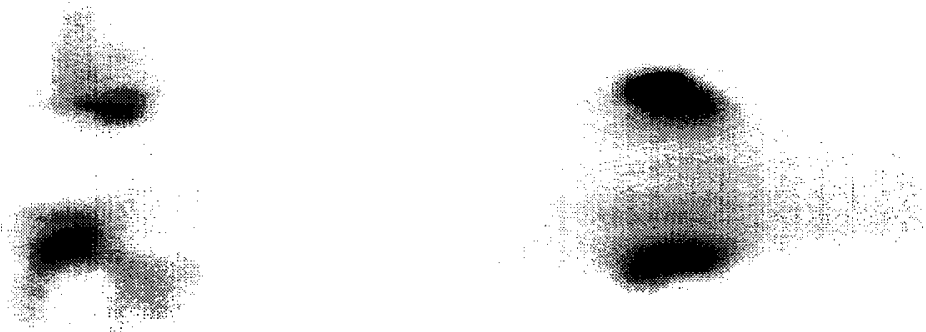
(a) $0.40-0.58 \mathrm{~ms}$
(b) $0.40-0.58 \mathrm{~ms}$

Figure B.3: Spray test rig repeatability - comparable images for test nozzle Sun 68 


\section{Appendix C}

\section{Air and Nitrogen Flow Test Rigs - Design}

The Pintle Clearance Air flow Test Rig, and the Needle Clearance Nitrogen Flow Test Rig, were both assembled on the same test bench shown in Figure C.1. Stainless steel, $\frac{1}{4}{ }^{\prime \prime}$ tubing, and Swagelok compression fittings were used to connect the components. Design drawings of the nozzle holders for each test rig are provided in the following sections.

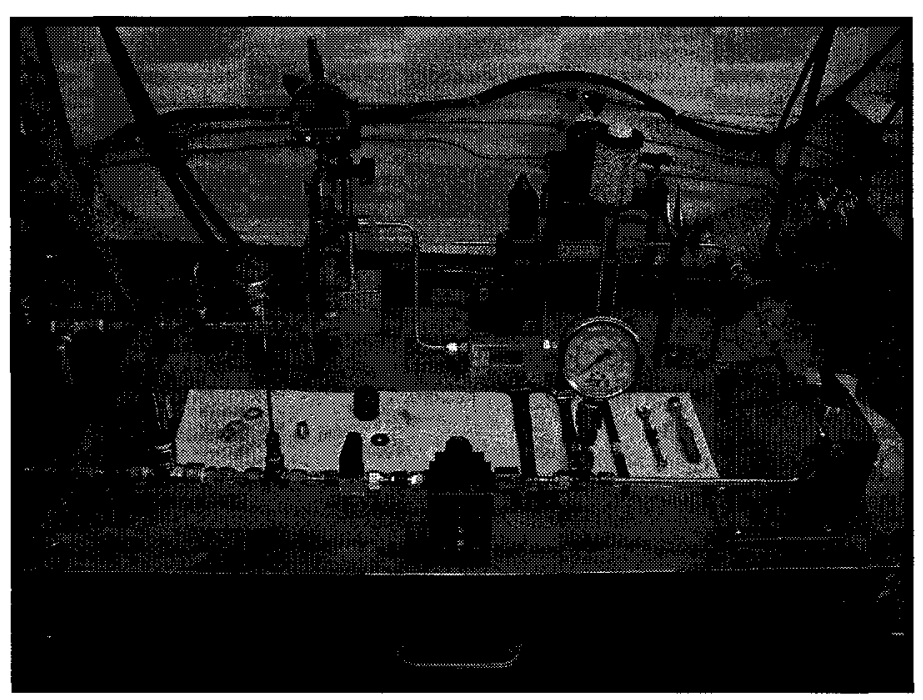

Figure C.1: Air and nitrogen flow test rigs - shared test bench 


\section{C.1 Air Flow Test Rig Drawings}

Drawings for the air flow test rig nozzle holder are summarized in Table C.1. Design drawings have been reduced to $75 \%$ of original size and are presented in Figures C. 2 to C.9.

Table C.1: Air flow test rig nozzle holder design drawings

\begin{tabular}{|c|l|}
\hline DWG \# & Title \\
\hline A-1A & Nozzle Holder Assembly \\
\hline A-2A & Collet Assembly \\
\hline A-3P & Nozzle Body \\
\hline A-4P & Lift Adjuster \\
\hline A-5P & Collet Tube \\
\hline A-6P & Lift Stopper \\
\hline A-7P & Collet Sleeve \\
\hline
\end{tabular}




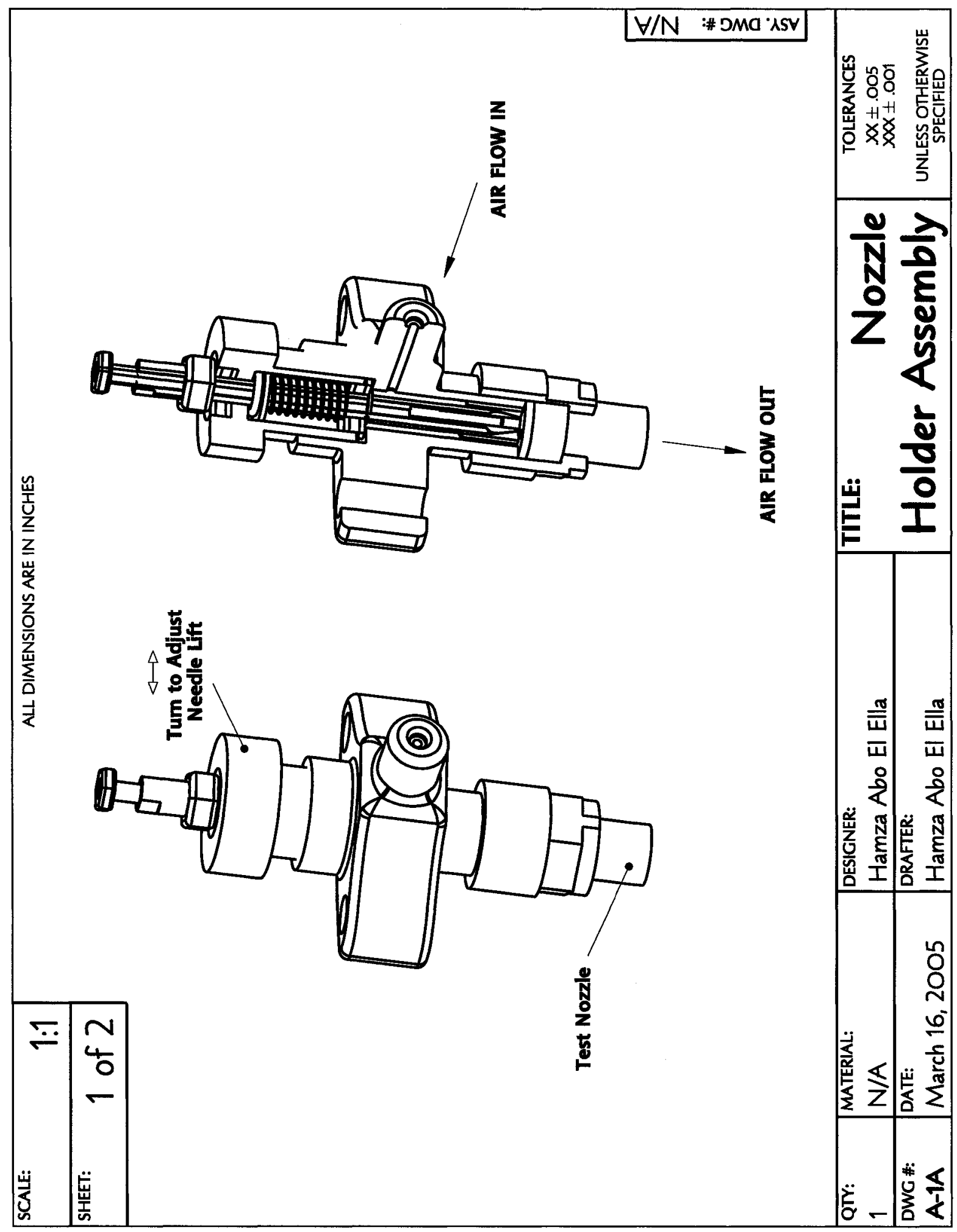

Figure C.2: Air test rig design drawings - Nozzle Holder Assembly Sh. 1 of 2 


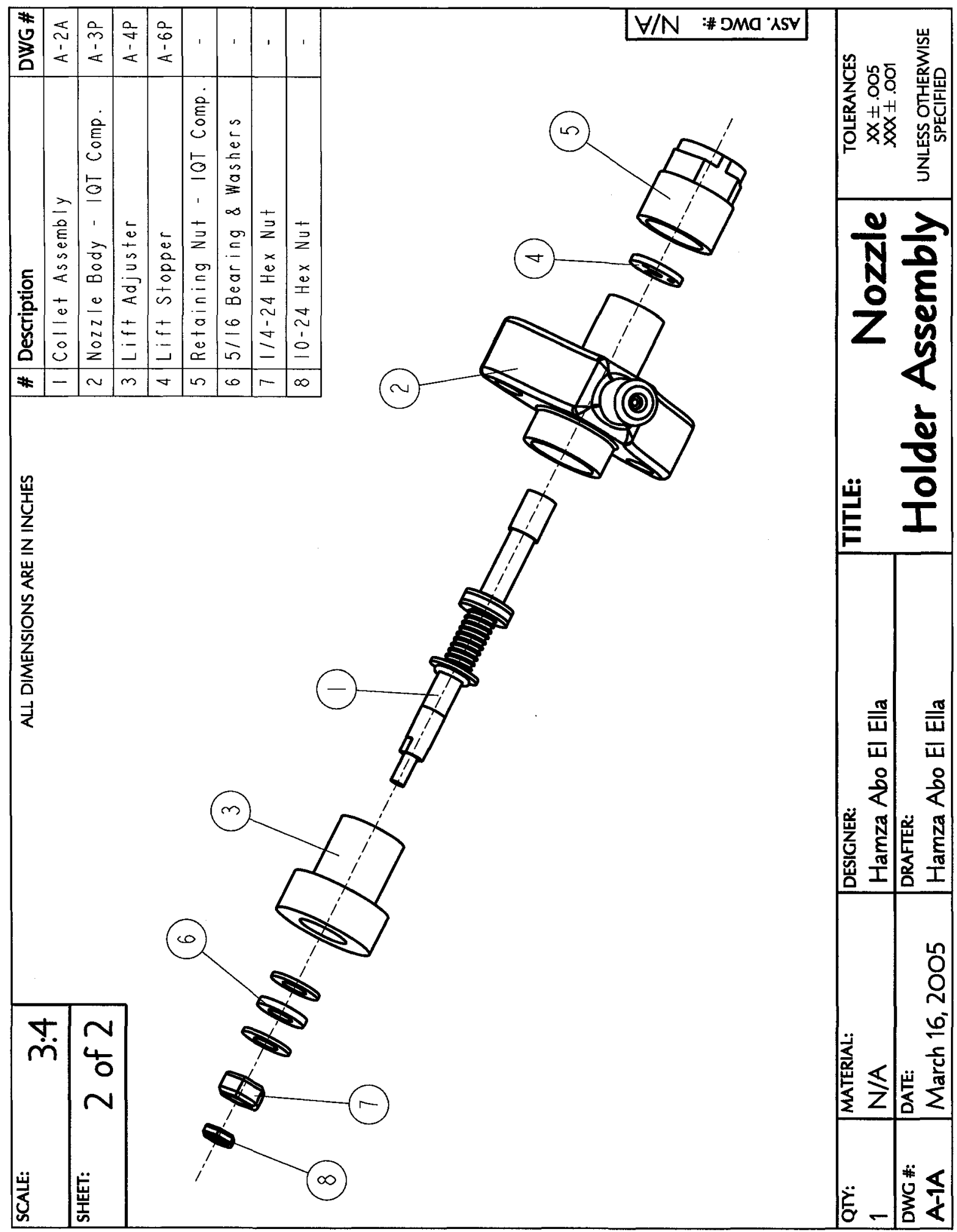

Figure C.3: Air test rig design drawings - Nozzle Holder Assembly Sh. 2 of 2 


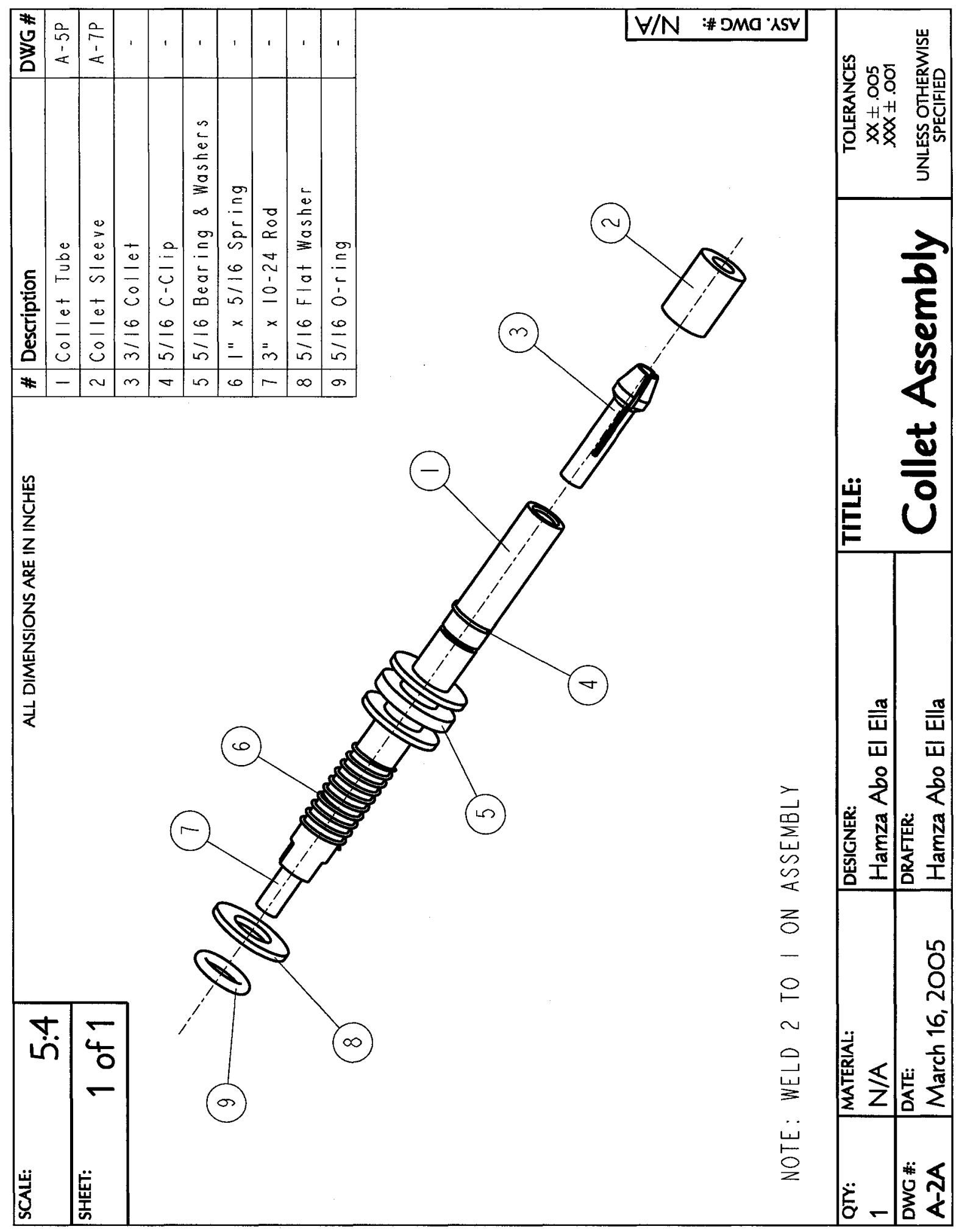

Figure C.4: Air test rig design drawings - Collet Assembly 


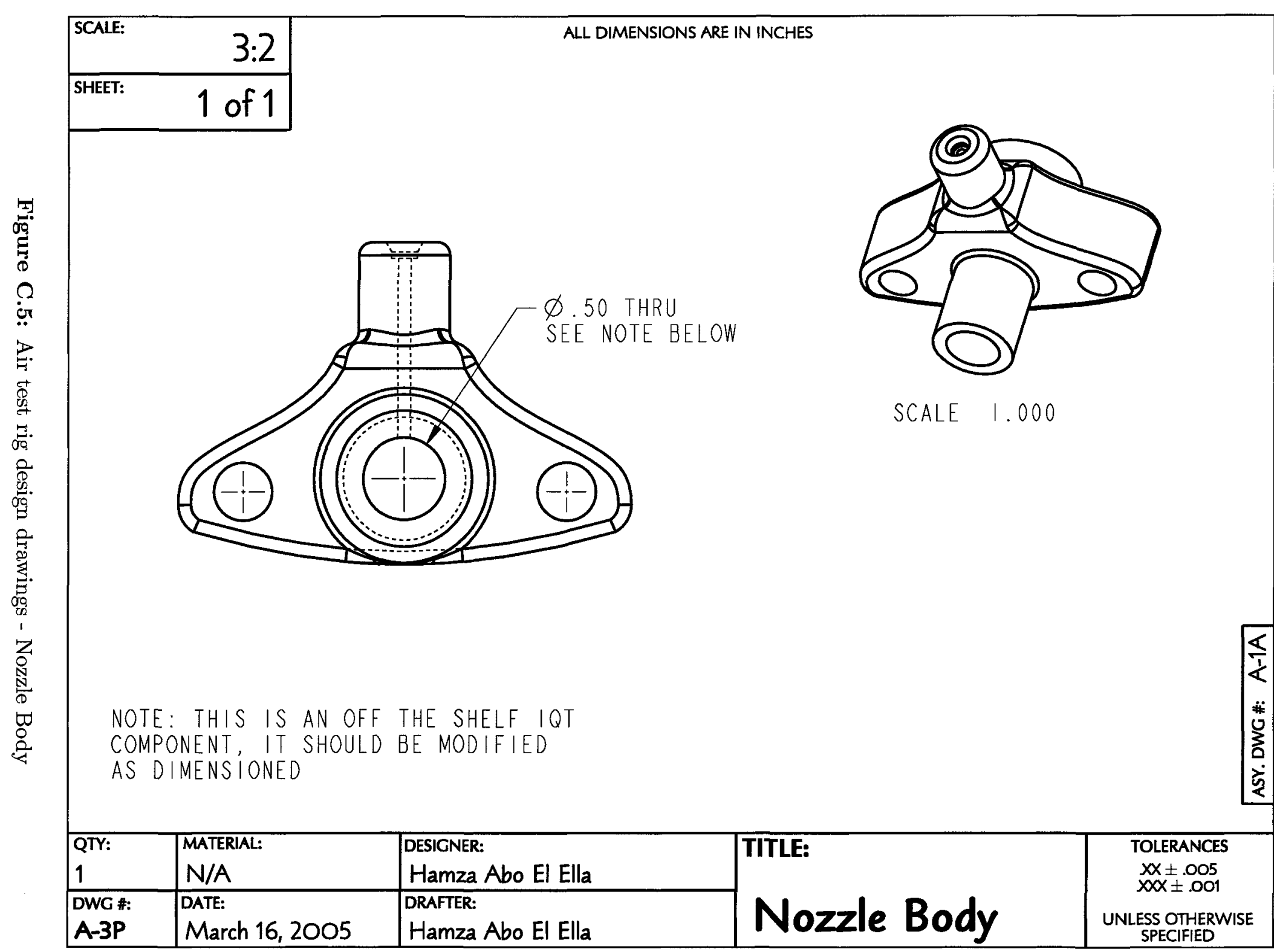




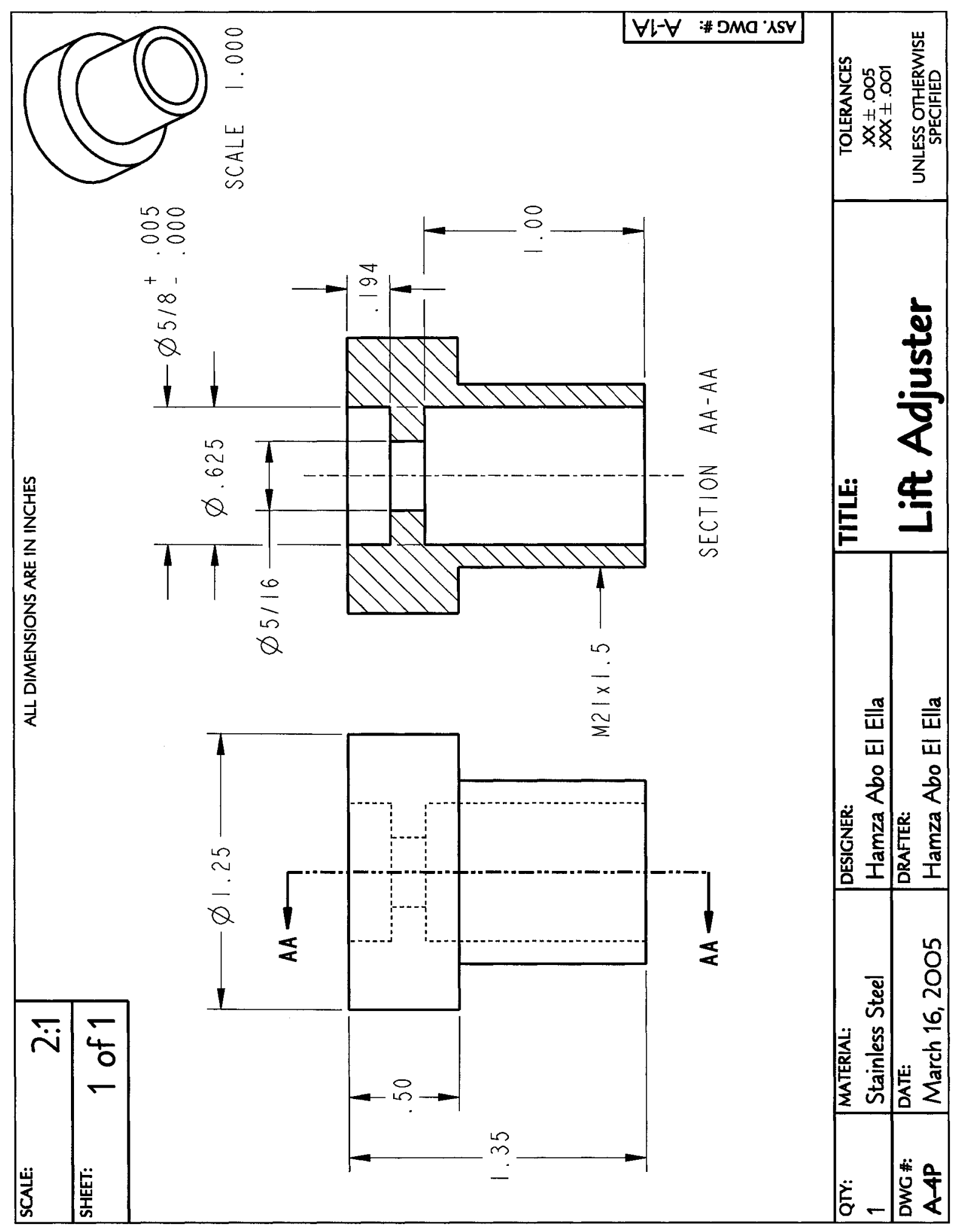

Figure C.6: Air test rig design drawings - Lift Adjuster 


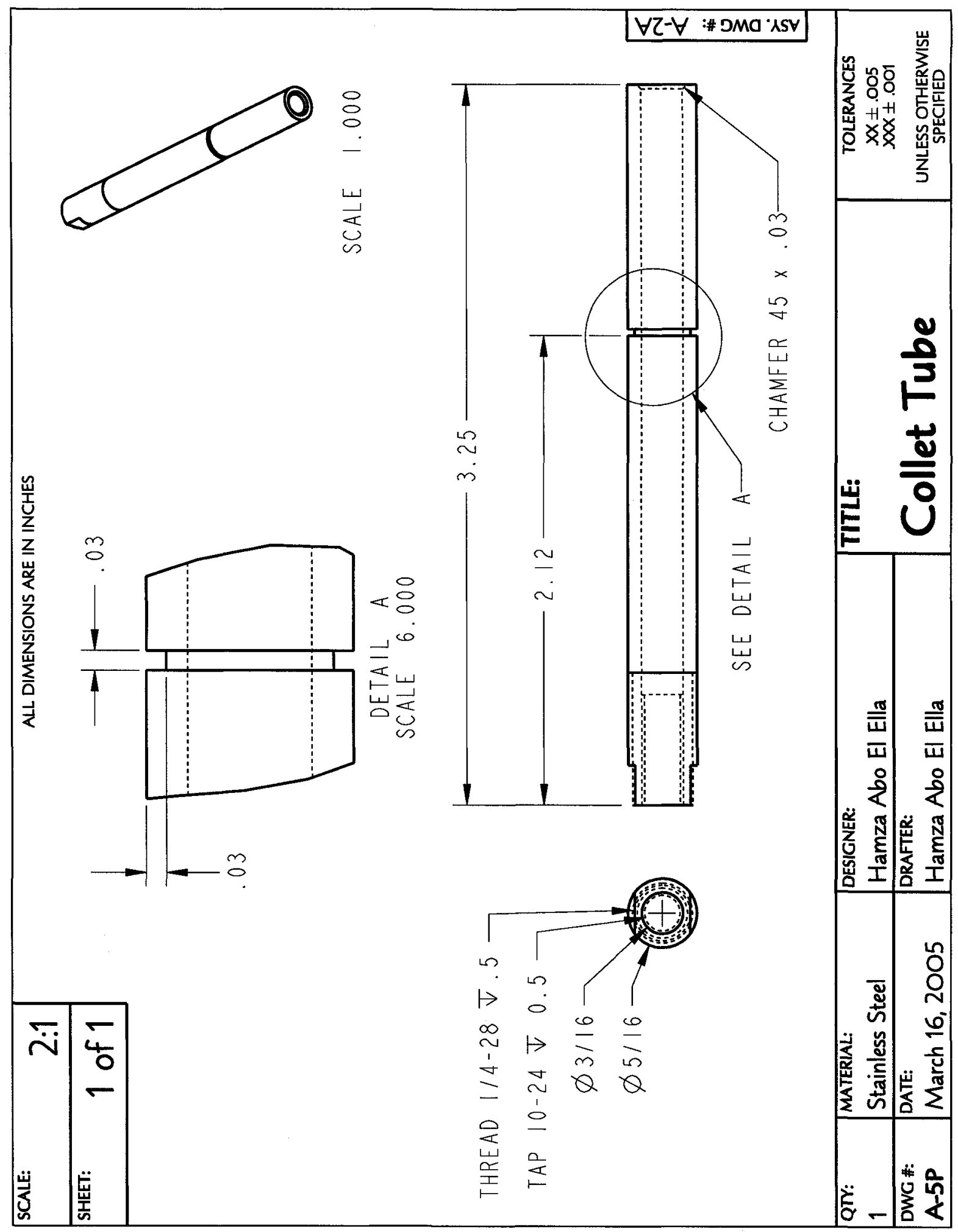

Figure C.7: Air test rig design drawings - Collet Tube 


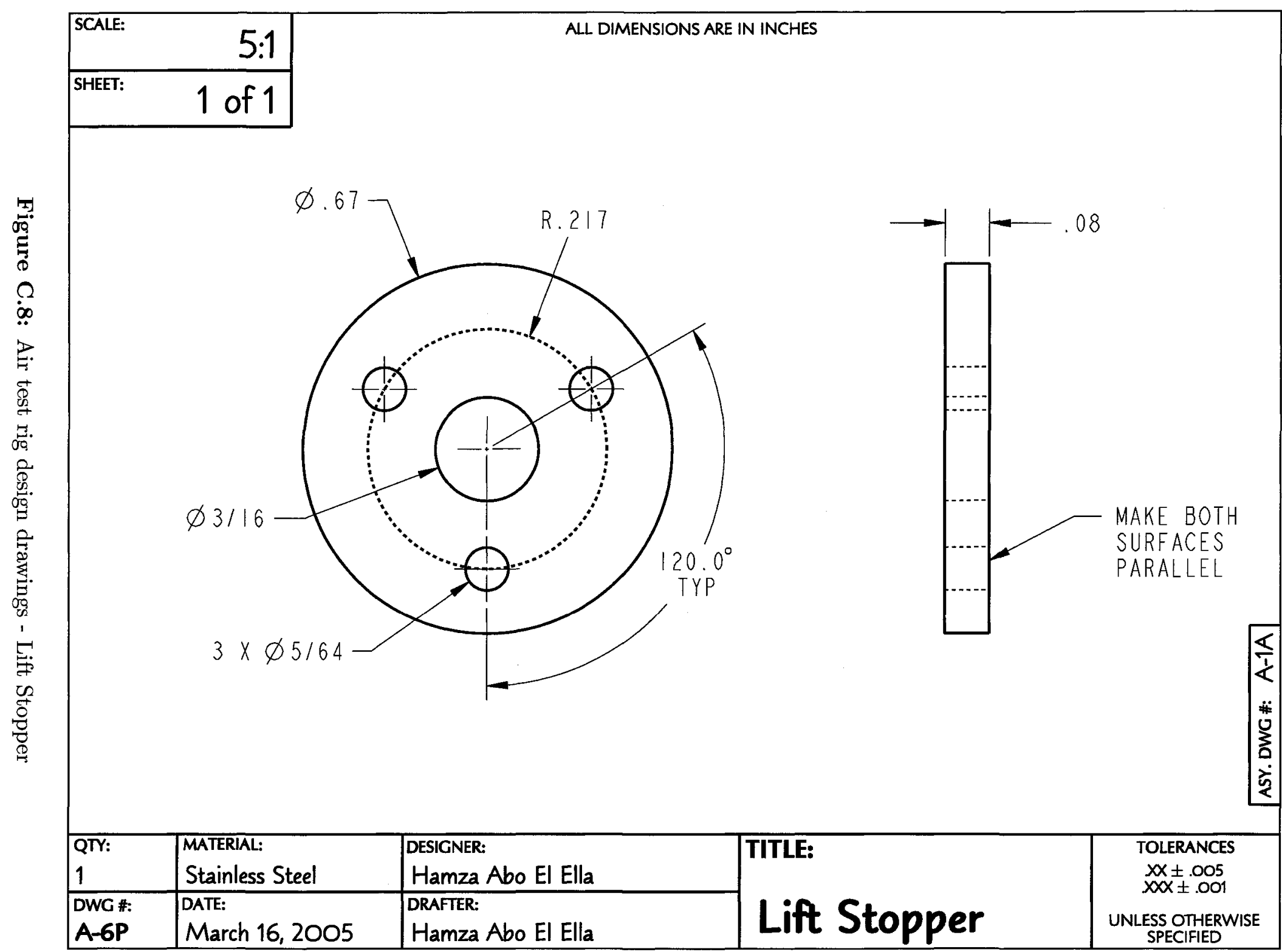




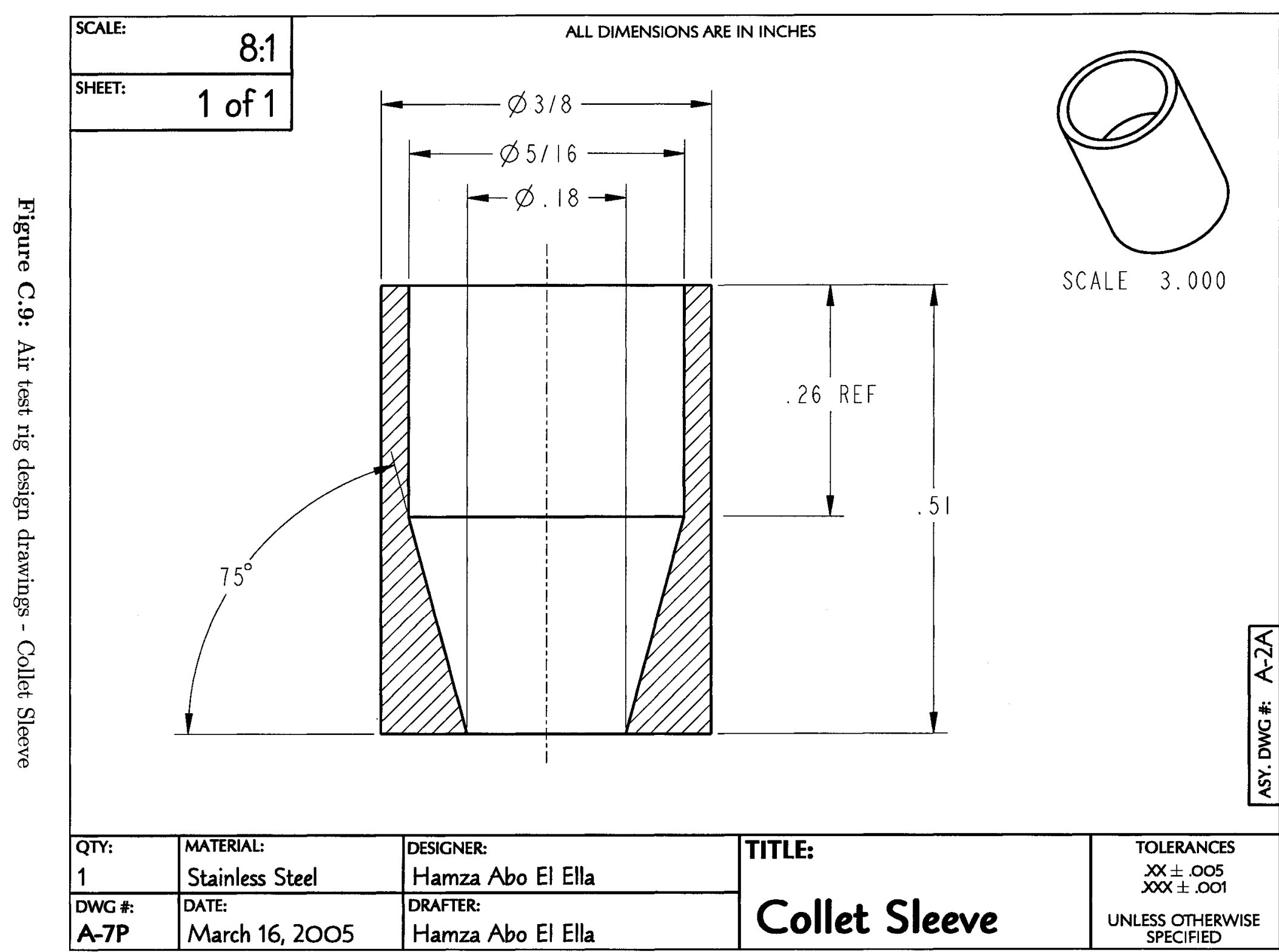

20 


\section{C.2 Nitrogen Flow Test Rig Drawings}

Drawings for the nitrogen flow test rig nozzle holder are summarized in Table C.2. Design drawings have been reduced to $75 \%$ of original size and are presented in Figures C.10 to C.13.

Table C.2: Nitrogen flow test rig nozzle holder design drawings

\begin{tabular}{|c|l|}
\hline DWG \# & Title \\
\hline N-1A & Nozzle Holder Assembly \\
\hline N-2P & Top Cap \\
\hline N-1X & Fixture Block \\
\hline
\end{tabular}




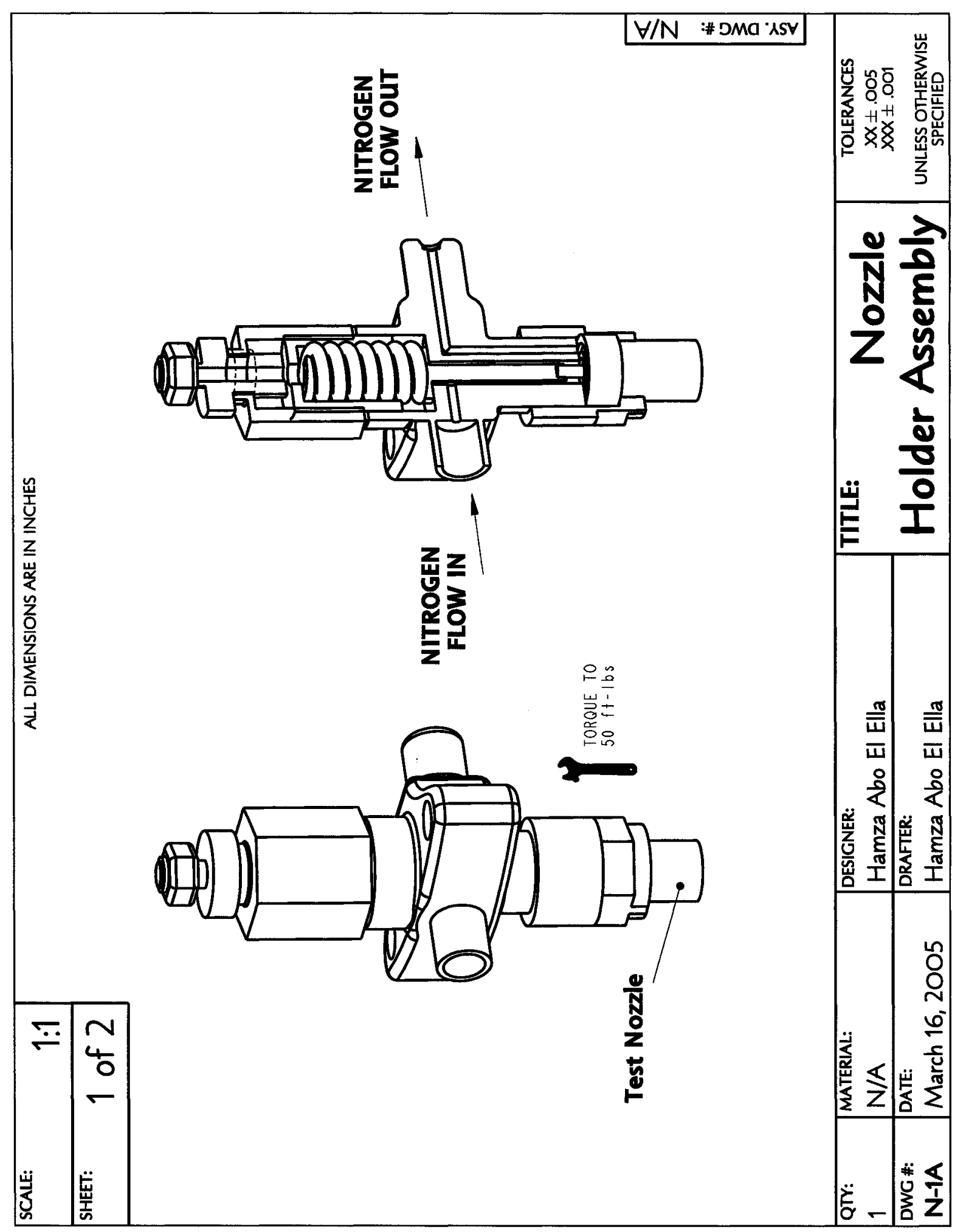

Figure C.10: Nitrogen test rig design drawings - Nozzle Holder Assembly Sh. 1 of 2 


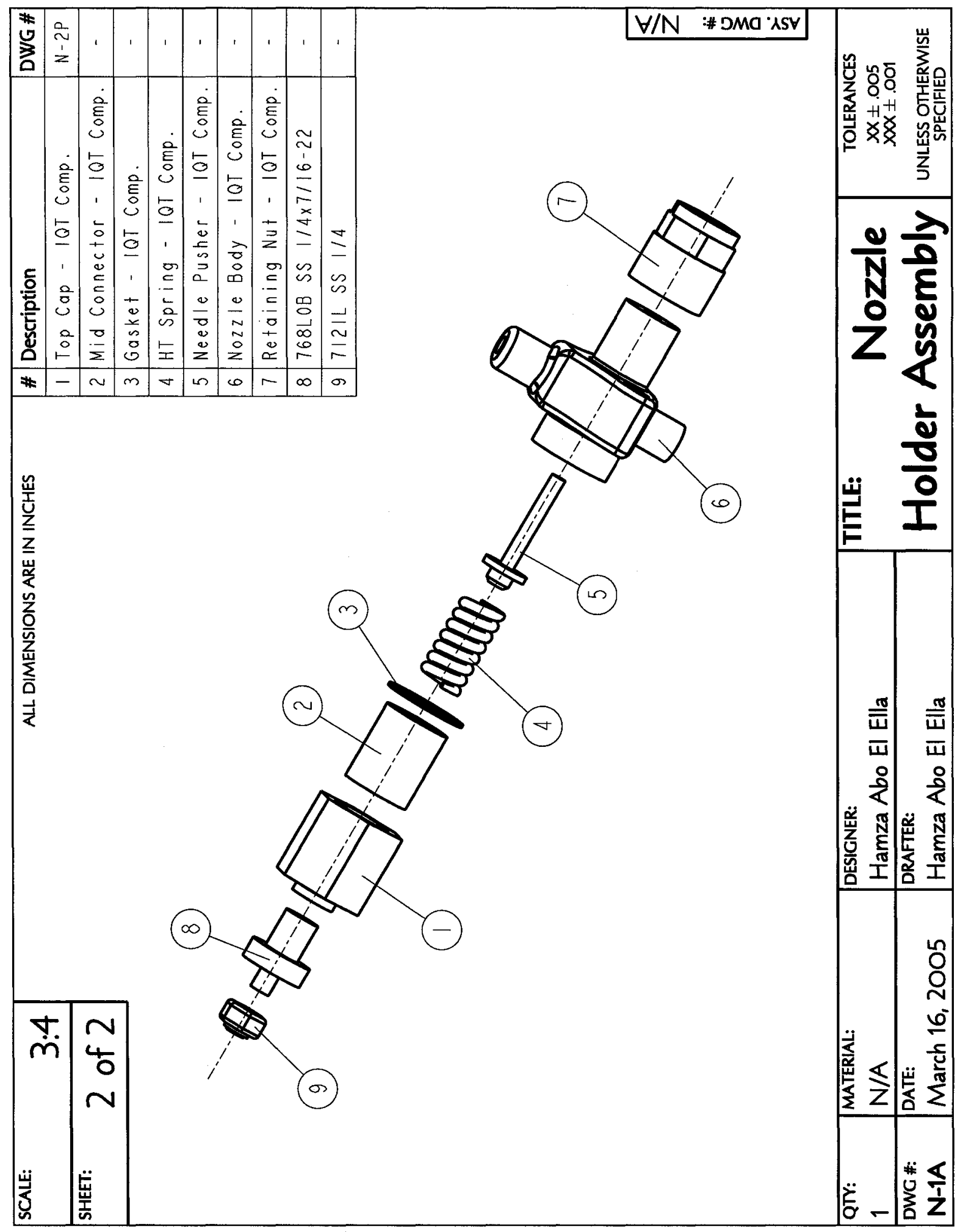

Figure C.11: Nitrogen test rig design drawings - Nozzle Holder Assembly Sh. 2 of 2 


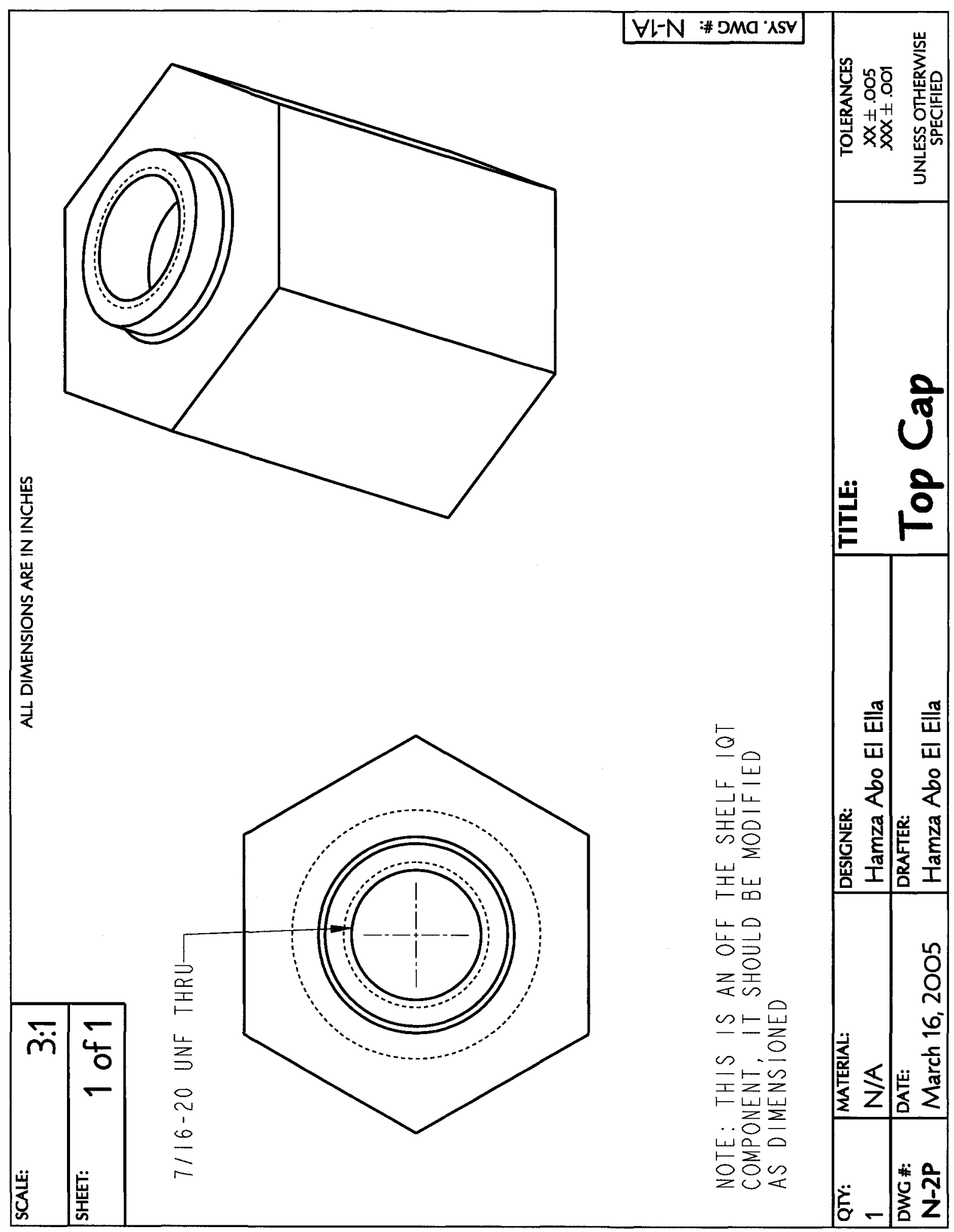

Figure C.12: Nitrogen test rig design drawings - Top Cap 


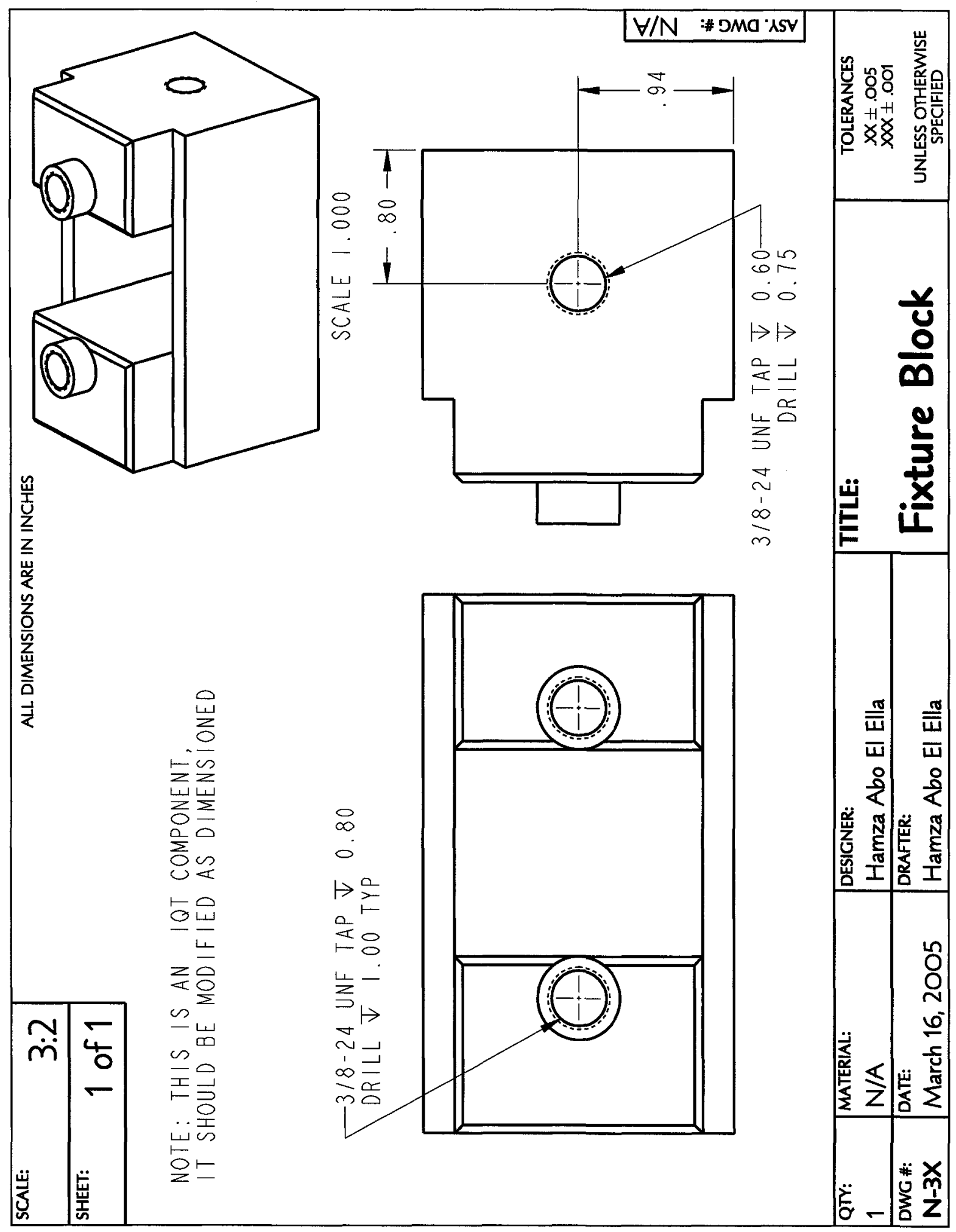

Figure C.13: Nitrogen test rig design drawings - Fixture Block 


\section{Appendix D}

\section{Air and Nitrogen Flow Test Rigs - DAQ System}

A data acquisition (DAQ) system was developed to be shared by the air and nitrogen flow test rig. The system employed a 12 bit ISA interface DAQ card, and a Pentium-III PC. The software was written in Visual Basic 6.0 and was contributed by Aaron Wilcox of Advanced Engine Technology. Table D.1 provides a list of the main components of the DAQ system, including the sensors. Wiring schematic is given in Figure D.1

Table D.1: Air and nitrogen flow test rig shared DAQ system main components

\begin{tabular}{|l|r|}
\hline Component & Model \\
\hline Data acquisition system card, 12-bit ISA interface & CIO-DAS16/Jr \\
\hline Thermocouple signal conditioner & 5B04 \\
\hline Two thermocouples & Type J \\
\hline Air thermal mass flowmeter & Brooks 5850S \\
\hline Air vacuum pressure transducer & Cole-Parmer 68075 \\
\hline Nitrogen thermal mass flowmeter & ASCO 40 \\
\hline Nitrogen pressure transducer & CUI T815 \\
\hline 24V DC powers supply & LM7805C \\
\hline 24V DC to 5V DC voltage regulator & Coler FMA1710 \\
\hline DAQ system wiring cabinet & Aluminium chassis BPA-1597 \\
\hline
\end{tabular}




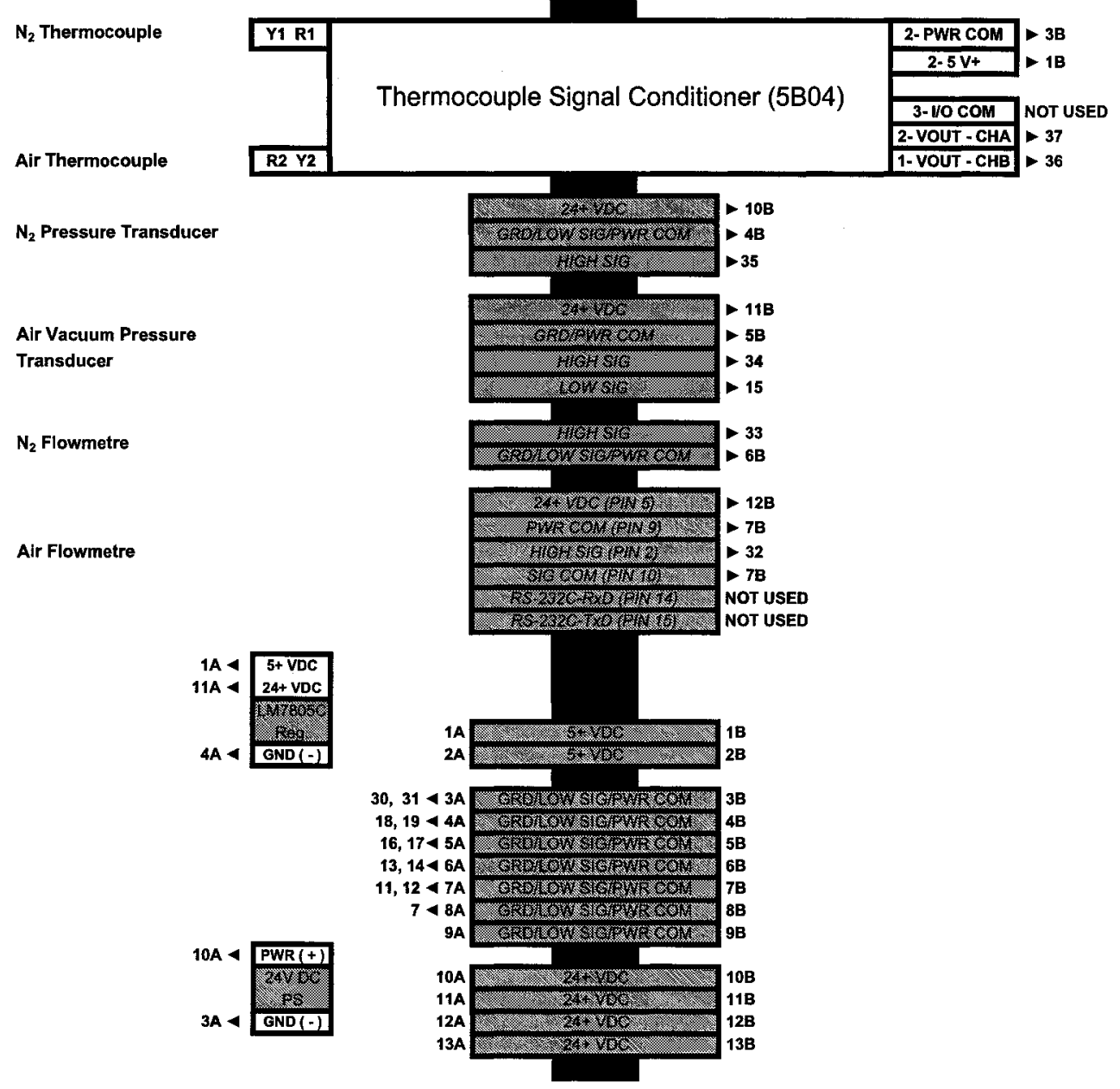

CIO-DAS16/Jr

1 5+VDCBUS

Air Thermocouple

Asi

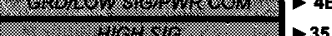

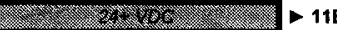

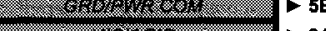

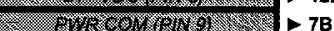

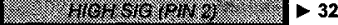

- 7 .

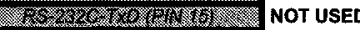

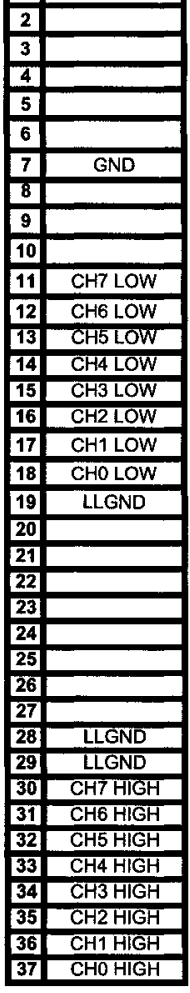

Figure D.1: Air and nitrogen flow test rig shared DAQ system wiring schematic 


\section{Appendix E}

\section{Air Flow Test Rig Calibration}

In this appendix, the manufacturer calibration data of the Brooks Model 5850S flowmeter is presented. A repeatability study of the entire test rig was conducted to determine the rig's precision, and is also presented in this appendix.

\section{E.1 Air Flowmetre Calibration}

The Brooks thermal mass flowmeter was manufacturer calibrated for air, at $21.1^{\circ} \mathrm{C}$ and 1013.25 mbar using calibration equipment traceable to the national standard [30]. The calibration data is provided in Table E.1.

Table E.1: Air flowmeter calibration data [30]

\begin{tabular}{|c|c|c|}
\hline Nominal Flow (L/min) & Actual Flow (L/min) & Error (\% of flow rate) \\
\hline 1.50 & 1.5024 & 0.16 \\
\hline 2.50 & 2.5035 & 0.14 \\
\hline 3.75 & 3.7612 & 0.30 \\
\hline 5.00 & 5.0088 & 0.18 \\
\hline
\end{tabular}




\section{E.2 Air Flow Test Rig Repeatability}

A delay pintle type nozzle, designated as Delphi 4-031 calibration nozzle, was used to conduct a repeatability study of the Pintle Clearance Air Flow Test Rig. The variation in the test rig's measurements was assumed to be of normal distribution. Since the correct flow rates at the different lift values for the nozzle were not known, it was estimated using a simple numerical average [31]. The calibration nozzle was repeatedly tested in the test rig 25 times as per the testing procedure in Appendix F. The standard deviation was then calculated using the following equation [31],

$$
\sigma=\sqrt{\frac{\sum x^{2}}{(n-1)}}
$$

The results of the study are illustrated in Figure E.1, and summarized in Tables E.2 and E.3.

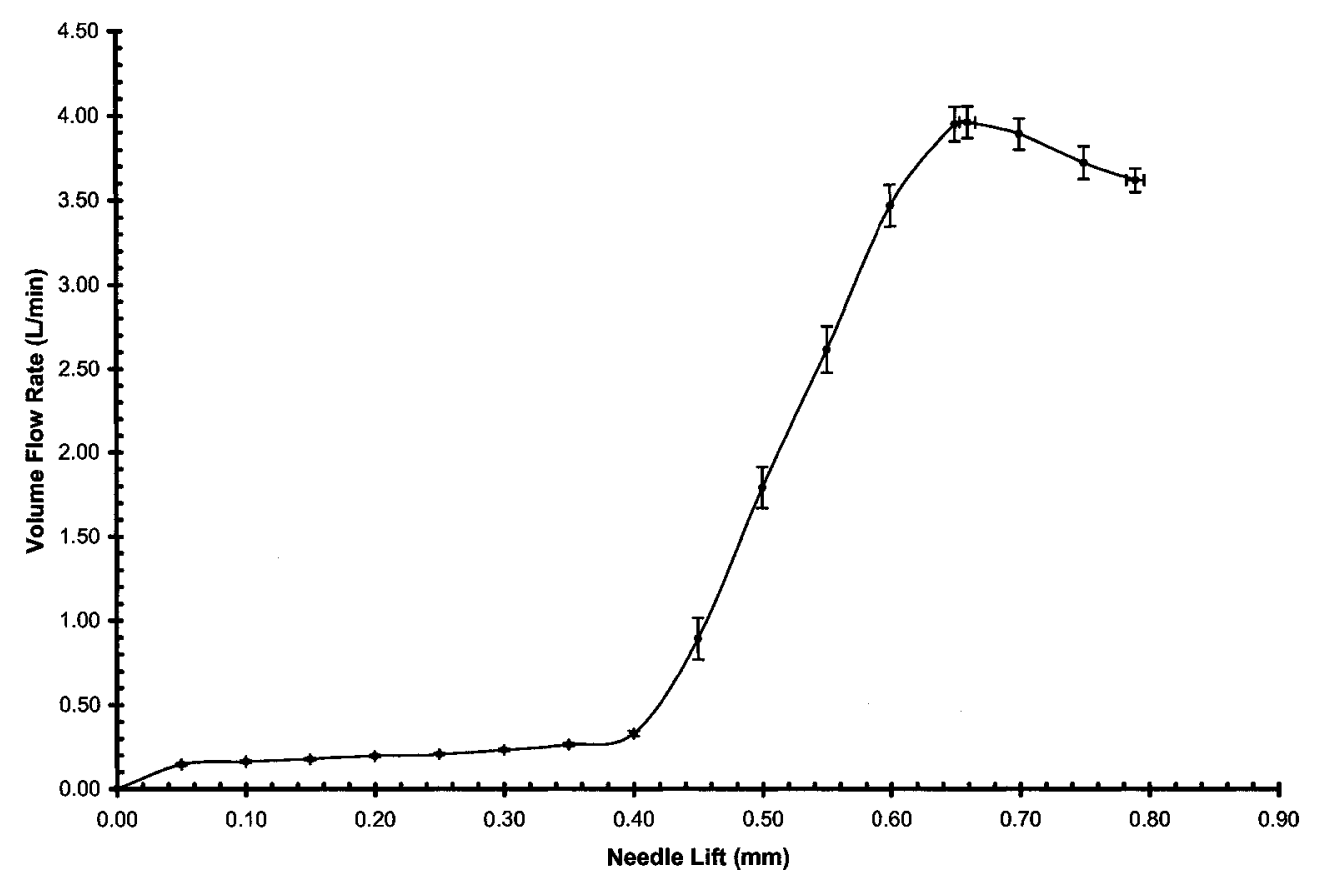

Figure E.1: Pintle clearance air test rig repeatability with one standard deviation 
Table E.2: Pintle clearance air test rig standard deviation

\begin{tabular}{|c|c|c|}
\hline Needle Lift (mm) & Estimated Actual Flow (L/min) & $\sigma(\mathbf{L} / \mathbf{m i n})$ \\
\hline 0.00 & 0.00 & 0.000000 \\
\hline 0.05 & 0.15 & 0.006091 \\
\hline 0.10 & 0.16 & 0.006096 \\
\hline 0.15 & 0.18 & 0.006264 \\
\hline 0.20 & 0.20 & 0.007862 \\
\hline 0.25 & 0.21 & 0.005986 \\
\hline 0.30 & 0.23 & 0.008104 \\
\hline 0.35 & 0.26 & 0.008885 \\
\hline 0.40 & 0.33 & 0.016134 \\
\hline 0.45 & 0.89 & 0.123532 \\
\hline 0.50 & 1.79 & 0.121634 \\
\hline 0.55 & 2.61 & 0.137098 \\
\hline 0.60 & 3.47 & 0.122985 \\
\hline 0.65 & 3.95 & 0.100850 \\
\hline 0.70 & 3.89 & 0.091542 \\
\hline 0.75 & 3.72 & 0.097938 \\
\hline & & \\
\hline
\end{tabular}

Table E.3: Pintle clearance air test rig standard deviation - end of lift, and maximum flow test points

\begin{tabular}{|l|l|l|}
\hline Test Point & Estimated Actual Value & Standard Deviation \\
\hline End of lift location & $0.79 \mathrm{~mm}$ & $0.006904 \mathrm{~mm}$ \\
\hline End of lift flow & $3.62 \mathrm{~mL} / \mathrm{min}$ & $0.069590 \mathrm{~mL} / \mathrm{min}$ \\
\hline Maximum flow location & $0.66 \mathrm{~mm}$ & $0.006000 \mathrm{~mm}$ \\
\hline Maximum flow & $3.96 \mathrm{~mL} / \mathrm{min}$ & $0.093348 \mathrm{~mL} / \mathrm{min}$ \\
\hline
\end{tabular}




\section{Appendix F}

\section{Air Flow Test Rig Testing Procedure}

The following testing procedure was followed for each test nozzle tested in the Pintle Clearance Air Flow Test Rig. Each of the nozzles was cleaned as per Appendix A.

All steps are to be performed while wearing safety glasses and rubber gloves in a clean dust free environment to ensure the safety of the operator and to avoid contamination of the test nozzles,

1. Take out the test nozzle from storage

2. Remove the two blue plugs from the air circuit

3. Record the Nozzle Type and Nozzle ID on the data sheet

4. Carefully insert the nozzle into the retaining hex nut

5. Insert the lift stopper on top of the nozzle inside the retaining hex nut, and hand tighten to the nozzle body

6. Using adequate force, insert the barrel (now attached to the nozzle body) into the yellow tubing of the air circuit 
7. Fasten the nozzle body to the mounting bracket using the two nuts and screws

8. Fasten the steel tubing connecting the flowmeter to the nozzle body using the appropriate wrenches

9. Ensure the lift adjuster is all the way to the bottom (i.e. at the zero lift position). DO NOT TIGHTEN OR TORQUE

10. Tighten the twist handle at the top using the appropriate wrenches

11. Roll down the top nut until it reaches the lift adjuster surface. DO NOT TIGHTEN OR TORQUE. Simply thread it down until it reaches the top surface of the lift adjuster

12. Place the dial gauge just touching and perpendicular to the top surface of the lift adjuster, and magnetize it to the metal plate behind the mounting bracket

13. Turn on the gauge and zero it

14. Launch the FIE software from the desktop by double clicking the shortcut icon

15. Open the green valve on the air circuit

16. Fully open the metering valve

17. Turn the pump on

18. Fully close the metering valve

19. Wait until the pressure goes over 0.8 bar, and the flow reading stabilizes, then ensure the flow reading is $0.00 \mathrm{~L} / \mathrm{min}$ on the monitor. Record this on the data sheet at the lift value of $0.00 \mathrm{~mm}$

20. Record the temperature on the data sheet 
21. Twist the lift adjuster to attain a needle life of $0.05 \mathrm{~mm}$ on the lift gauge

22. Once the flow reading stabilizes, record the value on the data sheet at the corresponding lift value

23. Repeat steps 21 to 22 for lift increments of $0.05 \mathrm{~mm}$ all the way until the end of lift point is reached. Record all the flow readings at the corresponding lifts, and also the end of lift point and its corresponding flow reading on the data sheet. This end of lift point will be when the lift adjuster can no longer twist (usually around 0.78 to 0.81 depending on the test nozzle). BE CAREFUL NOT TO FORCE THE LIFT ADJUSTER PAST THE END OF LIFT POINT

24. By varying the lift on the needle using the lift adjuster, find the maximum flow lift point and record the lift value and its corresponding flow rate on the data sheet (this point is usually around 0.64 to $0.66 \mathrm{~mm}$ depending on the test nozzle)

25. Return the lift adjuster to the zero lift position

26. Turn off the green valve

27. Shut down the pump

28. Turn off the dial gauge, remove it, and magnetize it to the left rail on the side of the bench

29. Untie the steel tubing connecting the flowmeter to the nozzle body

30. Untie the twist handle on the nozzle body to release the nozzle needle

31. Untie the screws and nuts fastening the nozzle body to the bracket

32. Remove the nozzle body by pulling the nozzle body to the right side causing the nozzle barrel to slip out of the yellow tubing 
33. Untie the retaining hex nut on the nozzle body and remove the nozzle and lift stopper

34. Carefully return the nozzle to storage

35. Place the disassembled nozzle holder on a clean paper towel on the bench to be ready for use

36. To test another nozzle, repeat steps 1 to 35 


\section{Appendix G}

\section{Nitrogen Flow Test Rig Calibration}

The manufacturer calibration data of the Cole-Parmer Model FMA1710 flowmeter is presented. A repeatability study of the entire test rig was conducted to determine the rig's precision, and is also presented in this appendix.

\section{G.1 Nitrogen Flowmetre Calibration}

The Cole-Parmer thermal mass flowmeter was manufacturer calibrated for nitrogen, at $21.1^{\circ} \mathrm{C}$ and $14.7 \mathrm{psi}(\mathrm{a})$ using calibration equipment traceable to NIST test \#18010C [32]. The calibration data is provided in Table G.1.

Table G.1: Nitrogen flowmeter calibration data [32]

\begin{tabular}{|c|c|c|}
\hline Nominal Flow (mL/min) & Actual Flow (mL/min) & Deviation (\% of F.S.) \\
\hline 0 & 0 & 0.0 \\
\hline 50 & 50 & 0.0 \\
\hline 100 & 100 & 0.0 \\
\hline 150 & 150 & 0.0 \\
\hline 200 & 200 & 0.0 \\
\hline
\end{tabular}




\section{G.2 Nitrogen Flow Test Rig Repeatability}

A delay pintle type nozzle, designated as Delphi 4-031 calibration nozzle, was used to conduct a repeatability study of the Needle Clearance Nitrogen Flow Test Rig. The variation in the test rig's measurements was assumed to be of normal distribution. Since the correct flow rate of the nozzle was not known, it was estimated using a simple numerical average [31]. The calibration nozzle was repeatedly tested in the test rig 25 times as per the testing procedure in Appendix H. The standard deviation was then calculated using equation E.1. The estimated actual flow was found to be $127.92 \mathrm{~mL} / \mathrm{min}$ with a standard deviation of $6.14 \mathrm{~mL} / \mathrm{min}$, or $4.80 \%$. 


\section{Appendix $\mathrm{H}$}

\section{Nitrogen Flow Test Rig Testing Procedure}

The following testing procedure was followed for each test nozzle tested in the Needle Clearance Nitrogen Flow Test Rig. Each of the nozzles was cleaned as per Appendix A.

All steps are to be performed while wearing safety glasses and rubber gloves in a clean dust free environment to ensure the safety of the operator and to avoid contamination of the test nozzles,

1. Ensure the nitrogen tank valve is closed

2. Ensure that the green and black valves on the nitrogen circuit are in the closed position

3. Remove the retaining hex nut at the end of the nozzle body on the nitrogen flow circuit using a torque wrench if necessary, and place on a clean paper towel on the aluminum surface on the bench

4. Take out the test nozzle from storage 
5. Carefully insert the nozzle inside the retaining hex nut, and hand tighten to the nozzle body

6. Carefully torque the retaining hex nut using a torque wrench to $50 \mathrm{ft}-\mathrm{lbs}$

7. Launch the FIE software from the desktop by double clicking the shortcut icon

8. Slowly open the nitrogen tank valve fully

9. Adjust the 2 nd pressure regulator until the nitrogen pressure sensor reads 20 bar on the software window on the monitor

10. Place the black valve in the flowmeter position (i.e. arrow pointing towards the flowmeter line)

11. Slowly open the green valve

12. Re-adjust the 2 nd pressure regulator until the nitrogen pressure sensor reads 20 bar on the software window on the monitor

13. Record the flow reading once it stabilizes on the data sheet (approximately after 5 minutes)

14. Return the green and black valves on the nitrogen circuit to the closed position

15. Vent the nitrogen in the circuit by placing the black valve in the vented position, and then return it to the closed position

16. Close the nitrogen tank valve fully

17. Remove the retaining hex nut containing the nozzle from the nozzle body using a torque wrench. 
18. Repeat steps 5 to 17 twice more rotating the nozzle needle with respect to the nozzle barrel by approximately 120 degrees between each repetition. Once done, place the nozzle back into storage, and hand tighten the retaining hex nut to the nozzle body

19. To test another nozzle, repeat steps 1 to 18 


\section{Appendix I}

\section{Experimental Data}

In this appendix all experimental data collected for all 15 test nozzles is presented. Ignition delay and cetane number values along with spray pattern data, internal geometry flow data, and needle profile data are presented in the following sections. 


\section{I.1 Ignition Delay Data}

Ignition delay and cetane number $(\mathrm{CN})$ values for all 15 test nozzles are presented in Table I.1. All values were obtained using ASTM D6890 test method employing an IQT ${ }^{\mathrm{TM}}$ with $\mathrm{CF} 12$ as the fuel.

Table I.1: Ignition delay and CN values for all 15 test nozzles

\begin{tabular}{|c|c|c|}
\hline Test Nozzle & Ignition Delay (ms) & Cetane Number \\
\hline Zexel 9 & 3.473 & 57.5 \\
\hline Zexel 15 & 3.477 & 57.4 \\
\hline Sun 1 & 3.443 & 58.0 \\
\hline Sun 32 & 3.561 & 55.9 \\
\hline Zexel 76 & 3.517 & 56.7 \\
\hline Zexel 22 & 3.585 & 55.5 \\
\hline Zexel 35 & 3.472 & 57.5 \\
\hline Sun 63 & 3.512 & 56.8 \\
\hline Sun 65 & 3.355 & 59.7 \\
\hline Sun 66 & 3.516 & 56.7 \\
\hline CAV 14 & 3.540 & 56.3 \\
\hline Zexel 70 & 3.582 & 55.6 \\
\hline Zexel 71 & 3.425 & 58.4 \\
\hline Sun 68 & 3.429 & 58.3 \\
\hline Sun 69 & 3.544 & 56.2 \\
\hline
\end{tabular}




\section{I.2 Spray Pattern Data}

The captured spray images for each of the 15 test nozzles using the Optical Spray Pattern Test Rig are presented in Figures I.1 to I.15 in order of increasing ignition delay values. Each spray image corresponds to a particular time in the test nozzle's injection event. All spray images are to the same scale.

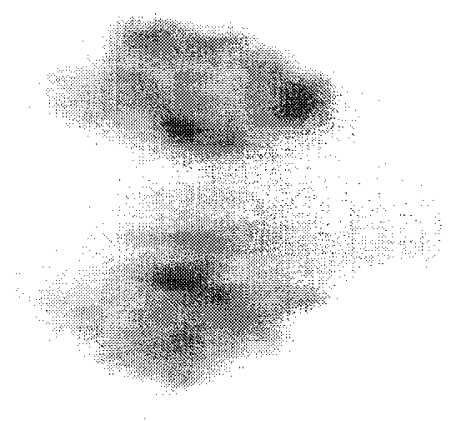

(a) $0.28-0.46 \mathrm{~ms}$

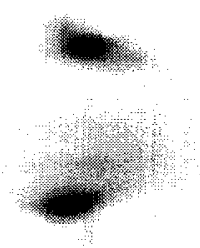

(b) $0.70-0.88 \mathrm{~ms}$
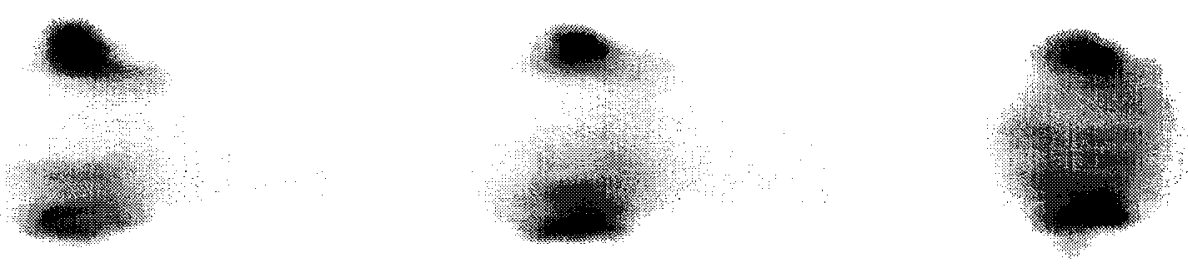

(c) $1.02-1.20 \mathrm{~ms}$

(d) $1.20-1.38 \mathrm{~ms}$

(e) $1.50-1.68 \mathrm{~ms}$

Figure I.1: Sun 65 captured spray images, 3.355 ms ignition delay 

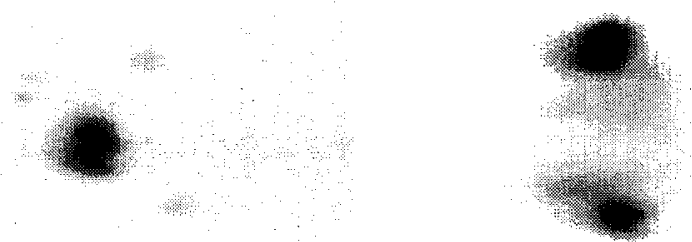

(a) $0.00-0.10 \mathrm{~ms}$

(b) $0.58-0.76 \mathrm{~ms}$
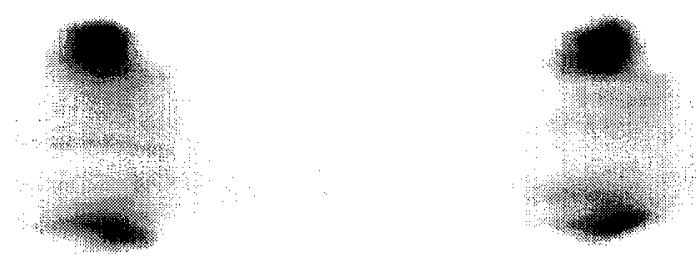

(c) $0.74-0.92 \mathrm{~ms}$

(d) $0.90-1.08 \mathrm{~ms}$
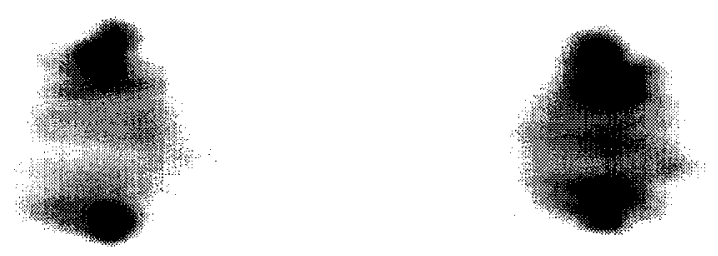

(e) $1.72-1.90 \mathrm{~ms}$

(f) $1.92-2.10 \mathrm{~ms}$

Figure I.2: Zexel 71 captured spray images, $3.425 \mathrm{~ms}$ ignition delay 


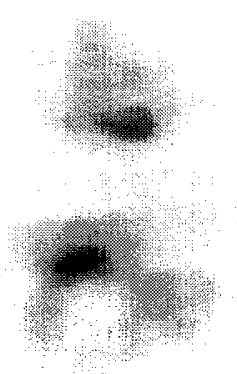

(a) $0.40-0.58 \mathrm{~ms}$

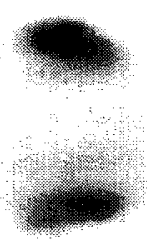

(b) $0.40-0.58 \mathrm{~ms}$

(c) $0.60-0.78 \mathrm{~ms}$
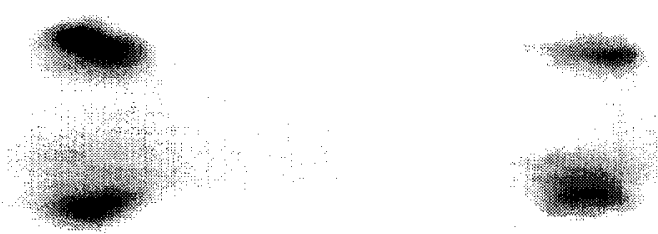

(d) $0.80-0.98 \mathrm{~ms}$

(e) $1.02-1.20 \mathrm{~ms}$

Figure I.3: Sun 68 captured spray images, $3.429 \mathrm{~ms}$ ignition delay 

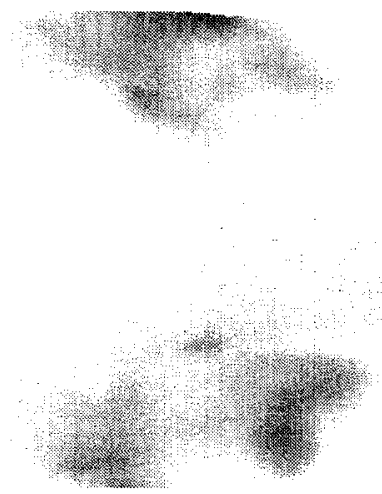

(a) $0.40-0.58 \mathrm{~ms}$

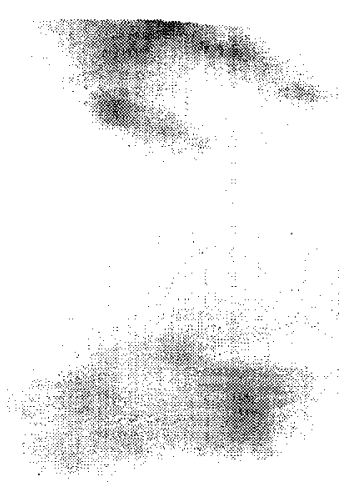

(b) $0.42-0.60 \mathrm{~ms}$

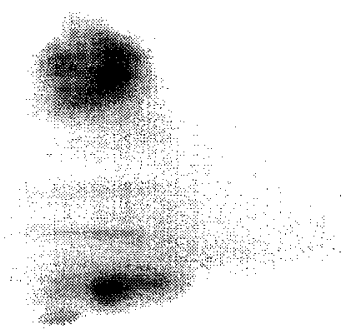

(d) $1.32-1.50 \mathrm{~ms}$

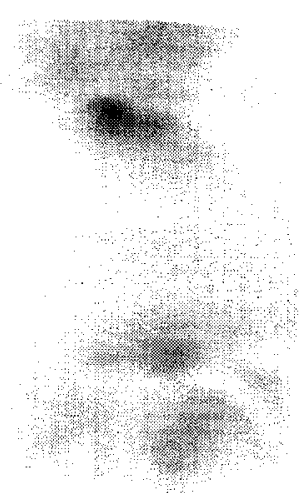

(c) $0.56-0.74 \mathrm{~ms}$

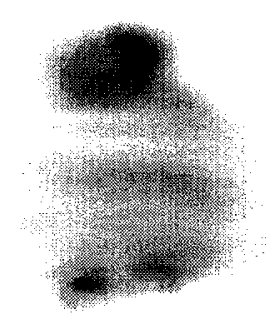

(e) $1.84-2.02 \mathrm{~ms}$

Figure I.4: Sun 1 captured spray images, 3.443 ms ignition delay 


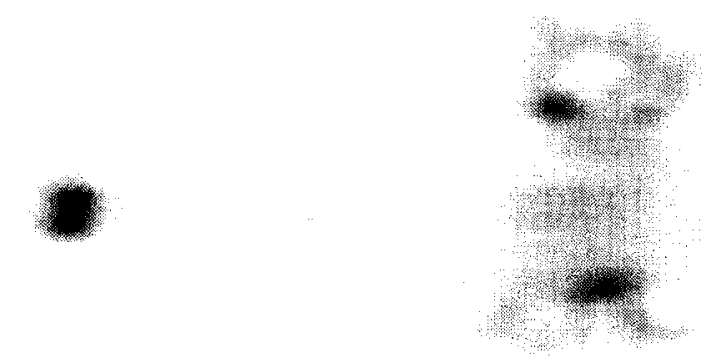

(a) $0.00-0.10 \mathrm{~ms}$

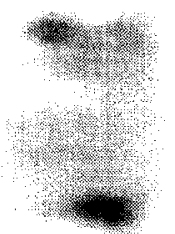

(c) $0.54-0.72 \mathrm{~ms}$

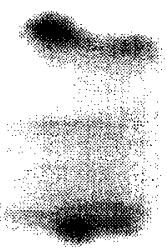

(e) $1.20-1.38 \mathrm{~ms}$ (b) $0.34-0.52 \mathrm{~ms}$

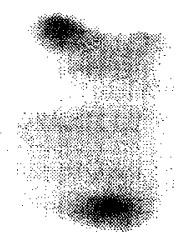

(d) $1.08-1.26 \mathrm{~ms}$

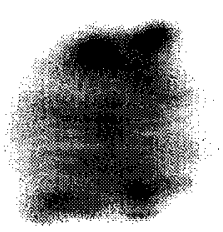

(f) $1.92-2.10 \mathrm{~ms}$

Figure 1.5: Zexel 35 captured spray images, $3.472 \mathrm{~ms}$ ignition delay 


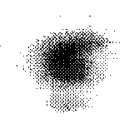
(a) $0.00-0.08 \mathrm{~ms}$
(b) $0.00-0.12 \mathrm{~ms}$

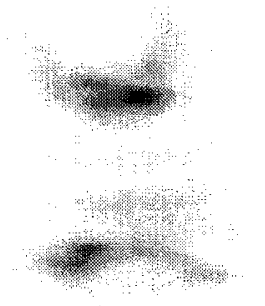

(c) $0.42-0.60 \mathrm{~ms}$

(d) $0.42-0.60 \mathrm{~ms}$
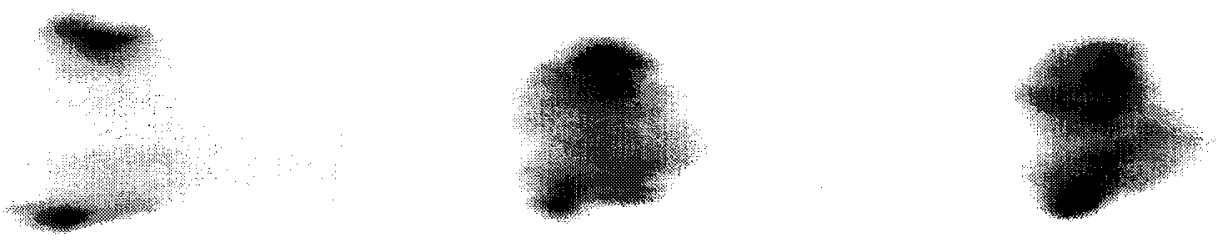
(e) $1.18-1.36 \mathrm{~ms}$
(f) $1.88-2.06 \mathrm{~ms}$
(g) $1.94-2.12 \mathrm{~ms}$

Figure I.6: Zexel 9 captured spray images, $3.473 \mathrm{~ms}$ ignition delay 

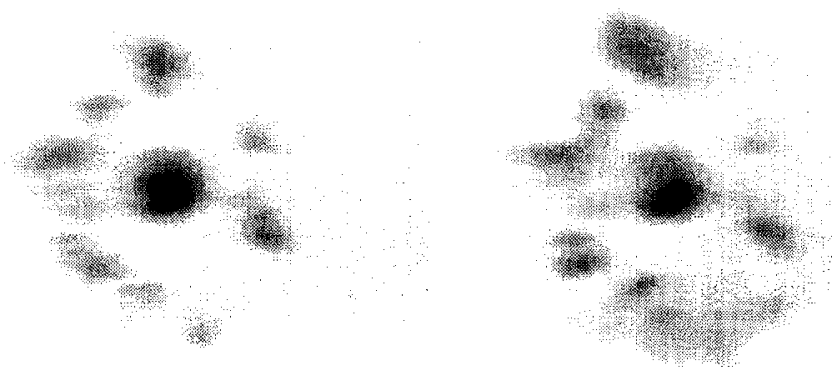

(a) $0.00-0.18 \mathrm{~ms}$

(b) $0.06-0.24 \mathrm{~ms}$
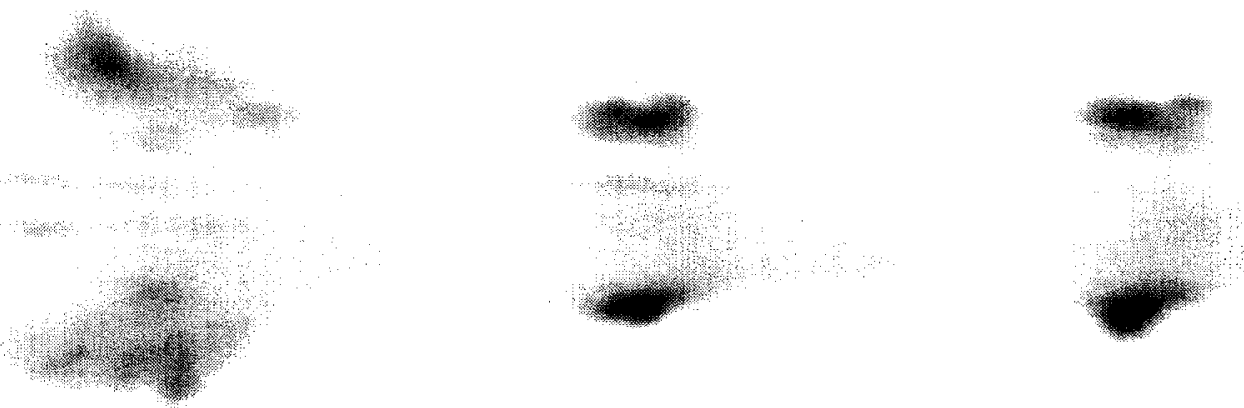

(c) $0.16-0.34 \mathrm{~ms}$

(d) $0.88-1.06 \mathrm{~ms}$

(e) $1.12-1.30 \mathrm{~ms}$
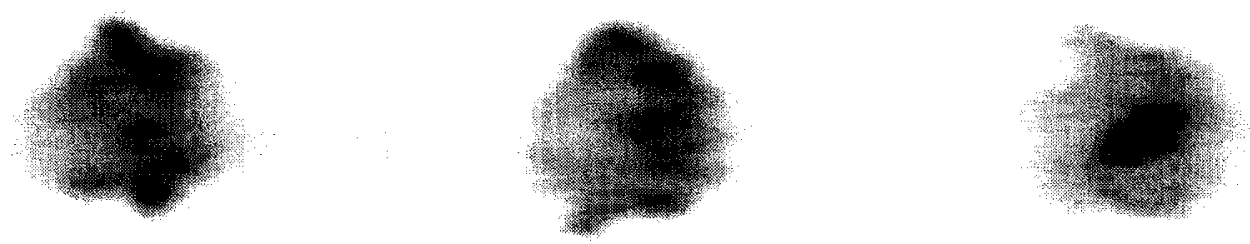

(f) $1.98-2.16 \mathrm{~ms}$

(g) $2.06-2.24 \mathrm{~ms}$

(h) $2.16-2.34 \mathrm{~ms}$

Figure I.7: Zexel 15 captured spray images, $3.477 \mathrm{~ms}$ ignition delay 


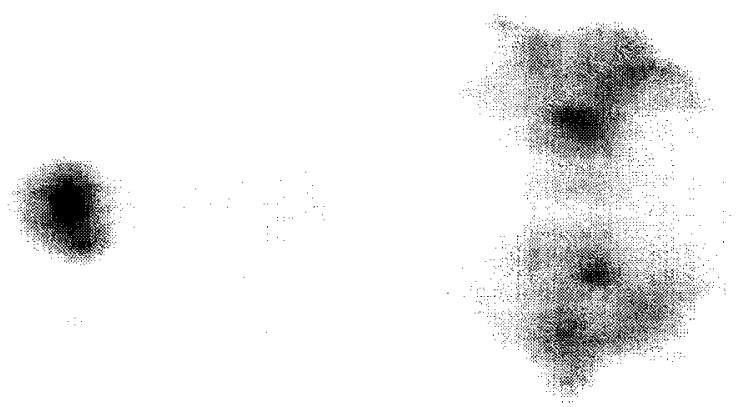

(a) $0.00-0.12 \mathrm{~ms}$

(b) $0.28-0.46 \mathrm{~ms}$
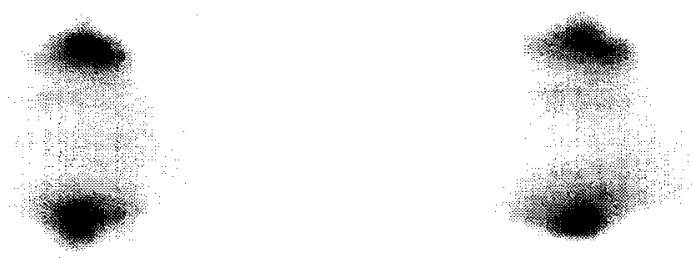

(c) $0.72-0.90 \mathrm{~ms}$

(d) $1.20-1.38 \mathrm{~ms}$
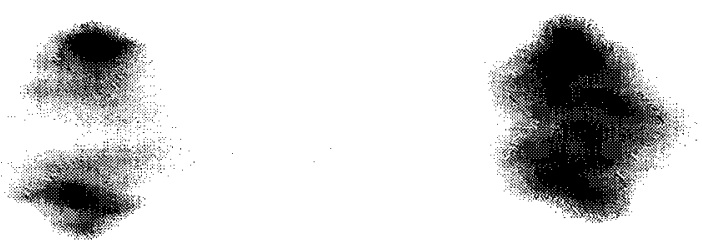

(e) $1.34-1.52 \mathrm{~ms}$

(f) $1.94-2.12 \mathrm{~ms}$

Figure I.8: Sun 63 captured spray images, $3.512 \mathrm{~ms}$ ignition delay 

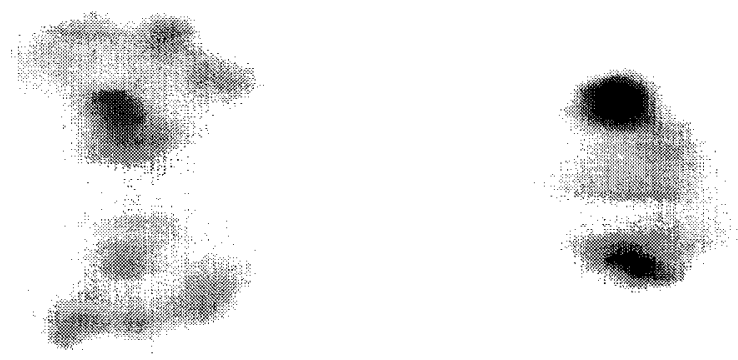

(a) $0.22-0.40 \mathrm{~ms}$

(b) $1.32-1.50 \mathrm{~ms}$
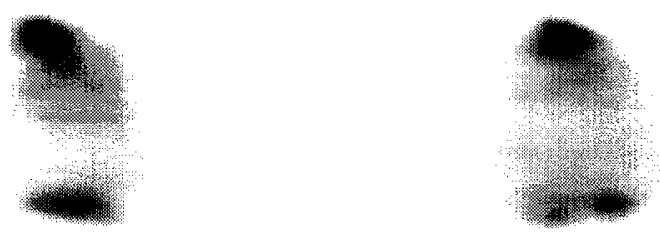

(c) $1.34-1.52 \mathrm{~ms}$

(d) $1.40-1.58 \mathrm{~ms}$
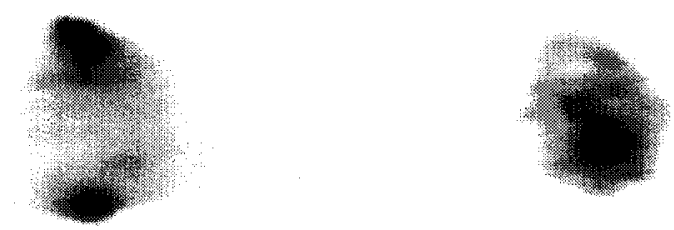

(e) $1.48-1.66 \mathrm{~ms}$

(f) $2.22-2.40 \mathrm{~ms}$

Figure I.9: Sun 66 captured spray images, $3.516 \mathrm{~ms}$ ignition delay 


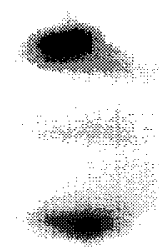

(a) $0.72-0.90 \mathrm{~ms}$
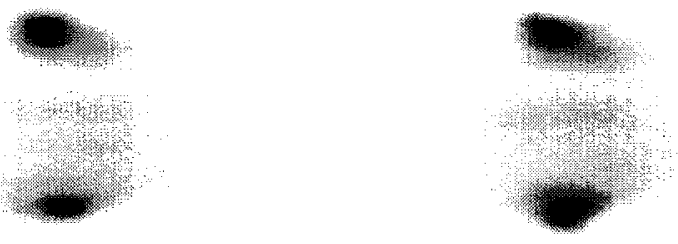

(b) $0.78-0.96 \mathrm{~ms}$

(c) $1.20-1.38 \mathrm{~ms}$
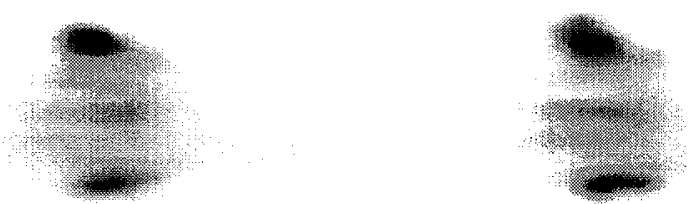

(d) $1.50-1.68 \mathrm{~ms}$

(e) $1.54-1.72 \mathrm{~ms}$

Figure I.10: Zexel 76 captured spray images, $3.517 \mathrm{~ms}$ ignition delay 


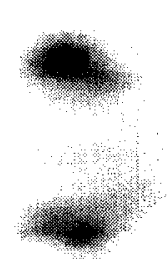

(a) $0.54-0.72 \mathrm{~ms}$
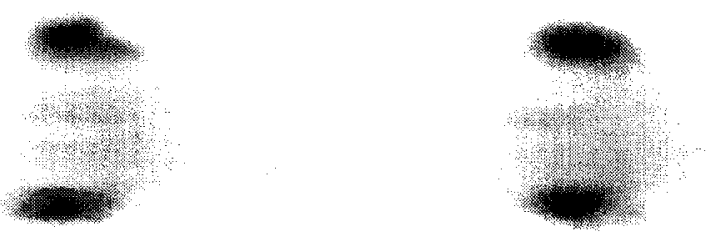

(b) $1.28-1.46 \mathrm{~ms}$

(c) $1.40-1.58 \mathrm{~ms}$
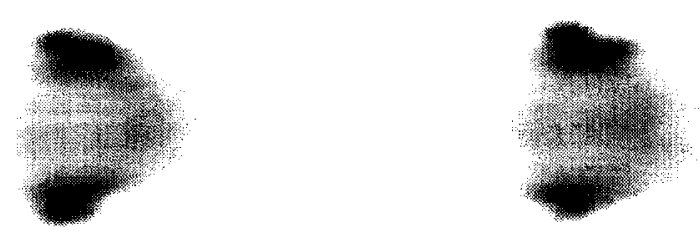

(d) $1.50-1.68 \mathrm{~ms}$

(e) $1.80-1.98 \mathrm{~ms}$

Figure 1.11: CAV 14 captured spray images, $3.540 \mathrm{~ms}$ ignition delay 


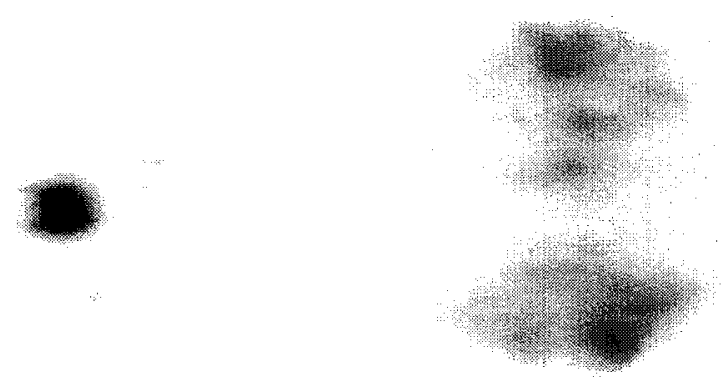

(a) $0.00-0.18 \mathrm{~ms}$

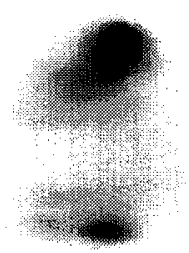

(c) $0.70-0.88 \mathrm{~ms}$ (b) $0.42-0.6 \mathrm{~ms}$

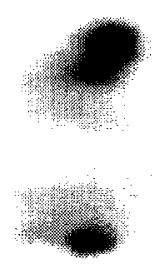

(d) $0.76-0.94 \mathrm{~ms}$
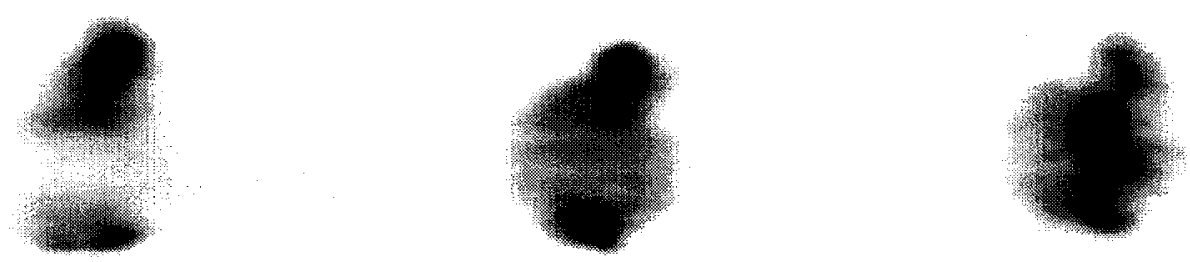

(e) $1.48-1.66 \mathrm{~ms}$

(f) $1.98-2.16 \mathrm{~ms}$

(g) $2.22-2.40 \mathrm{~ms}$

Figure I.12: Sun 69 captured spray images, $3.544 \mathrm{~ms}$ ignition delay 


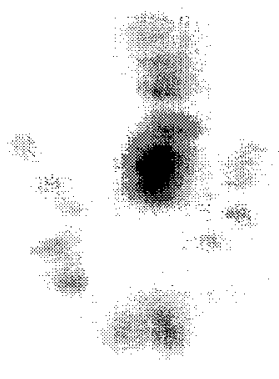

(a) $0.08-0.26 \mathrm{~ms}$

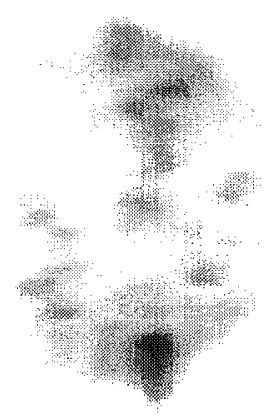

(b) $0.14-0.32 \mathrm{~ms}$

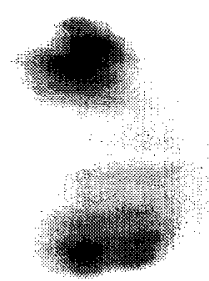

(d) $0.98-1.16 \mathrm{~ms}$
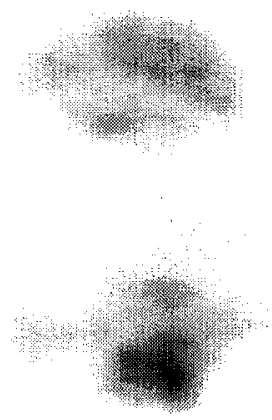

(c) $0.18-0.36 \mathrm{~ms}$

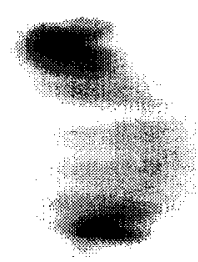

(e) $1.22-1.40 \mathrm{~ms}$

Figure I.13: Sun 32 captured spray images, $3.561 \mathrm{~ms}$ ignition delay 


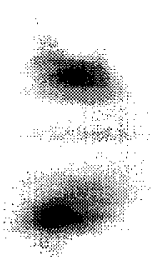

(a) $0.58-0.76 \mathrm{~ms}$
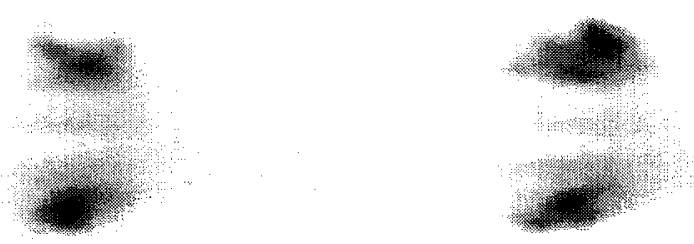

(b) $0.62-0.80 \mathrm{~ms}$

(c) $0.94-1.12 \mathrm{~ms}$
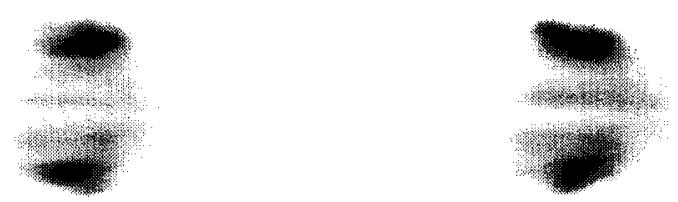

(d) $1.50-1.68 \mathrm{~ms}$

(e) $1.64-1.82 \mathrm{~ms}$

Figure I.14: Zexel 70 captured spray images, $3.582 \mathrm{~ms}$ ignition delay 


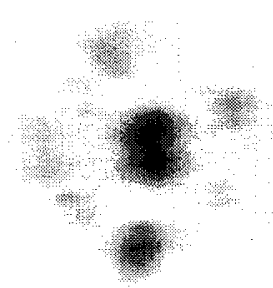

(a) $0.00-0.18 \mathrm{~ms}$

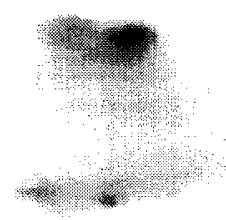

(c) $0.98-1.16 \mathrm{~ms}$

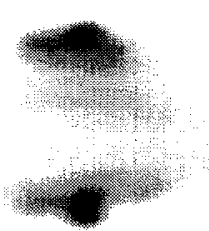

(e) $1.42-1.60 \mathrm{~ms}$

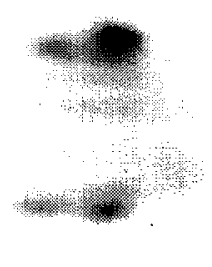

(b) $0.56-0.74 \mathrm{~ms}$

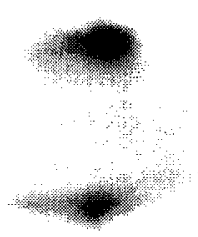

(d) $1.06-1.24 \mathrm{~ms}$

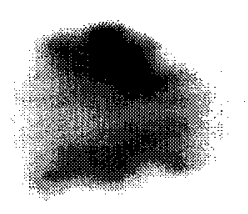

(f) $1.94-2.12 \mathrm{~ms}$

Figure I.15: Zexel 22 captured spray images, $3.585 \mathrm{~ms}$ ignition delay 


\section{I.3 Internal Geometry Flow Data}

Flow data for the 15 test nozzles gathered using the Pintle Clearance Air Flow Test Rig, and the Needle Clearance Nitrogen Flow Test Rig are given in Tables I.2 and I.3 respectively.

Table I.2: Pintle clearance air flow test rig data for all 15 test nozzles

(a) Flow values at corresponding needle lifts

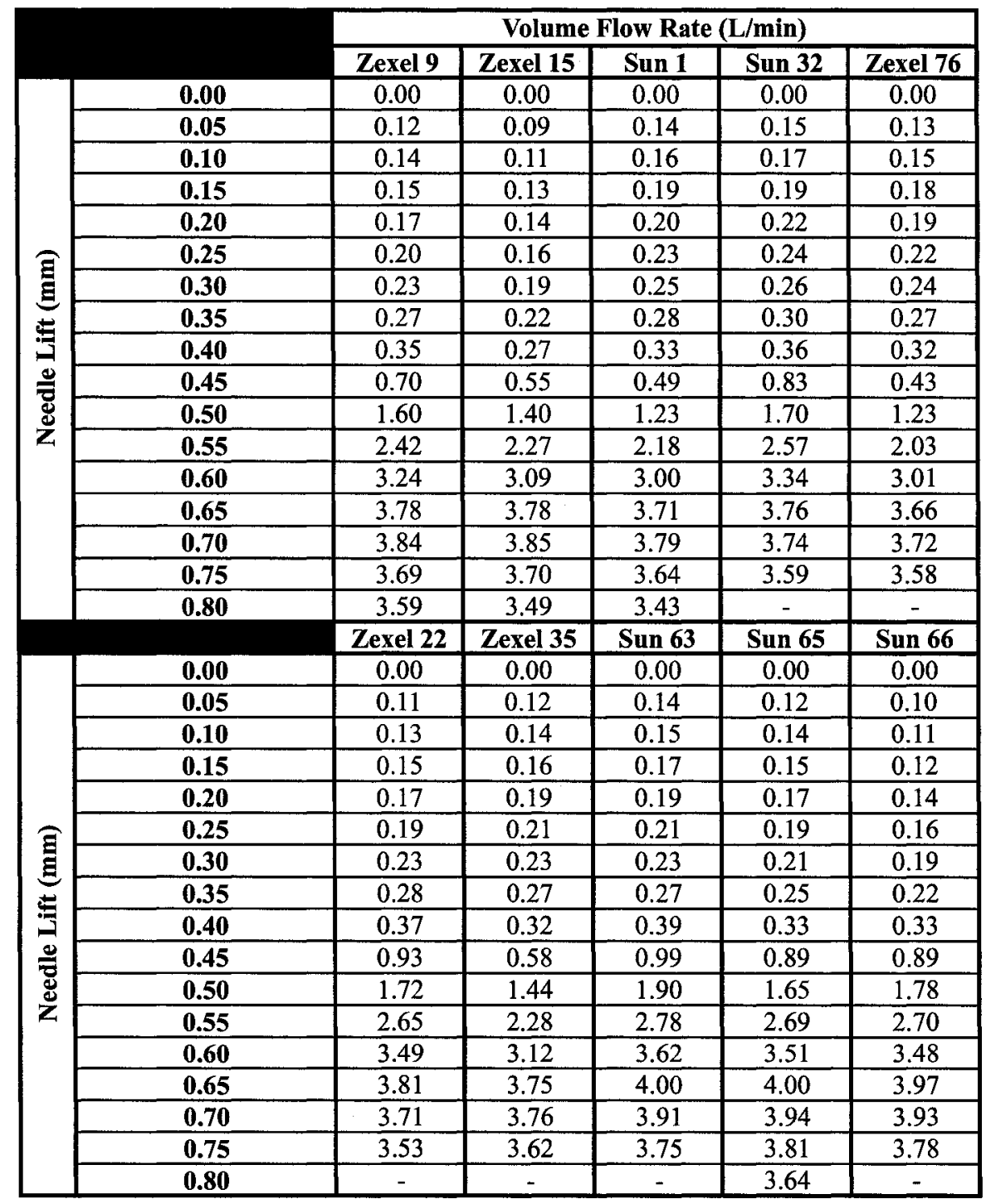




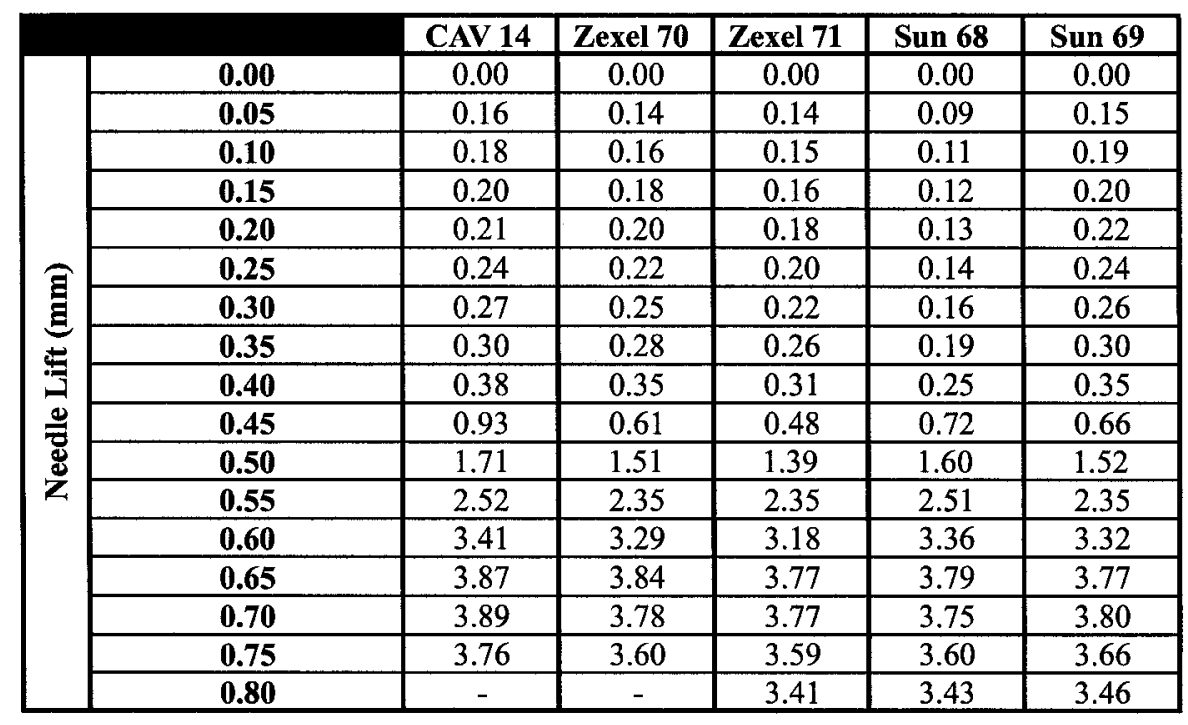

(b) Max flow and end of lift points

\begin{tabular}{|l|c|c|c|c|c|}
\hline & Zexel 9 & Zexel 15 & Sun 1 & Sun 32 & Zexel 76 \\
\hline Max Flow Lift (mm) & 0.68 & 0.70 & 0.69 & 0.66 & 0.69 \\
\hline Max Flow (L/min) & 3.89 & 3.85 & 3.80 & 3.80 & 3.74 \\
\hline End of Lift (mm) & 0.80 & 0.81 & 0.81 & 0.79 & 0.79 \\
\hline End of Lift Flow (L/min) & 3.59 & 3.49 & 3.34 & 3.45 & 3.46 \\
\hline Max Flow Lift (mm) & 0.65 & 0.67 & 0.65 & 0.66 & 0.67 \\
\hline Max Flow (L/min) & 3.81 & 3.80 & 4.00 & 4.02 & 3.98 \\
\hline End of Lift (mm) & 0.78 & 0.79 & 0.79 & 0.80 & 0.79 \\
\hline End of Lift Flow (L/min) & 3.48 & 3.50 & 3.63 & 3.64 & 3.62 \\
\hline & CAV 14 & Zexel 70 & Zexel 71 & Sun 68 & Sun 69 \\
\hline Max Flow Lift (mm) & 0.67 & $\mathbf{0 . 6 7}$ & 0.67 & 0.67 & 0.69 \\
\hline Max Flow (L/min) & 3.93 & 3.87 & 3.80 & 3.80 & 3.81 \\
\hline End of Lift (mm) & 0.78 & 0.79 & 0.80 & 0.80 & 0.80 \\
\hline End of Lift Flow (L/min) & 3.70 & 3.50 & 3.41 & 3.43 & 3.46 \\
\hline
\end{tabular}


Table I.3: Needle clearance nitrogen flow test rig data for all 15 test nozzles

\begin{tabular}{|c|c|c|c|c|c|}
\hline & Zexel 9 & Zexel 15 & Sun 1 & Sun 32 & Zexel 76 \\
\hline Average Flow (mL/min) & 125 & 109 & 44 & 69 & 98 \\
\hline & Zexel 22 & Zexel 35 & Sun 63 & Sun 65 & Sun 66 \\
\hline Average Flow (mL/min) & 95 & 125 & 76 & 64 & 80 \\
\hline & CAV 14 & Zexel 70 & Zexel 71 & Sun 68 & Sun 69 \\
\hline Average Flow (mL/min) & 47 & 144 & 176 & 51 & 88 \\
\hline
\end{tabular}




\section{I.4 Needle Profile Data}

Needle dimensions for all 15 test nozzles are given in Table I.4. Refer to Figure 3.13 for the dimension letters.

Table I.4: Needle profile dimensions for all 15 test nozzles

\begin{tabular}{|c|c|c|c|c|c|c|}
\hline & \multicolumn{5}{|c|}{ Dimension Value (mm) } \\
\hline & & Zexel 9 & Zexel 15 & Sun 1 & Sun 32 & $\overline{\text { Zexel 76 }}$ \\
\hline \multirow{12}{*}{ 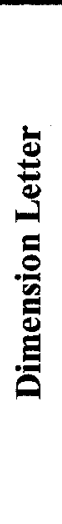 } & $\mathbf{A}$ & 0.73 & 0.77 & 0.77 & 0.74 & 0.80 \\
\hline & $\mathbf{B}$ & 1.00 & 0.99 & 0.99 & 0.99 & 0.99 \\
\hline & $\mathrm{C}$ & 0.20 & 0.23 & 0.22 & 0.22 & 0.24 \\
\hline & D & 0.81 & 0.83 & 0.74 & 0.65 & 0.76 \\
\hline & $\bar{E}$ & 0.85 & 0.87 & 0.84 & 0.83 & 0.86 \\
\hline & F (deg.) & 18.00 & 18.25 & 17.25 & 17.00 & 17.50 \\
\hline & $\mathbf{G}$ & 0.61 & 0.63 & 0.60 & 0.66 & 0.62 \\
\hline & $\overline{\mathbf{H}}$ & 0.98 & 0.98 & 1.03 & 1.02 & 0.98 \\
\hline & $\mathbf{I}$ & 1.64 & 1.63 & 1.63 & 1.65 & 1.60 \\
\hline & $\mathbf{J}$ & 2.49 & 2.51 & 2.54 & 2.51 & 2.51 \\
\hline & K (deg.) & 60.30 & 59.50 & 60.25 & 60.80 & 60.00 \\
\hline & L (deg.) & 82.00 & 83.50 & 85.00 & 80.75 & 86.00 \\
\hline \multirow{13}{*}{ 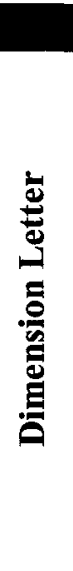 } & & Zexel 22 & Zexel 35 & Sun 63 & Sun 65 & Sun 66 \\
\hline & $\mathbf{A}$ & 0.75 & 0.75 & 0.71 & 0.71 & 0.67 \\
\hline & B & 0.99 & 1.00 & 1.00 & 1.02 & 0.99 \\
\hline & $\bar{C}$ & 0.20 & 0.22 & 0.24 & 0.24 & 0.23 \\
\hline & $\bar{D}$ & 0.81 & 0.79 & 0.76 & 0.76 & 0.76 \\
\hline & $\mathbf{E}$ & 0.86 & 0.89 & 0.83 & 0.85 & 0.89 \\
\hline & F (deg.) & 18.00 & 17.50 & 18.00 & 19.00 & 18.00 \\
\hline & $\mathbf{G}$ & 0.64 & 0.62 & 0.60 & 0.62 & 0.60 \\
\hline & H & 1.02 & 0.99 & 1.07 & 1.06 & 1.05 \\
\hline & I & 1.65 & 1.63 & 1.69 & 1.70 & 1.73 \\
\hline & $\mathbf{J}$ & 2.51 & 2.49 & 2.54 & 2.53 & 2.53 \\
\hline & K (deg.) & 59.75 & 60.00 & 60.50 & 60.75 & 60.75 \\
\hline & L (deg.) & 88.50 & 85.50 & 87.00 & 86.25 & 85.25 \\
\hline
\end{tabular}




\begin{tabular}{|c|c|c|c|c|c|c|}
\hline & CAV 14 & Zexel 70 & Zexel 71 & Sun 68 & Sun 69 \\
\hline \multirow{12}{*}{ 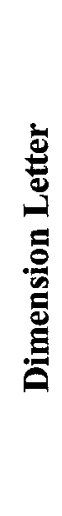 } & $\mathbf{A}$ & 0.77 & 0.72 & 0.74 & 0.72 & 0.74 \\
\hline & B & 0.99 & 0.99 & 1.00 & 0.99 & 1.00 \\
\hline & $\mathrm{C}$ & 0.20 & 0.19 & 0.23 & 0.23 & 0.23 \\
\hline & D & 0.81 & 0.81 & 0.77 & 0.76 & 0.75 \\
\hline & $\mathbf{E}$ & 0.86 & 0.86 & 0.86 & 0.83 & 0.83 \\
\hline & F (deg.) & 17.00 & 17.50 & 18.00 & 18.00 & 17.50 \\
\hline & $\mathbf{G}$ & 0.61 & 0.62 & 0.63 & 0.61 & 0.60 \\
\hline & H & 0.94 & 1.00 & 1.02 & 1.05 & 1.02 \\
\hline & I & 1.59 & 1.65 & 1.65 & 1.68 & 1.65 \\
\hline & $\mathbf{J}$ & 2.49 & 2.49 & 2.49 & 2.53 & 2.54 \\
\hline & K (deg.) & 60.75 & 60.00 & 60.00 & 60.00 & 60.50 \\
\hline & L (deg.) & 86.00 & 84.50 & 85.50 & 85.50 & 85.50 \\
\hline
\end{tabular}

